\title{
Review \\ Shape-Memory Materials via Electrospinning: A Review
}

\author{
Valentina Salaris ${ }^{1,2}$, Adrián Leonés ${ }^{1,2}$, Daniel Lopez ${ }^{1,2} \mathbb{D}$, José Maria Kenny ${ }^{3}$ and Laura Peponi ${ }^{1,2, *(D)}$ \\ 1 Instituto de Ciencia y Tecnología de Polímeros (ICTP-CSIC), C/Juan de la Cierva 3, 28006 Madrid, Spain; \\ v.salaris@ictp.csic.es (V.S.); aleones@ictp.csic.es (A.L.); daniel.l.g@csic.es (D.L.) \\ 2 Interdisciplinary Platform for "Sustainable Plastics towards a Circular Economy" (SUSPLAST—CSIC), \\ 28006 Madrid, Spain \\ 3 STM Group Strada di Pentima 4, Civil and Environmental Engineering Department and UDR INSTM, \\ University of Perugia, 05100 Terni, Italy; jose.kenny@unipg.it \\ * Correspondence: lpeponi@ictp.csic.es
}

Citation: Salaris, V.; Leonés, A.; Lopez, D.; Kenny, J.M.; Peponi, L. Shape-Memory Materials via Electrospinning: A Review. Polymers 2022, 14, 995. https://doi.org/ $10.3390 /$ polym 14050995

Academic Editor: Andrea Ehrmann

Received: 31 January 2022

Accepted: 26 February 2022

Published: 28 February 2022

Publisher's Note: MDPI stays neutral with regard to jurisdictional claims in published maps and institutional affiliations.

Copyright: () 2022 by the authors Licensee MDPI, Basel, Switzerland. This article is an open access article distributed under the terms and conditions of the Creative Commons Attribution (CC BY) license (https:// creativecommons.org/licenses/by/ $4.0 /)$.

\begin{abstract}
This review aims to point out the importance of the synergic effects of two relevant and appealing polymeric issues: electrospun fibers and shape-memory properties. The attention is focused specifically on the design and processing of electrospun polymeric fibers with shape-memory capabilities and their potential application fields. It is shown that this field needs to be explored more from both scientific and industrial points of view; however, very promising results have been obtained up to now in the biomedical field and also as sensors and actuators and in electronics.
\end{abstract}

Keywords: electrospinning; nanocomposites; shape memory; biopolymers; smart materials; electrospun fibers; biomedical applications

\section{Introduction}

Shape-memory polymers (SMPs) are an emerging class of smart materials that have been widely studied since the 1980s and are capable of recovering their initial shape from a temporary shape through the application of external stimuli: light, temperature, $\mathrm{pH}$, magnetism, electricity, or moisture [1-4], as schematically represented in Figure 1. Furthermore, such materials are able to memorize one temporary shape (two-way SMPs) or several shapes (multi-shape SMPs) [5].

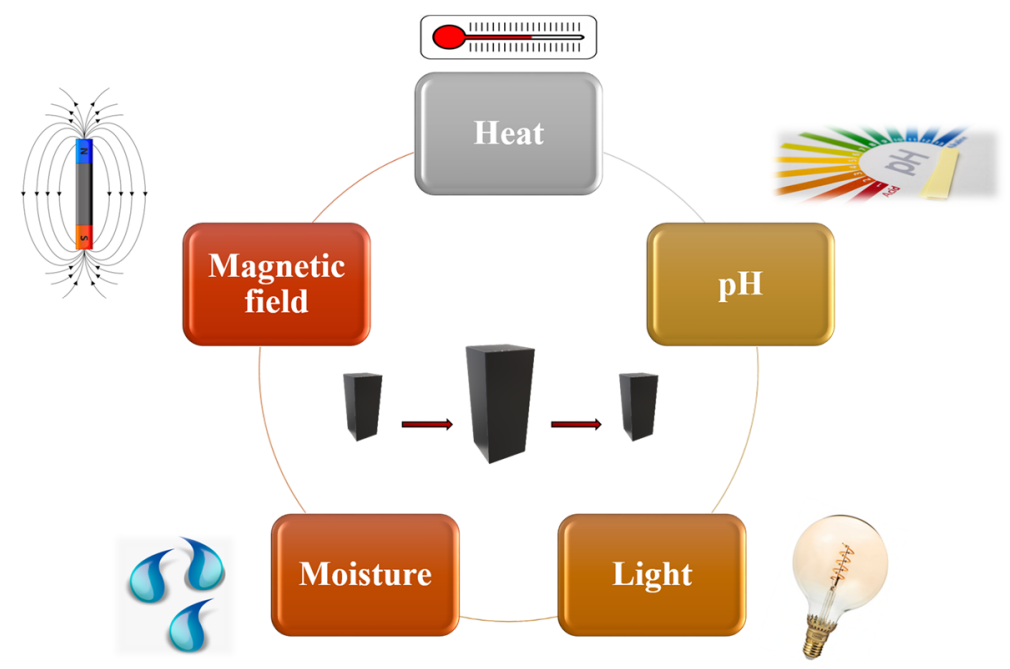

Figure 1. Stimuli-responsive shape-memory polymers.

However, the shape-memory behavior is not an intrinsic characteristic but can be achieved by designing the molecular structure of the polymer and by setting both the 
programming and the recovering stages that are generally required in order to fix the temporary shape and to recover the original shape of the polymer, respectively [6]. In particular, an SMP requires switching domains, constituted by side chains or chain fragments in which the interactions between such segments stabilize the temporary shape [6] and net-points (network), formed by covalent bonds (chemical cross-linking) or by intermolecular interactions, molecule entanglement, crystalline phases, or interpenetrated networks. These chemical or physical network points determine the original shape while the switching segments, which are the part of the material that responds to the external stimulus, fix the temporary shape [7].

Different transitions may be used to establish the temporary shape, including crystallization/melting transitions, vitrification/glass transitions, liquid crystal anisotropic/ isotropic transitions, reversible molecule cross-linking, and supramolecular association/ disassociation [8] (Figure 2).

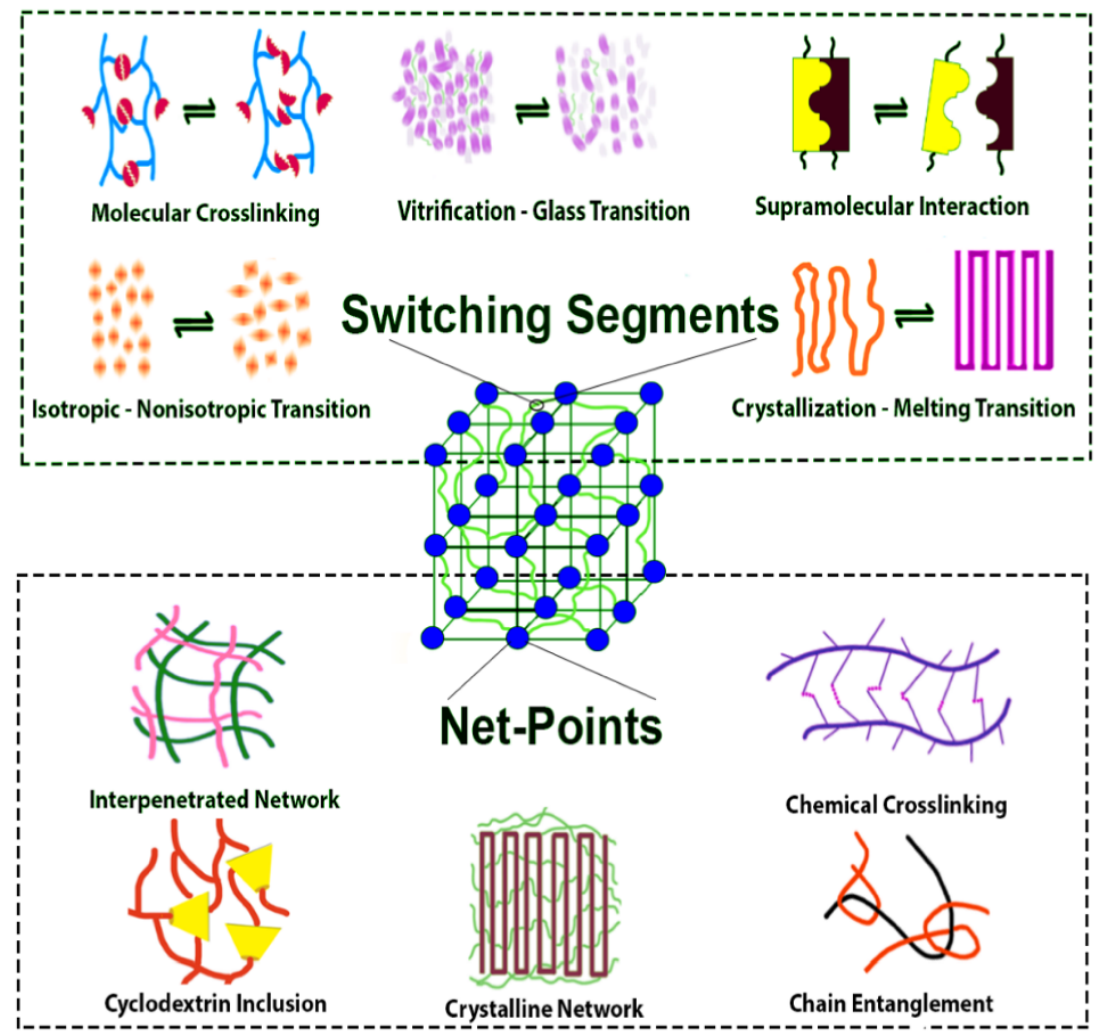

Figure 2. Shape-memory polymers architecture and possible transitions [9].

Actually, the most-used SMPs are thermally-induced shape-memory polymers. Their typical mechanism involves heating above a specific temperature, called the transition temperature $\left(\mathrm{T}_{\text {trans }}\right)$, which can initiate some of the transformations mentioned above. One of the most-used temperatures is the glass transition temperature $\left(T_{g}\right)$, at which the materials turn from a rigid state to a soft state. This phenomenon occurs due to the increased mobility of the polymeric chains when heating the sample above $\mathrm{T}_{\mathrm{g}}$, and therefore, when an external force is applied, the material can be deformed into a desired temporary shape that corresponds to a change in the molecular conformation and entropy. When cooling below $\mathrm{T}_{\mathrm{g}}$ and by gradually removing the external force, the temporary shape can be fixed through freezing the molecular chains and the applied force is stored as entropic energy inside the system. Upon reheating above the $\mathrm{T}_{\mathrm{g}}$, the polymeric chains acquire more mobility, allowing the release of the entropic energy, which is the driving force of the process, and the material is driven back to its entropically favorite state that corresponds to the initial shape [10] (Figure 3). 


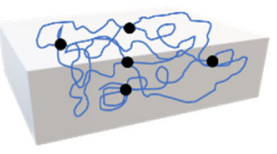
$\underset{T}{\text { HEATING }}>\mathbf{T}_{\text {trans }}$

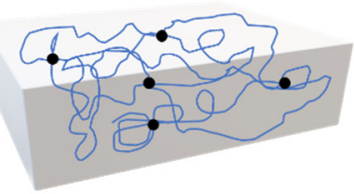

HEATING
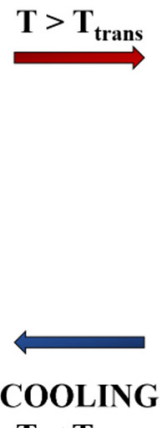

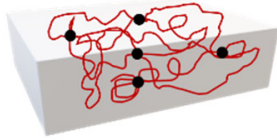

STRESS

INDUCED

DEFORMATION

$$
\mathbf{T}<\mathbf{T}_{\text {trans }}
$$

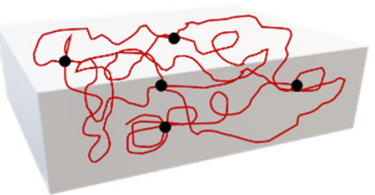

Figure 3. Mechanism of thermally induced shape-memory polymers.

The performance of an SMP can be evaluated through specific parameters: the strain fixity ratio $R_{f}$ and the strain recovery ratio $R_{r}$, which refer to the capability of the material to fix the mechanical deformation and to memorize its permanent and original shapes, respectively, and can be easily estimated by the following equations [11,12]:

$$
\begin{gathered}
R_{f}(N)=\frac{\varepsilon_{\mathrm{u}}(N)}{\varepsilon_{\mathrm{m}}} \times 100 \% \\
R_{r}(N)=\frac{\varepsilon_{\mathrm{m}}-\varepsilon_{p}(N)}{\varepsilon_{\mathrm{m}}-\varepsilon_{p}(N-1)} \times 100 \%
\end{gathered}
$$

where $\varepsilon_{\mathrm{m}}$ is the maximum strain after cooling and before releasing the stress. When cooling at $\mathrm{T}<\mathrm{T}_{\text {trans }}$ and the stress is removed, the sample strain corresponds to a fixed strain, $\varepsilon_{\mathrm{u}}$. By reheating, the sample returns to its original shape, leading to a recovered strain, $\varepsilon_{p}$.

The shape-memory properties of a specific material can be studied through thermomechanical cycles, as reported in Figure 4.

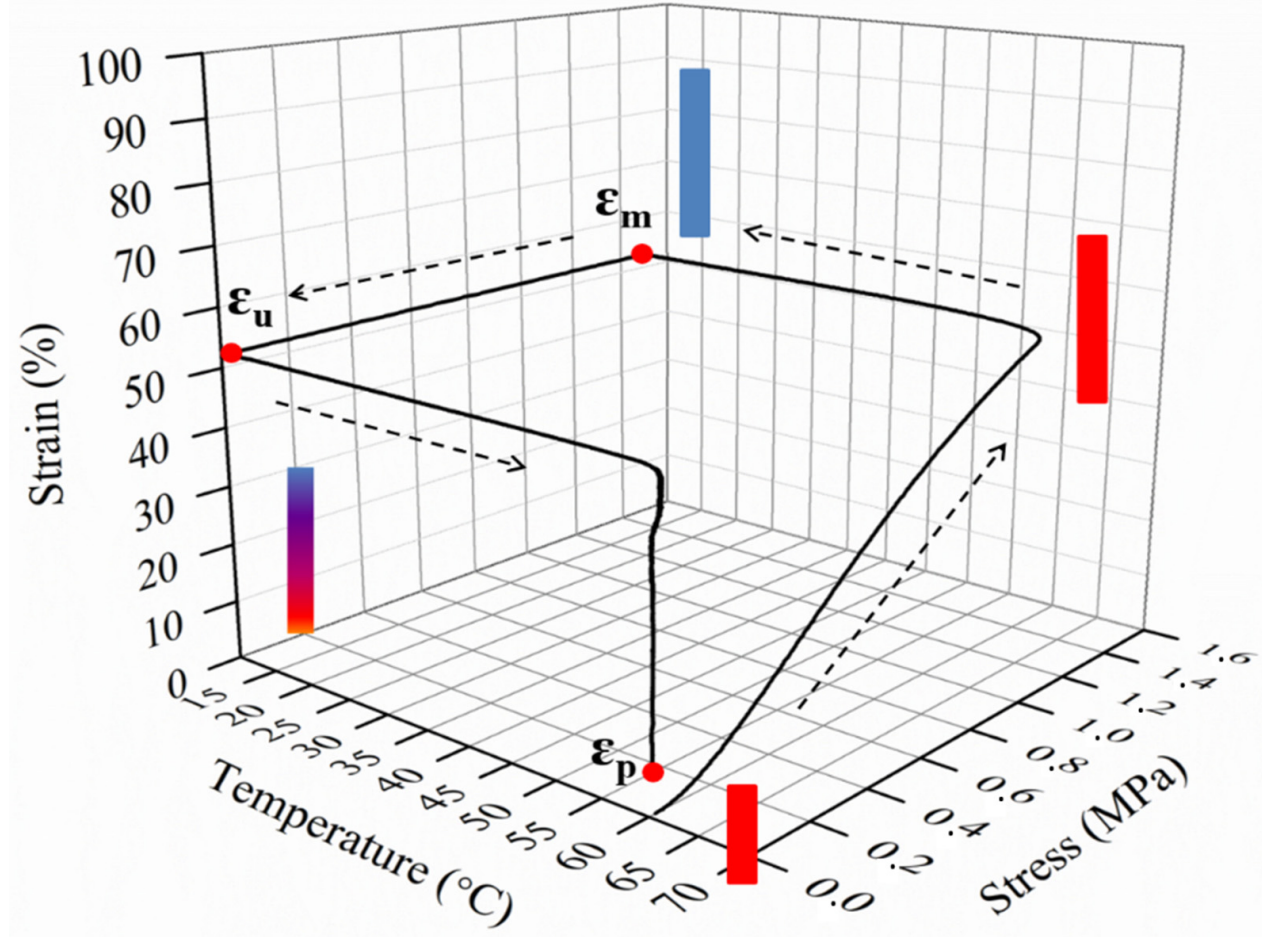

Figure 4. Schematic diagram of a 3D thermo-mechanical cycle and main parameters. 
Many researchers have focused their attention on SMPs due to the various advantages compared with shape-memory alloys: low density and relatively low cost, high recoverable strain (up more than $200 \%$ for most of the materials) [11], biocompatibility, and biodegradability. In addition, the transition temperature of SMPs with respect to SMA can be easily tailored. SMA presents a well-defined transition temperature, while for polymers it can be tailored through different approaches. That is, by the specific molecular design of the material, by blending, copolymerizing, as well as reinforcing the polymers, or by inducing crystallization in the material and therefore varying the stiffness of the polymer and, indeed, its transition temperature [13]. Furthermore, SMPs can be widely applied in many areas, such as in biomedical devices [14], aerospace [15], packaging [16], sensors [17], bionics engineering [18], electronic engineering [19], nano-optoelectronic applications [20], etc.

Among these materials, shape-memory fibers have been studied since the fibers possess particular intrinsic features such as a high axial ratio, and compared with shapememory polymer bulk, shape-memory fibers exhibit excellent mechanical properties because of their molecular orientation. Many polymers have been used for electrospinning, such as poly(vinyl pyrrolidone) (PVP), poly(vinyl acetate) (PVAc), polystyrene (PS), poly(vinyl alcohol) (PVA), poly(ethylene oxide) (PEO), polyacrylonitrile (PAN), polyethersulfone (PES), poly( $\varepsilon$-caprolactone) (PCL), and poly(lactic acid) (PLA) [21-24]. Several spinning techniques are adopted to produce conventional fibers: wet spinning, dry spinning, reaction spinning, gel spinning; however, electrospinning has received great attention since it has been proved to be a simple and promising technique $[25,26]$ for processing polymeric fibers.

Electrospinning was developed by Formhals in 1934 [27] and produces a mat of fibers by applying an electrostatically driven jet of polymer solution or polymer melt. A solution electrospinning system consists of three major constituents: a high voltage supply, a spinneret, and a collecting plate. A high voltage power supply is required to obtain an electrically charged jet of the solution. Indeed, the electric field between the capillary tip and a collector induces charges on the surface of the solution or melt [28]. By increasing the electric field, the hemispherical shape of the pendant drop at the end of the capillary tip is charged and assumes a conical shape, known as a "Taylor Cone" [29]. When the electric field is induced above a critical value, the surface tension is overcome by the repulsive electrical forces, the charged jet of the solution is ejected from the tip, and the fibers are collected [30] (Figure 5). This method requires the application of high electric voltages, in a range between 10 and $30 \mathrm{kV}$, and large distances $(15-30 \mathrm{~cm})$ between the electrodes. Additionally, the fiber formation strongly depends on several variables such as surface tension, viscosity, the concentration of the solution, solvent, etc. [31].

Electrospinning is a technique that produces polymeric fibers of nanometer to micrometer sizes in diameter [32] and has been widely used to produce fibers with diameters ranging from 50 to $500 \mathrm{~nm}$ [33]. Indeed, if the fiber diameter is reduced from micrometers to nanometers, certain properties can be significantly modified; in particular, small pore size and high specific surface area [34], features that can be exploited in soldier protective clothing, filtration, membranes, reinforcing fibers in composite materials, optical and electronic applications, drug delivery, cosmetics, supports for enzymes or catalysts, scaffolds for tissue engineering, $\mathrm{H}_{2}$ production, environmental protection, antibacterial properties, etc. [35-42].

In the last decades, researchers have tried to combine the features of polymer electrospun nanofibers with SM behavior, developing materials with improved properties. However, this is still considered a new, challenging research topic, since there are not many documents regarding shape-memory fibers (Figure 6): fewer than 15 scientific papers/year in the last 7 years. The first publications were mostly focused on the study of the morphology and optimization of the various parameters in order to fabricate fibers with a lack of defects and controlled diameters, whereas successive publications were mainly centered on the development of fibers for specific applications, in particular in the biomedical field, such as tissue engineering, wound dressing, drug delivery, and others such as catalysis, 
sensors, robotics, aerospace technologies, and more. All these works are reported and described in the present review.

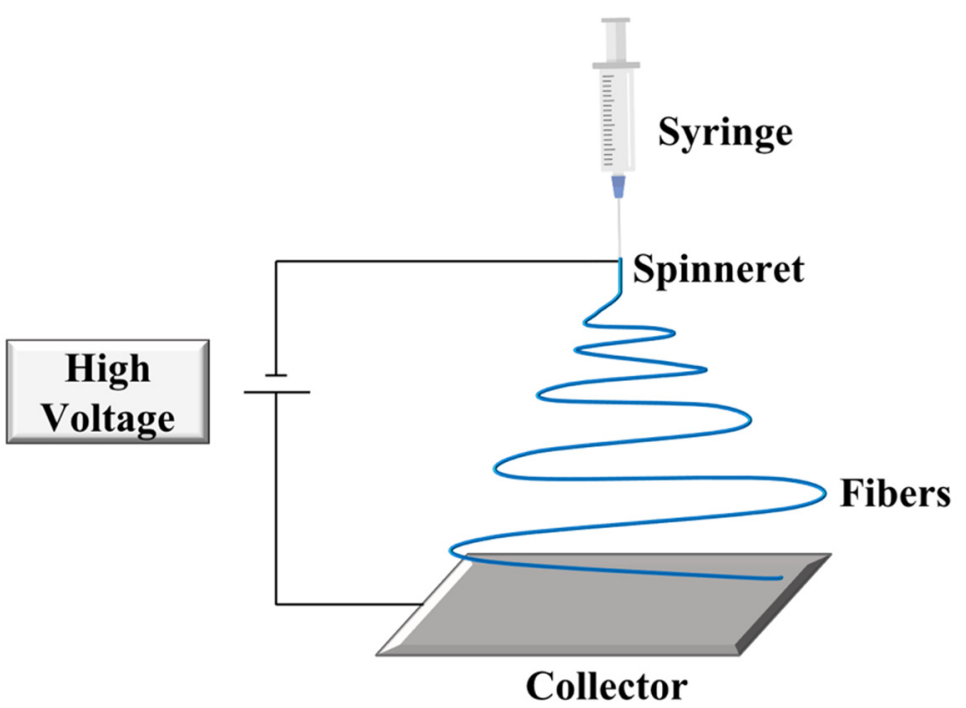

Figure 5. Schematic representation of an electrospinning setup.

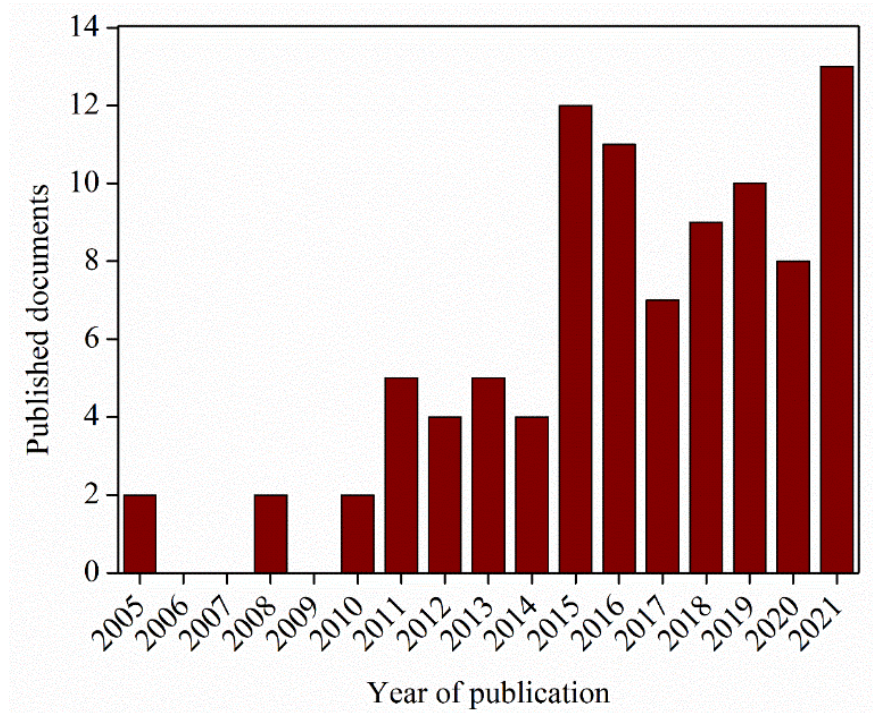

Figure 6. Diagram of the number of documents regarding shape-memory fibers per year (Scopus Source).

\section{Study of SMP Structure and Properties}

Shape-memory polymers (SMPs) have received great attention for their potential applications in many fields. Indeed, the number of published papers has increased in recent years. Figure 7 a reports the schematic trend of scientific articles from the Scopus database, searching with keywords "shape memory" and "polymer", in which we can see the exponential growth that started 20 years ago. In Figure 7b, for comparison, we report the same schematic trend using, as keywords, "shape memory", "polymer", and "electrospinning". In particular, shape-memory fibers have been widely studied for designing functional materials for human beings, finding applications in clothing fabrication [25], the biomedical field [14], robotics [15], catalysis, and air and water filters [7,43]. 
a)

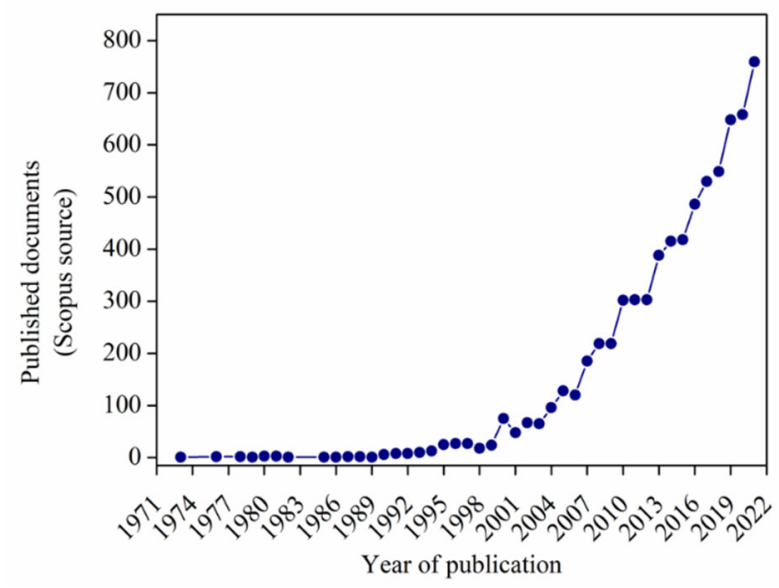

b)

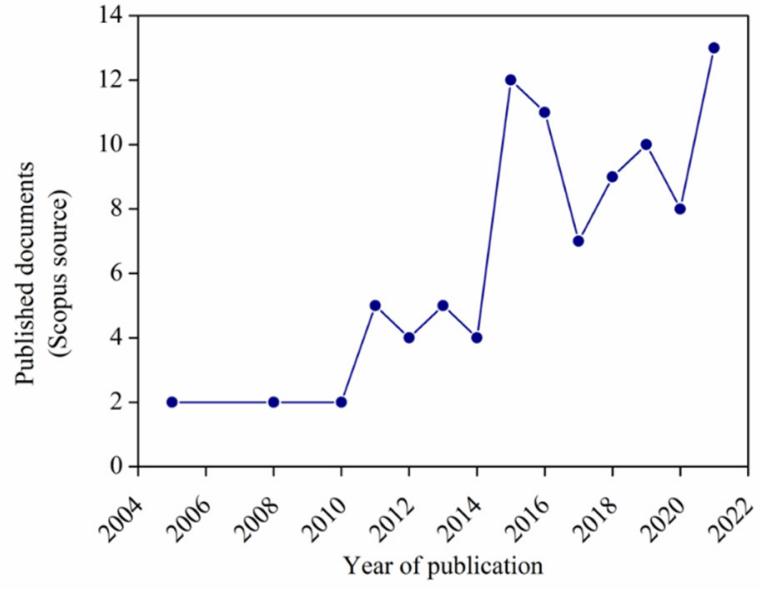

Figure 7. Number of published scientific papers looking for keywords: (a) "shape memory" + "polymers"; (b) "shape memory" + "polymers" + "electrospinning".

Therefore, in recent years, new polymer fibers have been developed and significant advances have been carried out in the production of high-performance fibers, elastic fibers, and nanofibers by using the electrospinning method [25]. The first works were mainly focused on the study of the structure and on controlling the diameter of fibers and the properties of these materials. Boland et al. [44] characterized the mechanical properties of polydioxanone (PDS) fibers, which are generally extruded into a filament to use as sutures. They noticed that, as the solution concentration increased, the diameter of the fibers increased linearly, and as the diameter of the fibers increased, the values of the Young modulus, peak stress, and strain at failure increased as well. However, mechanical tests revealed the anisotropic properties of the oriented mat.

One of the most studied shape-memory polymers is the class of polyurethanes (PUs), introduced by Mitsubishi in 1988 [45]. Shape-memory PU consists of hard and soft segments, where hard segments, which can be formed through hydrogen bonds and crystallization, are built from diisocyanates and act as physical crosslinks, while soft segments are polyols and are responsible for the shape-memory effect [46,47]. Cha, et al. [48] prepared shape-memory PU block copolymers with various hard-segments ratios, and the mechanical analysis revealed that the tensile strength increased as the hard-segment concentration increased, owing to the effect of the rigid diphenyl methylene moiety combined with hydrogen bonding and the dipole-dipole interaction. In addition, the tensile strength improved as the viscosity increased; indeed, at low viscosity, the woven no-woven electrospun PU assumed a beaded-on-fibers structure, where the beads act as defects. Lastly, they obtained more than $80 \%$ of shape recovery with hard segment concentration of 40 and $50 \%$.

Peponi et al. studied a shape-memory poly(ester-urethane) based on triblock copolymers based on poly(L-lactic acid) (PLLA) and PCL [11,49]. They obtained excellent shapememory responses at $40{ }^{\circ} \mathrm{C}$ in terms of both $R_{r}$ and $R_{f}$ [11]. They also used this polymer as a matrix for nanocomposites reinforced with cellulose nanocrystals, maintaining their shape-memory behavior at $35^{\circ} \mathrm{C}$ [49]. However, they did not obtain electrospun fibers without defects of this material [50].

In order to combine the properties of SMPs with nanofibers, Zhuo et al. [34] tried to develop shape-memory polyurethane nanofibers by electrospinning, noting that the diameters of the fibers decreased by increasing the applied voltage and by decreasing the concentration: nanofibers with a diameter of 50-100 nm were electrospun from the $3.0 \mathrm{wt}$ \% solution, a diameter of $200-400 \mathrm{~nm}$ from the $7.0 \mathrm{wt} . \%$ solution, and a diameter of 500-700 nm from $12.0 \mathrm{wt}$ \% solution. Cyclic tensile tests were executed to investigate the SM performances: the membrane showed an $R_{r}$ value of $98 \%$ and an $R_{f}$ value of $80 \%$ after several cyclic times. 
In general, SMPU possesses unique properties such as low production cost, low density, flexibility, good processability, and high deformation, but still has some disadvantages such as poor surface wettability, low shape-memory effect, and mechanical strength, thus additives or reinforcements are often incorporated in order to improve these features [51]. Rana et al. [52] prepared core-shell nanofibers by co-electrospinning made of PU core and PU composite shells reinforced with multi-walled carbon nanotubes (MWNTs). Compared with pure PU nanofiber webs, the incorporation of MWNTs lead to a better shape-memory behavior (especially with $1.0 \mathrm{wt} \%$ MWTNs content) due to the high thermal conductivity coefficient of MWNTs [53] and the higher internal stress stored by PU/MWNTs, owing to the strong interaction between matrix and reinforcement.

Comparing carbon nanotubes and graphene, the graphene oxide (GO), which possesses several oxygen-containing groups [54] and weakens the van der Waals interactions between the GO sheets, is easier to disperse into a polymer matrix. Tan et al. [51] fabricated a series of GO-reinforced SMPU nanofibers and the SM behavior was evaluated. In particular, they reported that all the samples showed an $R_{f}$ and $R_{r}$ above $90 \%(92.1 \%$ for the sample with the highest content in GO); instead, the neat sample revealed an $R_{f}$ value of $89.2 \%$. These results were explained by the presence of GO as reinforcement with a large specific surface area and a very good dispersion into the matrix, and therefore, it improved the modulus, which is advantageous for a better shape fixation [55].

Subsequent studies have been based on the production of polymer-based scaffolds. In 2015, Zhang et al. [56] developed a fiber scaffold constituted by hollow microfibers composed of a degradable shape-memory copolyetheresterurethane (PDC). PDC was constituted by crystallizable oligo(p-dioxanone) (OPDO) hard and oligo( $\varepsilon$-caprolactone) (OCL) switching segments. The hollow microfibers were fabricated by coaxial electrospinning where poly(ethylene glycol) (PEG) was used as a "sacrificial" core and was removed afterward with water. The microfibers were produced with the same average diameter of $1.4 \mu \mathrm{m}$ but with different degrees of hollowness-that is 0,13 , and 33\%-and they observed that the shape-memory performance improved (shape recovery in particular) with the increase in fiber hollowness.

Another interesting study was carried out by Alhazov et al. [57], by developing an electrospun thermoplastic polyurethane (TPU) and studying its thermomechanical behavior and shape-memory capabilities. In previous work, they observed that upon heating at $\sim 70{ }^{\circ} \mathrm{C}$, the nanofibers were subjected to contraction, while the TPU cast film was subjected to expansion [58]. Therefore, the thermomechanical and SM properties of the nanofibers were studied and compared to those of the TPU cast films, which was submitted to a typical thermomechanical cycle. During electrospinning, the fibers underwent deformation followed by a contraction due to the decreased molecular mobility caused by the rapid solvent evaporation, thus the electrospinning process was identified to be like the programming cycle, while the contraction effect was identified as the recovery phase. Basically, the contraction of electrospun TPU materials could be considered an electrospinning-induced shape-memory effect.

Other studies based on PU were performed by Budun et al. [59], by fabricating shapememory block co-polymer PU fibers with four different solution concentrations $(5,10$, 15 , and $20 \mathrm{wt} . \%)$ and three different voltages $(30,35$, and $38.9 \mathrm{kV})$ and shape-memory properties were evaluated: all calculated $R_{f}$ were above $80 \%$ and all $R_{r}$ around $100 \%$.

Moreover, some researchers have been focusing their attention on the processing of copolymers to achieve porous structures. Especially, Ang et al. [60] fabricated waterresponsive urethane-based shape-memory polymers constituted by PEG, PCL, and poly (dimethylsiloxane) (PDMS). In particular, a water-responsive SMP system should consist of hydrophilic parts as switching segments and hydrophobic parts as hard segments. In contact with water, hydrophilic components swell, leading to a disruption of the crystalline structure, and deformation is achieved (programming). Therefore, the temporary shape can be set by drying, and the crystalline structure is reinstated [61] (Figure 8). 


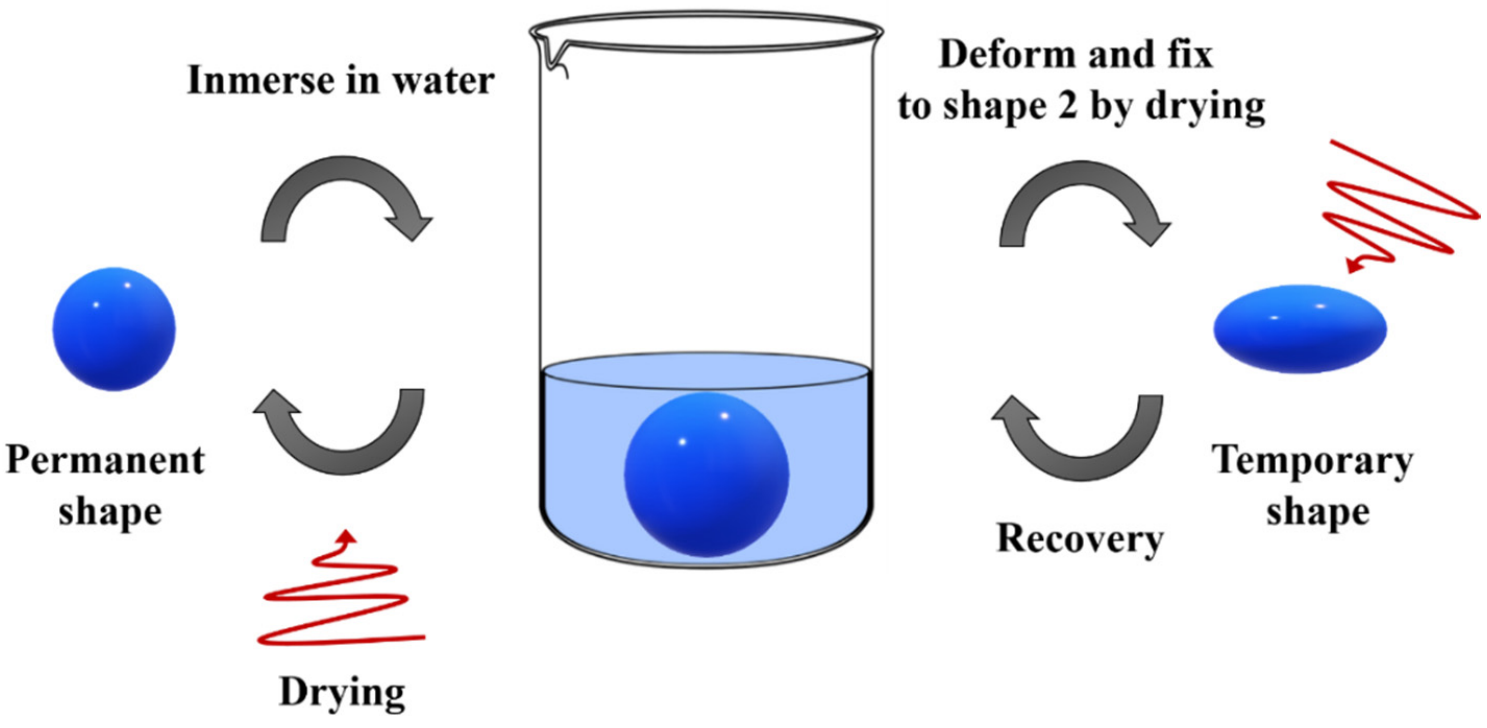

Figure 8. Mechanism of water-responsive shape recovery.

The electrospinning technique has been used also to produce porous structures in order to increase the content of water incorporated, and indeed their surface area [62,63]. The PEG crystals constitute the hydrophilic component, which is able to interact with water, whereas PCL and urethane linkages constitute the hydrophobic component, holding the permanent structure. The corresponding electrospun mat exhibited a faster recovery than the bulk SMP due to the higher surface area in contact with water.

Induced, crystallization is quite an innovative manner in which to obtain shapememory materials. Sessini et al. [64] proposed inducing crystallization in an ethylene-vinyl acetate (EVA)-thermoplastic starch (TPS) system in order to obtain both thermally and humidity-activated shape-memory materials. At the same time, the induced crystallization in the PCL domains of PU was used by Castillo et al. [65] to obtain shape-memory materials with potential applications as vascular grafts. In this regard, one of the most recent works based on polyurethane was performed by Nissenbaum et al. [66], by combining polycaprolactone-diol (PCL-diol)/2,4,2,6-toluene diisocyante (TDI) and ethylene glycol as a chain extender to obtain SMPU nanofibers by electrospinning. Moreover, they studied strain-driven crystallization, which is the mechanism that regulates the SMPU fixation state in semi-crystalline SMPUs [67]. In fact, they reported that when the polymer chains are deformed under strain, the co-alignment keeps the chains close and induces crystallization [68], while when cooling below the transition temperature, usually the melting temperature $\left(\mathrm{T}_{\mathrm{m}}\right)$, the strain-induced crystallization fixes the temporary shape. However, after heating, the SMPU becomes amorphous and maintains this state for more than $60 \mathrm{~h}$, delaying its crystallization. This effect allows for a complete shape-memory cycle to be carried out without using the effect of crystallization, and the authors observed the excellent shape-memory performance of the SMPU in the amorphous state even without the help of the crystallization. Therefore, they suggested that the fixation and recovery shape mechanisms are caused by the inhibition of the chain mobility caused by interlocking the hard segments when decreasing the temperature below the transition temperature, and subsequent heating allows free chain movement and the recovery of the initial shape (Figure 9). The electrospun SMPU fibers they studied showed a value of $~ 100$ and $97 \%$ for strain recovery and fixity ratios, respectively. 


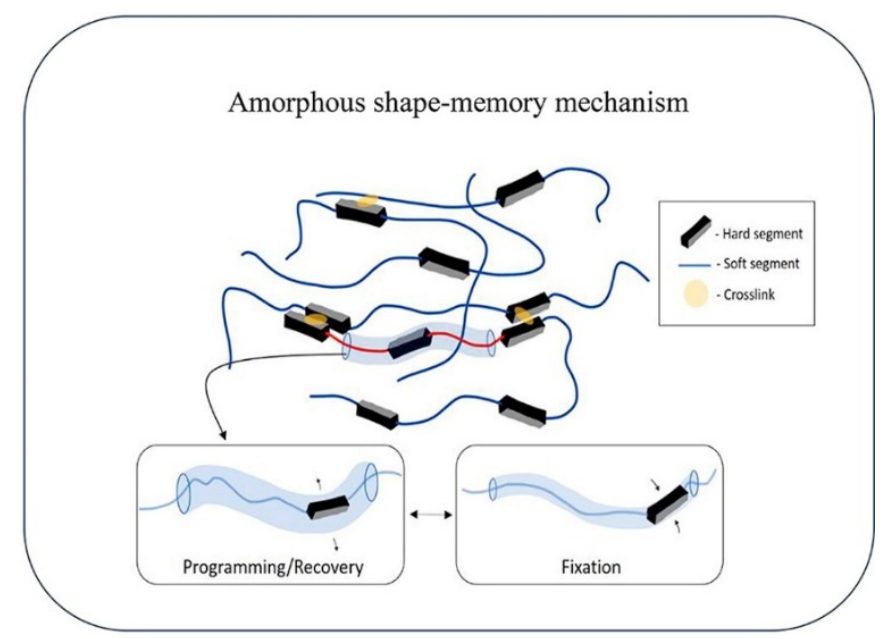

Figure 9. Shape-memory amorphous mechanism [66].

Chen et al. [69] designed a shape-memory film by using as a precursor a $\gamma$-aminopropyltriethoxysilane (APS) end-capped polyurethane oligomer (ASPU) that was subsequently hydrolyzed and condensed through the ethoxysilane groups, and finally crosslinked through a sol-gel process after electrospinning. The shape-memory performance was evaluated by carrying out three cycles in the temperature range of 0 and $60^{\circ} \mathrm{C}$ and by applying a strain of $150 \%$ obtaining $R_{f}$ and $R_{r}$ values of $99.1 \pm 0.4 \%$ and $81.3 \pm 0.8 \%$, respectively.

In addition to the class of polyurethanes, PCL has been extensively studied. As one of the biodegradable polyesters and for its great biocompatibility, it can be used in the biomedical field and packaging applications [70,71]. Nevertheless, the applications of these polymers are limited because of their deficient physical properties; indeed, polymer/inorganic layered material nanocomposites or the copolymers of PCL have been investigated. Matsumoto et al. [72] explored the shape-memory behavior of the electrospun woven no-woven fabrics of a multiblock copolymer named PDLCL, constituted by poly(xpentadecalactone) (PPDL) as hard segments and PCL as soft and switching segments. They calculated the shape-memory capability at 40 and $60{ }^{\circ} \mathrm{C}$ and by using two different methods: method (A), where a maximum strain of $\varepsilon_{m}=25 \%$ was applied for each cycle, while in method (B), $\varepsilon_{\mathrm{m}}$ was subsequently increased from 25 to $50 \%$, and $R_{r}$ values between $89 \%$ and $95 \%$ and $R_{f}$ values of $82-83 \%$ after the second cycle were obtained when small deformations at clinically relevant temperatures were applied.

Luo et al. [73] incorporated thermoplastic fibers of a low $\mathrm{T}_{\mathrm{m}}$ semicrystalline polymer into a $\mathrm{T}_{\mathrm{g}}$-based SMP matrix to develop triple-shape polymeric composites (TSPCs), which are a class of smart materials capable of fixing two temporary shapes besides their permanent shape [74]. PCL and epoxy were chosen for this purpose. In fact, epoxies are very interesting materials frequently used due to properties such as chemical resistance, high stiffness, good adhesion, and versatility [75]. In particular, they reported that the programming of the two temporary forms was set at two temperatures: the melting temperature of the PCL crystals $\left(\mathrm{T}_{\mathrm{m}}\right.$ of $\left.40^{\circ} \mathrm{C}\right)$ and the $\mathrm{T}_{\mathrm{g}}$ of EP $\left(\mathrm{T}_{\mathrm{g}}\right.$ of $\left.80^{\circ} \mathrm{C}\right)$, and dual and triple SM performances were investigated, revealing $R_{f}$ and $R_{r}$ values close to $100 \%$ for the former case, whereas $R_{f}$ and $R_{r}$ values for the second shape were lower than the values of the first one.

A similar approach was applied by Fejos et al. [76] by developing a triple shapememory polymer (TSMPs) of epoxy (EP)/PCL with diverse structures. PCL was present as a nanoweb, electrospun with and without graphene (graphene was incorporated as reinforcement and as a spacer to increase the impregnation with EP) and in situ formed with a co-continuous phase structure. Both the $\mathrm{T}_{\mathrm{g}}$ of the EP and the $\mathrm{T}_{\mathrm{m}}$ of PCL were used as transition temperatures to fix the two temporary shapes. From the shape-memory performance, it was observed that EP/PCL nanoweb with graphene showed worse SM properties than the unreinforced material, and additionally, EP/PCL with a co-continuous 
structure revealed the best properties with $R_{f 1}, R_{f 2}, R_{r 1}$, and $R_{r 2}$ values of $81-82 \%, 94-95 \%$, $94 \%$, and $85 \%$, respectively.

Yao et al. [77] elaborated a thermosetting/thermoplastic system comprised of EP resin and PCL, where PCL microfibers were used as plasticizers and as hard segments to set the temporary shape. The mechanism of the shape-memory effect was attributed to the structure acquired (structural design) by the thermoplastic network inside the thermosetting matrix rather than the molecular structure itself. The recovery of the initial shape was triggered by placing the spiral strip (temporary shape) in hot water $\left(70^{\circ} \mathrm{C}\right)$ and an $R_{\mathrm{r}}$ around $97 \%$ was observed over the 20 cycles, and an $R_{f}$ around $95.5 \%$.

Birjandi et al. [78] reported in 2016 the incorporation of PCL electrospun fibers into a shape-memory EP matrix in order to develop a shape memory-based self-healing coating. In particular, shape memory can be used to fabricate self-healing $(\mathrm{SH})$ polymers that are able to close and repair cracks when thermally activated [79].

In 2016, Yao et al. [80] fabricated a two-way shape-memory composite of electroactive $(\mathrm{EAP}) / \mathrm{PCL}$, where PCL was used as a hard segment and the EAP matrix as a soft segment. EAP are generally subjected to deformation when exposed to an electric field. Furthermore, their biocompatibility and similarity with muscles make them suitable for applications as artificial muscles in the biomedical field [81]. This composite showed the ability to change its shape without the pre-programming step by increasing the temperature above the $T_{m}$ of PCL, thus the PCL crystal melts, meanwhile a voltage is applied on the EAP, causing the deformation. Once the material assumed the desired shape, the heat was removed while the voltage was still applied to keep the shape, and when the temperature reached values below the $T_{m}$, the temporary shape was fixed and the voltage was removed. The initial shape was recovered by heating the composite (Figure 10). In this case, the shape-memory behavior was evaluated, revealing an $R_{r}$ value of $99 \pm 0.3 \%$.

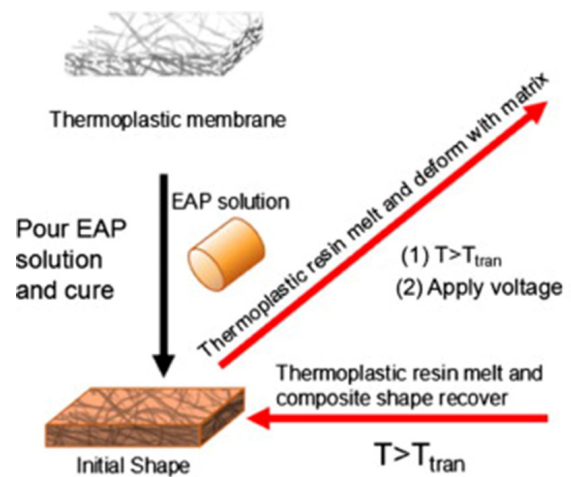

(a)

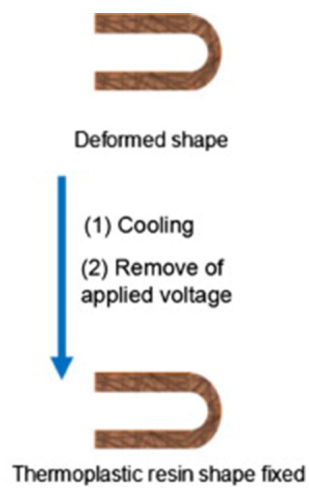

Thermoplastic resin shape fixed

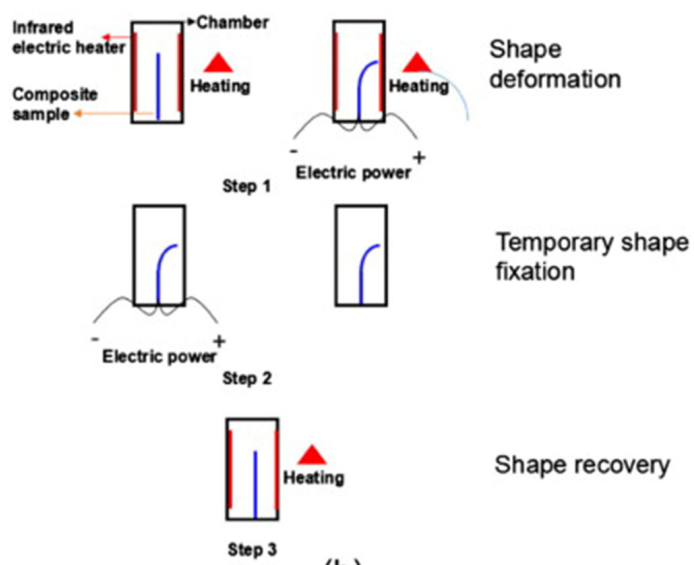

(b)

Figure 10. (a) Representation of composite fabrication and shape-memory cycles; (b) schematic experimental setup for two-way SMPs [80]. 
In 2016, Marlettini et al. [82] developed an electrospun mat constituted by $\alpha, \omega$ triethoxysilane-terminated PCL to produce beads-free fibers by using electrospinning and sol-gel reaction in order to obtain a material with a high crosslinking degree. The evaluation of the shape-memory properties revealed high values of $R_{f}(100 \%)$ and $R_{r}(98 \%)$ and the independence of these properties from the content of crosslinking.

In 2017, Iregui et al. [83] obtained an electrospun mat constituted by a blend of the diglycidyl ether of bisphenol A (DGEBA) and PCL that was subsequently reticulated by exposition to UV radiation, avoiding the melting of the PCL crystals. Iodonium salt was used as a photo-initiator, which also improved the spinnability of the solution, leading to the formation of fibers without defects. The produced mats exhibited high shape-memory properties through several cycles, with an $R_{f}$ of $95-99 \%$ and an $R_{r}$ of $88-100 \%$, respectively. Moreover, on the basis of this work, they evaluated the effect of the solution concentration, photo-initiator concentration, and blend composition (PCL/epoxy ratio) on the spinnability and shape-memory properties [84]. They noticed that the concentration of PCL did not affect the fixation process, which is regulated by the melting and re-crystallization of PCL: in fact, the degree of crystallinity (ranging from 23 to $40 \%$ ) was high enough to maintain the temporary shape. However, the concentration of PCL affected the morphology of the fibers and their recovery capability. Indeed, when increasing the solution concentration, the fiber diameter increased. Apparently, a higher diameter of fibers yields better performance in recovering the permanent shape. Moreover, the epoxy and/or the photo-initiator amount showed no effects on the shape-memory behavior, probably due to the high curing degree, as revealed by Fourier Transform Infrared Spectroscopy (FTIR) analysis. In any case, all samples showed excellent shape-memory behavior with $R_{f}$ and $R_{r}$ values between 95\% and $100 \%$.

Furthermore, many studies were focused on the processing of multiphase shapememory materials. For instance, Buffington et al. [85] designed quadruple shape-memory composites, which are materials that can recover their original shape from three formerly programmed shapes [86], constituted by an electrospun mat of PCL, epoxy monomer, and poly(methyl methacrylate) (PMMA), and with three distinct transition temperatures. Sessini et al. [87] obtained a sandwich-type structure based on two external films of shapememory Surlyn ${ }^{\circledR}$ and an inner layer of electrospun PLA mat.

Further studies based on PCL were performed by Yao et al. [88] based on the production of a PCL/PEO membrane by electrospinning, where PEO was added to improve the hydrophilicity of the membrane. PCL was irradiated with UV light to obtain cross-linked PCL in order to present shape-memory behavior: when deformed, the membrane, which presents a honeycomb-like structure, opens the structure, and the fibers are connected by cross-links. They studied the shape-memory effect for the PCL/PEO membrane in dry and wet conditions at $55^{\circ} \mathrm{C}$ and it was observed that water (for the wet hybrid membrane) increased the recovery speed of the permanent shape, taking $12 \mathrm{~s}$, in comparison with the dry hybrid membrane, which took $20 \mathrm{~s}$.

PEO has been added several times in solution to adjust some properties. For example, Zhang et al. [89] used PEO to modify the viscosity of a Nafion ${ }^{\circledR}$ solution and consequently to improve the electrospinnability in order to produce Nafion ${ }^{\circledR}$ nanofibers with shapememory properties stimulated by heat. In particular, DuPont Nafion ${ }^{\circledR}$ PFSA is composed of a polytetrafluorethylene backbone and perfluorovinyl ether pendant side chains terminated by a sulfonate ionic group and is characterized by high chemical and thermal stability, acidity and electrical conductivity, and mechanical properties [90]. The fibers were subsequently annealed at different temperatures-140,160, and $180{ }^{\circ} \mathrm{C}$, respectively-to obtain a network, leading to an increase in the diameter of the fibers. Lastly, they studied SM properties by subjecting the nanofibers to three consecutive cycles. The fibers achieved excellent $R_{f}$ and $R_{r}$ values of $95-96 \%$ and $87-89 \%$, respectively. Afterward, they investigated such properties by modifying the PEO content: $0.3,0.5$, and $0.7 \mathrm{wt} . \%$, and $R_{f}$ and $R_{r}$ values of around $90 \%$ were obtained for all samples. An increasing trend in $R_{f}$ and a decreasing trend in $R_{r}$ were observed by increasing the PEO content [91]. 
Further studies focused on Nafion ${ }^{\circledR}$ have been carried out by researchers to take advantage of its different, interesting properties. In 2016, Hu et al. [92] aimed to develop a composite with shape-memory behavior induced by electrically resistive Joule heating, which can be used when direct heating is not readily applicable [93]. The composite was obtained by grafting carbon nanotubes and Nafion/silica nanofibers onto carbon fiber mats, where carbon fiber was used as an electric conductor to trigger the electrically resistive Joule heat, CNT as a thermal conductor to transfer the heat to the SMP matrix, and Nafion/silica additionally worked as an insulator to slow down the heat exchange between the carbon fiber and the surrounding environment. They reported that the recovery of the permanent form was activated by applying a constant $4.0 \mathrm{~V} \mathrm{DC}$ voltage and it took $150 \mathrm{~s}$, achieving an $R_{r}$ of approximately $92 \%$.

Another polymer investigated by researchers is PVA. Shirole et al. [94] fabricated a shape-memory composite constituted by electrospun fibers of semicrystalline PVA as the switching element (by using $\mathrm{T}_{\mathrm{g}}$ as transition temperature) and a thermoplastic polyether block amide elastomer (PEBA) as the matrix, by melt impregnation/compaction (Figure 11). The shape-memory performance revealed an $R_{f}$ of $66 \pm 14 \%$ and an $R_{r}$ of $98 \pm 2 \%$ at low strain $(3-5 \%)$.

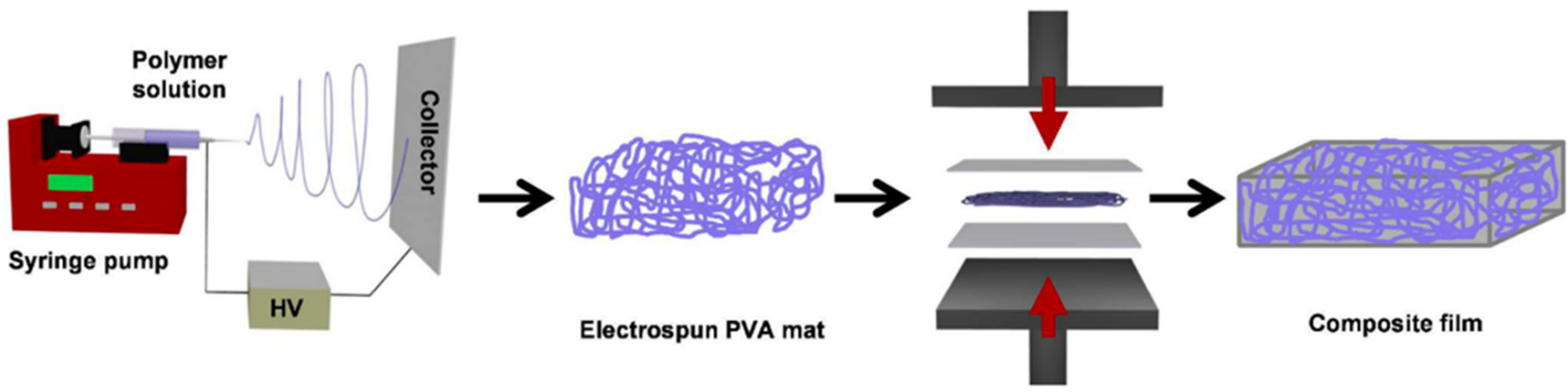

Figure 11. Representation of the production process of PEBA/PVA composite. Reprinted with permission from [94]. Copyright 2016 American Chemical Society.

In 2020 Guan et al. [95] studied the variation of mechanical and shape-memory properties of PU nanofibers by changing nanofiber alignments: random, $0^{\circ}$ (parallel to tensile direction), $45^{\circ}$, and $90^{\circ}$, respectively. Nanofibers with a $0^{\circ}$ alignment degree showed excellent shape-memory properties with an $R_{r}$ higher than $93 \%$ and an $R_{f}$ higher than $90 \%$ and increased the yield stress, elastic modulus, tensile strength, and breaking strain by 22.6, $213.1,35$, and $39.5 \%$, respectively, compared with randomly oriented nanofibers, due to the higher compactness and density of aligned nanofibers. Furthermore, it was observed that when the alignment angle decreases from $90^{\circ}$ to $0^{\circ}$, mechanical properties are enhanced due to an increase in the volume fraction of nanofibers along the strain direction, which better bears the applied loading.

Further research in order to optimize practical parameters was carried out by Banikazemi et al. [96] by fabricating shape-memory PCL-based PU fibers and studying the effect of solution concentration, type of solvent, feeding rate, needle-to-collector distance, and applied voltage. Beads-free fibers were obtained with a concentration of $5 w / v \%$ of PU in 60/40 (DMF/chloroform) solvent. They observed that the fiber diameter decreased by increasing the needle-to-collector distance and the applied voltage; however, further increases led to an increase in the average diameter, while the diameter was also increased by increasing the feeding rate. The peculiar porous structure of the fibers where cavities act as weak points diminished the mechanical properties compared to those of bulk film, showing lower Young modulus, tensile strength, and elongational break as well as $R_{f}$ values. However, the electrospun scaffolds revealed $R_{r}$ values of $100 \%$.

Nahavandizadeh et al. [97] fabricated in situ-polymerized shape-memory polyurethane hydroxyapatite (HA) scaffold and studied the effect of HA nanoparticles on electrospun fibers and shape-memory properties. The addition of HA led to a larger fiber diameter and 
a decrease in the degree of crystallinity, which derives from PCL soft segments, caused by the formation of hydrogen bonds between isocyanate molecules and $\mathrm{OH}$ - groups present on the nanoparticle surface, avoiding the introduction of PCL chains into the crystals. Furthermore, the increase in nanoparticle content limited the fast reformation of soft segments, leading to higher $R_{f}$, and due to the small content of hard segments, the material showed $R_{r}$ values of $100 \%$.

One of the most recent works in the scientific literature, focused on the development of a material with improved thermal and mechanical properties and with shape-memory properties, was reported in 2021 by Liu et al. [98]. They prepared a composite film by electrospinning, constituted by perylene-bisimide-functionalized graphene nanosheet (PBIGN) obtained via $\pi-\pi$ stacking between PBI, graphene, and PLA. The obtained material showed improved mechanical and thermal properties in terms of tensile strength and elongation at break and higher maximum thermal decomposition temperature and glass transition temperature. Additionally, the presence of PBI-GN improved the shape-memory capabilities of the material with respect to neat PLA (36.3\% higher).

Another way to tailor the shape-memory behavior of SMPs directly involves some effects that are observed in many electrospun membranes-for example, the shrinkage that is caused by the stretched conformation of the macromolecular chains [99]. Other techniques are focused on the modification of the geometrical features of the fibers-for example, Sauter et al. [100] investigated the influence of the fiber diameter in the mechanical and shape-memory behavior of randomly electrospun polyetherurethane (PEU) meshes. Indeed, the mechanical and shape-memory properties strongly depend on the molecular orientation along with the orientation of the fiber, which is increased by the reduction in the fiber diameter from the micrometer to the nanometer range. Fibers with a diameter below $100 \mathrm{~nm}$ presented excellent shape recovery, while the shape fixity decreased with decreasing fiber diameter.

In 2019, Leonés et al. [12] developed a PLA-based material and studied the modulation of the $T_{g}$ of PLA through plasticization by blending PLA with oligomers of lactic acid (OLA), obtaining, for the first time, thermally-activated shape-memory electrospun fibers of neat and plasticized PLA for potential biomedical applications. In fact, OLA was revealed to be particularly compatible with PLA due to its chemical composition. Furthermore, OLA and lactic acid are the degradation products of PLA inside the body, which can be metabolized or eliminated through breath or urine [101].

They observed a decrease in the average diameter of fibers by increasing the content of OLA, from $757 \pm 193 \mathrm{~nm}$ for neat PLA to $768 \pm 207 \mathrm{~nm}, 620 \pm 121 \mathrm{~nm}$, and $476 \pm 80 \mathrm{~nm}$ for PLA-OLA 90:10, 80:20, and 70:30 ratios, respectively. Moreover, the system containing OLA presented a lower $T_{g}$ than neat PLA $\left(T_{g}=60^{\circ} \mathrm{C}\right)$, and the $T_{g}$ decreased by increasing the OLA content from $50^{\circ} \mathrm{C}$ (PLA-OLA: 90:10) to $35^{\circ} \mathrm{C}$ (PLA-OLA: 80:20) and $20^{\circ} \mathrm{C}$ (PLA-OLA: 70:30). The shape-memory properties were evaluated at $45^{\circ} \mathrm{C}$ and $40{ }^{\circ} \mathrm{C}$, temperatures close to that of the human body, with PLA-OLA ratios of 80:20 and 70:30, respectively. From the tests executed at $45^{\circ} \mathrm{C}$, with the formulation PLA-OLA 80:20, $R_{f}$ and $R_{r}$ values of $100 \%$ were achieved $\left(R_{f}>95 \%\right.$ after the first thermomechanical cycle), while at $40{ }^{\circ} \mathrm{C}$ it showed an $R_{f}=98 \%$ and a slightly low value of $R_{r}$ due to the smaller temperature difference between the transition temperature and its $\mathrm{T}_{\mathrm{g}}$. PLA-OLA 70:30 (with lower $\mathrm{T}_{\mathrm{g}}$ ) presented better SM behavior at $40{ }^{\circ} \mathrm{C}$ than $45^{\circ} \mathrm{C}$. Indeed, at $45^{\circ} \mathrm{C}$ it showed an $R_{f}=90 \%$ and $R_{r}=70 \%$, whereas at $40{ }^{\circ} \mathrm{C}$ the $R_{f}$ and $R_{r}$ values were $92 \%$ and $75 \%$, respectively. Among the studied materials, PLA-OLA with $20 \%$ of OLA was identified as the ideal material for biomedical applications, revealing the best mechanical properties at both testing temperatures, as reported in Figure 12. 
a)
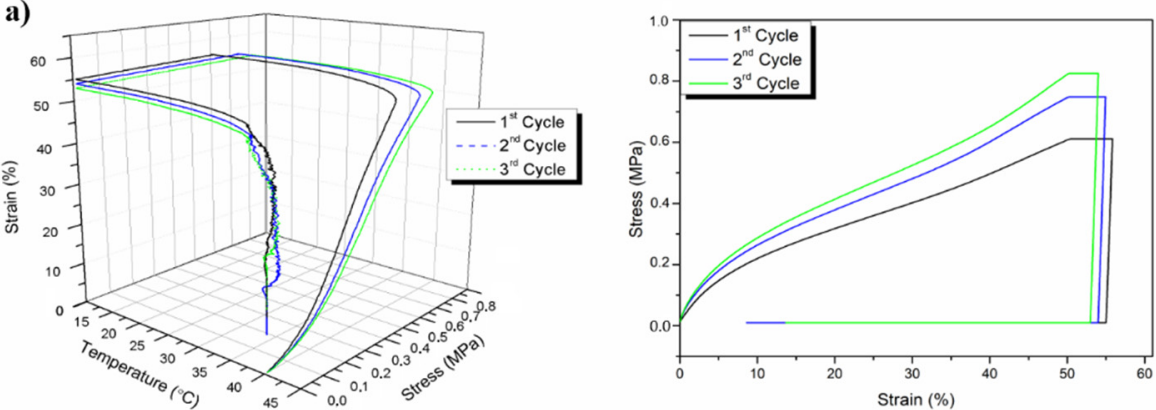

b)
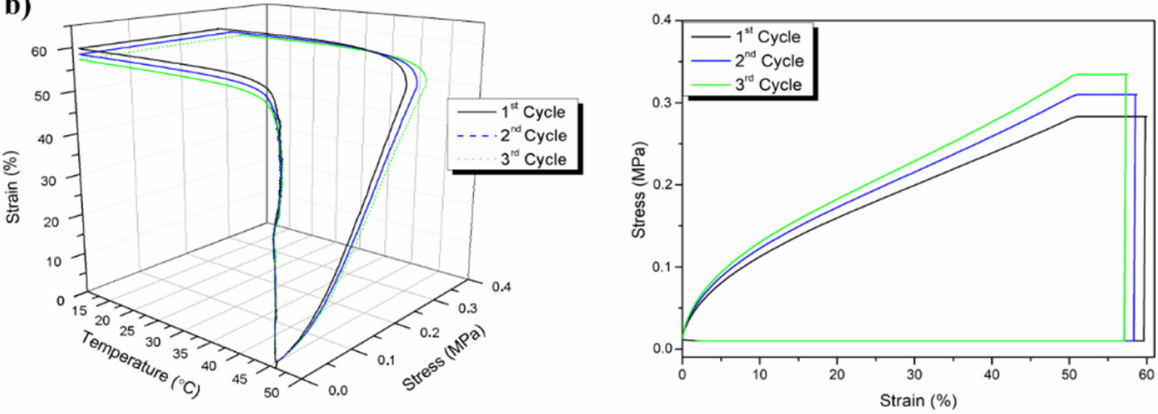

Figure 12. Thermo-mechanical shape-memory cycles of PLA-OLA (80:20) at (a) $40{ }^{\circ} \mathrm{C}$ and (b) $45^{\circ} \mathrm{C}[12]$.

Many researchers have been focusing on the study of structure, properties, and the optimization of parameters in order to obtain SMP fibers with high performance to be used for several applications. In particular, one of the areas in which SMP fibers have been widely used is the biomedical field, as reviewed in the following section.

\section{Biomedical Applications}

SMPs have been extensively used to develop scaffolds, implants, and biomedical devices due to their high biocompatibility and large shape deformation properties [102]. These purposes often require a quick shape recovery and sensitive response [14], and one of the challenges has been improving these properties without altering others.

Potential biomedical applications for shape-memory electrospun nanofibers have gained increasing attention, in particular, in tissue engineering, drug delivery, wound dressing, and the development of biomedical devices and medical imaging.

\subsection{Tissue Engineering}

In 2013, Tseng et al. [103] developed a PU-based shape-changing scaffold for tissue engineering, especially to control the cell body orientation [104]. First, they deformed an initial random mesh (permanent form), obtaining an aligned mesh in a temporary shape, then human adipose-derived cells (ASCs) were cultured on the temporarily aligned scaffold. They observed that the cells preferentially oriented themselves according to the fiber orientation and that such preferential orientation was lost when the material recovered the permanent shape by heating at $37^{\circ} \mathrm{C}$; thus, the cells remained randomly orientated. However, in this case, the scaffold presented high shape-memory behavior with a shape fixing ratio of $99-100 \%$ and a shape recovery ratio of $94-96 \%$.

Gong et al. [105] fabricated polymer composite nanofibers by electrospinning, composed of a chemically cross-linked PCL (c-PCL) as the polymer matrix and multiwall carbon nanotubes coated with iron oxide $\left(\mathrm{Fe}_{3} \mathrm{O}_{4}\right)$ nanoparticles (Figure 13) as reinforcement. The shape-memory effect can be triggered by hot water and by heat generated from $\mathrm{Fe}_{3} \mathrm{O}_{4}$ nanoparticles in an alternating magnetic field via hysteresis loss [106]. Actually, both stimuli induced shape recovery, but the recovery of the permanent form was reached faster when triggered by direct heat. This was probably caused by the high porosity that 
slowed the thermal conduction, recovering the initial shape more slowly when heated indirectly. Furthermore, the cytotoxicity of the material was evaluated through Alamar blue assay [107] by culturing osteoblast populations, revealing that the nanofibers, as well as their degradation product, were characterized by good biocompatibility, which is a fundamental property in tissue engineering.

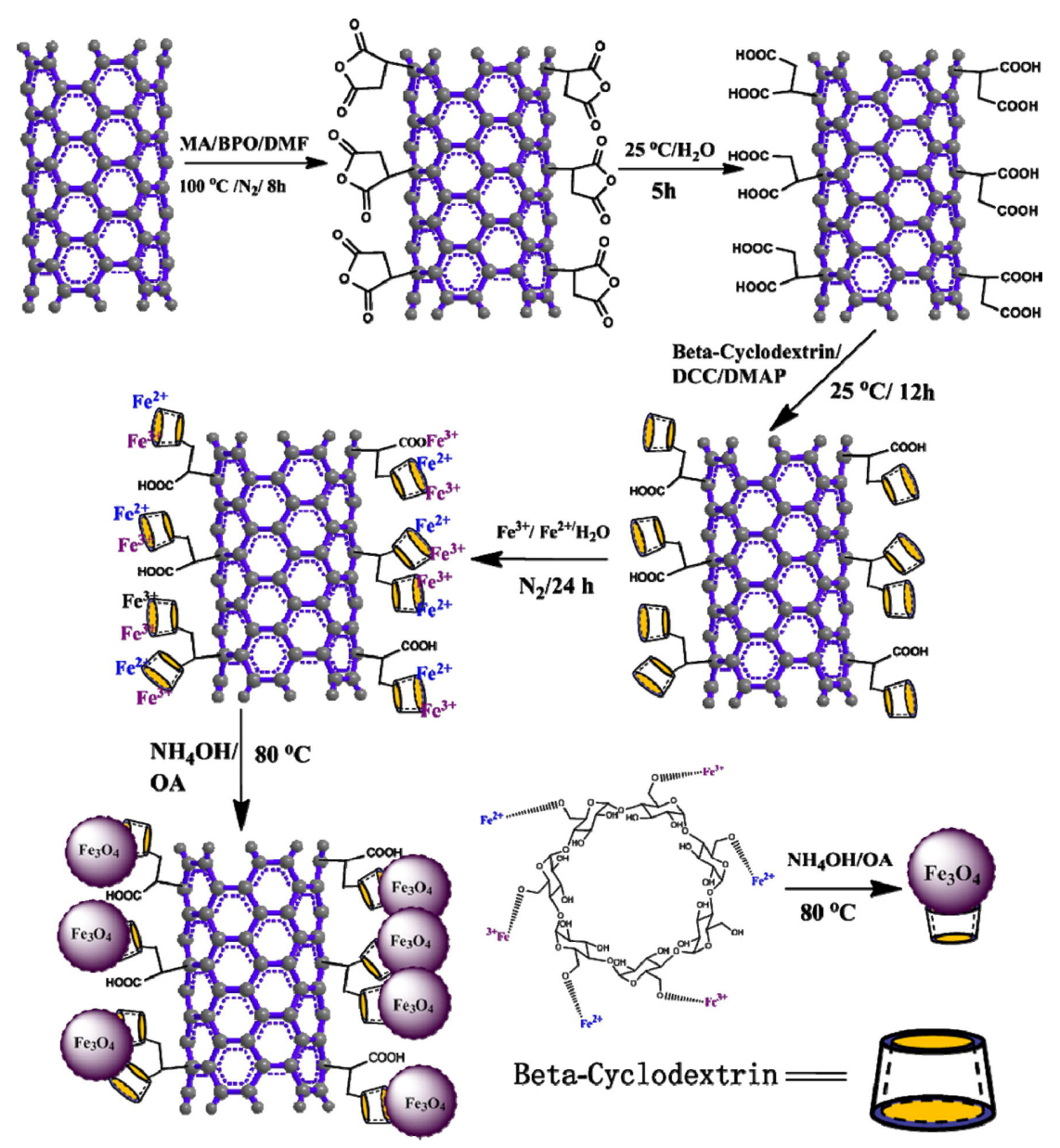

Figure 13. Synthesis of $\mathrm{Fe}_{3} \mathrm{O}_{4} @ \mathrm{CD}-\mathrm{M}$ nanoparticles. MWNTs were firstly functionalized by grafting maleic anhydride (MA) on their surface through a free radical reaction, subsequently modified by $\beta$-cyclodextrin ( $\beta$-CD), and finally the formation of $\mathrm{Fe}_{3} \mathrm{O}_{4}$ nanoparticles by the co-precipitation of $\mathrm{Fe}^{2+}$ and $\mathrm{Fe}^{3+}$ using $\beta-\mathrm{CD}$ as depositional locus [105].

Another interesting study was reported in 2014 by Bao et al. [108]. They prepared a thermoresponsive and biomimetic tissue engineering scaffold by electrospinning, constituted by poly(D,L-lactide-co-trimethylene carbonate) (PDLLA-co-TMC), obtained from copolymerization of the D,L-lactide (DLLA) monomer and the trimethylene carbonate (TMC) monomer. Following this procedure, they modulated the recovery temperature of the scaffold for applications in the human body and to regulate the mechanical and degradation properties by changing the molar ratio DLLA/TMC [109,110]. A decrease in the diameter of the fibers was observed: $1526 \pm 120 \mathrm{~nm}, 1073 \pm 201 \mathrm{~nm}, 790 \pm 204 \mathrm{~nm}$, and $682 \pm 146 \mathrm{~nm}$ by varying the monomer ratio DLLA/TMC from 5:5 to 7:3, 8:2, and $9: 1$, respectively, also causing a variation of the $\mathrm{T}_{\mathrm{g}}$ that can be exploited for biomedical applications. A DLLA/TMC ratio of $8: 2$ with a $\mathrm{T}_{\mathrm{g}}$ of $36.7^{\circ} \mathrm{C}$ and 9:1 with $\mathrm{T}_{\mathrm{g}}=44.2^{\circ} \mathrm{C}$ were chosen for these purposes. In fact, molar ratios of 5:5 and 7:3 showed lower $\mathrm{T}_{\mathrm{g}}$, and those materials with $T_{\text {trans }}$ close to room temperature and human body temperature are subjected to automatically induced shape changes after implantation, while $T_{\text {trans }}$ is slightly higher than body temperature, allowing better control of this behavior [111]. Shape-memory per- 
formances were evaluated and the fibers showed excellent shape-memory properties with an $R_{r}$ value above $94 \%$ and an $R_{f}$ value above $98 \%$. Moreover, they investigated the bone formation by culturing rat calvarial osteoblast on the fibrous PDLLA-co-TMC scaffolds in vitro to verify the cytocompatibility as well as biomineralization-relevant outcomes, including alkaline phosphatase expression and mineral deposition.

With the aim of developing functional, environmentally-friendly materials, Wei et al. [112] produced an electrospun chitosan (CS)/PEO membrane with different mass ratios where CS acted as the hard domain and PEO as the soft domain. The material showed $R_{f}$ and $R_{r}$ values above $90 \%$ after five cycles.

Among the biomedical applications, the replacement of metal hardware for the treatment of bone fractures has been investigated, since the removal of such devices can cause microtrauma and can leave empty screw holes that can lead to a risk of refracture [113]. With the aim of developing a biomimetic nanofibrous scaffold/implant, in 2016, Bao et al. [114] incorporated nano-HAp into poly(D,L-lactide-co-trimethylene carbonate) (PLMC), which is a copolymer with shape-memory properties, by co-electrospinning. HAp was loaded at different contents-1, 2, and $3 \mathrm{wt} . \%$-and the modulation of $\mathrm{T}_{\mathrm{g}}$ was observed in the range between 43.5 and $51.3^{\circ} \mathrm{C}$ by changing the HAp percentage. Furthermore, the composite material showed great SM properties, achieving $R_{r}$ and $R_{f}$ values above $99 \%$. In this case, biological assay results confirmed that the incorporation of HAp in PLMC nanofibers considerably promoted osteoblast growth, alkaline phosphatase secretion, and mineral deposition in bone formation.

Another biomedical issue concerns nerve regeneration. The peripheral nervous system (PNS) can be damaged as a consequence of different types of trauma, such as traffic accidents, natural disasters, and others. Generally, when the injuries are small, the nerve can regenerate itself, but when injuries are larger they need to be surgically treated with nerve grafts taken from other parts of the body [115]. Therefore, the production of flexible tubular scaffolds was studied to adopt new approaches [116] and, especially, the production of materials that present a prolonged and gradual recovery to mimic the regeneration process [117].

Chen et al. [118] developed a smart nerve conduit (SNC) with an automatic gradual lengthening of both proximal and distal nerve stumps through electrospinning. Such biodegradable SMP achieved gradual self-shrinkage in body water $\left(36^{\circ} \mathrm{C}\right)$. In order to obtain a prolonged recovery time, they fabricated a trisegment SMP with different glass transition temperatures for each segment (Figure 14).

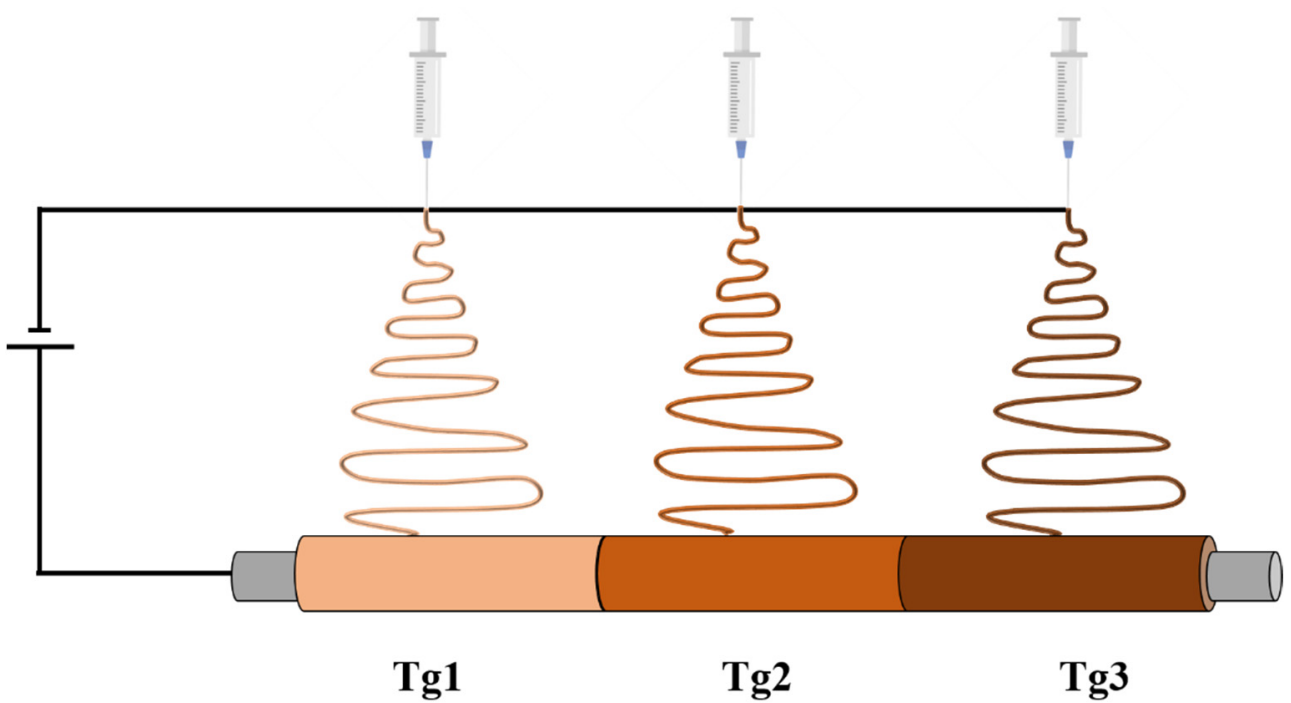

Figure 14. Representation of the fabrication of the trisegment SMP by electrospinning. 
PLLA was modified by substituting L-lactide with rac-lactide and then glycolide was incorporated into the network. Finally, poly(rac-lactide-co-glycolide) was obtained and the $\mathrm{T}_{\mathrm{g}}$ was tuned by varying glycolide monomer constituents. The SM properties were evaluated: all networks showed an $R_{f}$ value of $\sim 99 \%$ after ten thermomechanical cycles, whereas $R_{r}$ decreased from $90 \%$ to $50 \%$ during the first five cycles and the value stayed constant after the sixth cycle. This fact can be explained by a loss of physical crosslinks during the programming; however, the device will require only one activation.

Many other researchers have studied the fabrication of SM scaffolds for tissue engineering applications. Kai et al. [119] developed an SM polyurethane copolymer constituted by organic PCL and inorganic PDMS at different ratios of PCL/PDMS (9:1, 8:2, 7:3) by electrospinning. The ratio variation led to different fiber diameters and thermal and mechanical properties. Moreover, the SM properties were evaluated, revealing an $R_{r}$ above $90 \%$ and an $R_{f}$ above $92 \%$ after seven cycles. Furthermore, the biocompatibility of the material was proven, since the copolymer supported the proliferation of human fetal osteoblastic (hFOB) cells in in vitro culture. The authors subsequently investigated the properties of the same material, also incorporating carbon black to fabricate electrically conductive nanofibers [120]. Indeed, it was observed that the electrospun conductive nanofibrous scaffolds enhanced the nerve regeneration process [121]. They also observed an increase in the fiber diameter from $399 \pm 76 \mathrm{~nm}$ to $619 \pm 138 \mathrm{~nm}$ by adding carbon black (since the presence of the filler increases the viscosity of the solution) and a decrease in the resistivity from $3.6 \mathrm{G} \Omega \mathrm{mm}^{-1}$ to $1.8 \mathrm{k} \Omega \mathrm{mm}^{-1}$. From the evaluation of $\mathrm{SM}$ properties, they noticed the almost complete independence of the SM behavior from the addition of the fillers, given that the $R_{f}$ and $R_{r}$ values showed a slight decrease, however, maintaining the shape recovery ratio above $90 \%$ and the shape fixity ratio above $82 \%$, even after five cycles. In addition, the nanofibers showed good biocompatibility. PC12 cells were cultured on the scaffold and the nerve cells showed increased interactions.

Mejia et al. [122] used gelatin, which is a natural polymer derived from the controlled hydrolysis of collagen with high biodegradability and biocompatibility [123], and SMPU, both combined with carbon nanotubes to construct a scaffold through electrospinning. Among the materials produced, SMPU with MWCNTs presented the best performance in terms of morphology, with nanofibers of an average diameter of $451 \mathrm{~nm}$ and greater mechanical properties with a tensile strength of $1.912 \mathrm{MPa}$ and a high ratio of volume/surface.

In 2017, Marlettini et al. [124] developed a biodegradable and biocompatible scaffold starting from lactic acid, 1,3-propanediol, azelaic acid, and sebacic acid to obtain a PLLAbased triblock copolymer where the central block is poly(propylene azelate-co-propylene sebacate) (P(Paz60PSeb40)) random copolymer, which showed a thermally induced shapememory effect in the physiological temperature range. In particular, $\mathrm{P}(\mathrm{Paz60PSeb} 40)$ acted as switching segments while PLLA blocks, with higher $\mathrm{T}_{\mathrm{m}}$, acted as the physical network. In addition, instead of tuning the shape recovery temperature by varying the composition of copolymers, they used an alternative approach that consists of thermal annealing, where the sample is submitted to a controlled temperature for a limited time [125], which leads to an increased crystal phase perfection and consequently to a higher $\mathrm{T}_{\mathrm{m}}$. After annealing at $15{ }^{\circ} \mathrm{C}$, the material started the recovery at $25^{\circ} \mathrm{C}$ and finalized it at $40{ }^{\circ} \mathrm{C}$, while, after annealing at $30{ }^{\circ} \mathrm{C}$, the recovery started at $35^{\circ} \mathrm{C}$ and was completed at $55^{\circ} \mathrm{C}$. Both the samples exhibited very high values of $R_{f}$ and $R_{r}$, that is $98 \%$ for the sample annealed at $15^{\circ} \mathrm{C}$ and $99 \%$ for the one annealed at $30^{\circ} \mathrm{C}$. Moreover, the biocompatibility of the proposed scaffold was demonstrated by using NIH/3T3 fibroblast cells, showing high spread and cell proliferation.

SMPs for biomedical applications were also explored by Pandini et al. [126] by fabricating PCL-based fibrous mats through a combination of electrospinning and sol-gel reaction and, by varying the extent of the sol-gel reaction, two materials with a low and high crosslinking degree were obtained [127] (PCL-low and PCL-high, respectively). PCL-high, in particular, showed larger elongation-contraction effects and, as a result of biological investigation, higher cell proliferation and spreading. Since electrospinning permits the 
production of micro-porous structures similar to extracellular tissue where cells can be cultivated and proliferate [128], many studies were focused on the production of scaffolds, to develop implants for cardiovascular diseases that are functionally similar to blood vessels [129]. Montoya et al. [130] cultivated cardiac fibroblasts for more than 10 days of incubation in an SMPU membrane (Irogran) fabricated with two thicknesses, one with a thickness between $0.2 \mathrm{~mm}$ and $0.9 \mathrm{~mm}$ (sample 0 ) and the other between $0.9 \mathrm{~mm}$ and $1.0 \mathrm{~mm}$ (sample +1 ), and observed that sample +1 improved the growth and proliferation of the tissue cells in comparison to sample 0 , since it presented less porosity and a drop in the permeability values due to the growth of the tissue cells.

Many other studies were carried out to find scaffolds that mimic the extracellular matrix (ECM), which permits cell motility during tissue repair [131], but also to control the cell migration in disease progression [132]. To mimic the dynamic behavior of ECM, Wang et al. [133] fabricated a synthetic 3D biomaterial scaffold, which in the presence of cells can modify the fiber alignment in cytocompatible conditions by triggering the shape change at temperatures from 30 to $37^{\circ} \mathrm{C}$ when hydrated. The study of cellular response was conducted by choosing the fibrosarcoma cell line HT-1080 and the murine mesenchymal stem cell line $\mathrm{C} 3 \mathrm{H} / 10 \mathrm{~T} 1 / 2$, as they present high metastatic cancer cell motility and classic fibroblastic mobility, respectively. They found that both kinds of cells could be switched between polarized motility along the direction of fiber alignment and non-polarized motility between aligned and unaligned morphologies. Furthermore, they observed that cell velocity can be increased by increasing the fiber alignment.

Another field where SMPs have been applied concerns the treatment of spinal cord injuries (SCI) that lead to the destruction of nervous tissue [134]. The regeneration of these tissues can be promoted by the transplantation of stem cells that supply new neurons [135], but, unfortunately, this technique is affected by low cell viability and uneven cell distribution. In order to solve these problems, in 2018, Wang et al. [136] developed an injectable cell delivery system based on hydrogel with shape-memory properties. Hydrogels are often employed for these purposes because of their biodegradability, easy processability, and minimally invasive and present structural properties similar to tissues and ECM [137]. The injectable composite was fabricated by embedding poly(D,L-lactic acid-co-trimethyl carbonate (P(DLLA-co-TMC)), fabricated by electrospinning, in gelatin-acrylated $\beta$-cyclodextrin $(\beta-C D)$ polyethylene glycol-hydrogel (GCP-hydrogel), where the matrix created a local microenvironment for cell assembly: embryonic stem cells (ESCs) were used in this case and acted as a lubricant. The electrospun fibers showed an average diameter of $800 \pm 200 \mathrm{~nm}$, which remained unchanged when incorporated in the matrix. By observing the mechanical properties at $37^{\circ} \mathrm{C}$, it was noticed that nanomesh slightly reinforced the GPC-hydrogel. Furthermore, the shape-memory properties were evaluated by incubating the wrinkled hydrogel at $37^{\circ} \mathrm{C}$, the temperature at which it recovers its initial shape, and it was observed that the material recovers its original morphology in $\sim 15 \mathrm{~s}$ with an $R_{r}>95 \%$. The authors discovered that the composite was capable of significantly improving the viability of ESCs and their differentiation towards motor neurons both in vitro and in vivo.

The fabrication of materials to be used in the biomedical field and tissue engineering was studied also by Yao et al. [138] by incorporating Fe nanowire in an EVA matrix by electrospinning. The shape-memory behavior was obtained by a pre-treatment of the EVA sol with UV radiation to crosslink the material. The shape-memory behavior was investigated by applying two different stimuli: $55^{\circ} \mathrm{C}$ hot water (contact stimuli) and light radiation (non-contact stimuli). The material recovers its initial shape in hot water after $6 \mathrm{~s}$, whereas it took $100 \mathrm{~s}$ when irradiating, due to the fact that Fe nanowires are able to convert light energy to heat energy.

Inverardi et al. [139] produced another scaffold based on crosslinked PCL, and instead of changing the microstructure by modifying the electrospinning set-up [140], they took advantage of its SM behavior in modulating the fiber alignment by fixing different temporary shapes with different microstructures. The material is able to fix and recover the temporary and permanent shapes even when high deformation was applied (100\%). 
Moreover, neural stem cells derived from human iPSCs (induced Pluripotent Stem Cells) were seeded on both randomly and aligned fiber mats, showing cytocompatibility. It seems that in the randomly orientated mats, cell growth proceeded in all directions, while in the aligned fibrous mats, cell growth proceeded preferentially along with the fiber orientation.

SMPs have also been studied to develop scaffolds to be used for treating vascular disorders that are generally caused by endothelial cell malfunctions by causing damage to the arterial wall [141]. The rapid formation of a confluent endothelial monolayer is paramount for vascular remodeling and regulating coagulation since the endothelial surface is constantly exposed to humoral factors, inflammatory mediators, and physical forces [142]. With the aim of producing artificial vascular grafts (tubular scaffolds), Zhao et al. [143] designed a shape-morphing scaffold capable of converting from a 2D planar shape (temporary shape) into a 3D tubular shape (permanent shape) at physiological temperature and where endothelial cells were previously seeded. The scaffold is obtained by the co-electrospinning of PCL and gelatin methacrylate (GelMA). PCL was chosen because it presents similar mechanical properties to blood vessels [144], while GelMA supports cell adhesion, proliferation, and migration [145]. In this case, the shape-morphing scaffold exhibited the characteristics required regarding structure, supporting cell attachment and growth.

Further studies regarding biomedical applications were carried out by Niiyama et al. [43] by developing a temperature-responsive nanofiber mesh of a PCL-based polyurethane with different ratios of soft segments (PCL diol) and hard segments (hexamethylene diisocyanate (HDI) /1,4-butanediol (BD)). They observed that mechanical, fiber processability and stability, $\mathrm{T}_{\mathrm{m}}$, and SM properties can be changed by varying the PCL/HDI/BD ratio. The nanofibers exhibited great shape-memory performance, in particular PCL/HDI/BD 1:4:3. The nanofibers were placed in water at $60{ }^{\circ} \mathrm{C}$ and then stretched to different elongation degrees $(200,300$, and $400 \%)$. Finally, they recovered their original shape when placed again in hot water (at $\left.60^{\circ} \mathrm{C}\right)$, showing high $R_{r}(>89 \%)$, even when deformed at the greatest elongation (400\%). Moreover, human mesenchymal stem cells (hMSCs) were cultured on the meshes, showing alignment along with the fiber orientation, thereby demonstrating the biocompatible nature of the material.

Recently, multiple shape-memory polymers have attracted much attention, since they can be easily tailored by changing the transition temperatures without resorting to the synthesis of other polymers, and, besides, can be designed in several ways [146]. MultipleSMPs are usually produced by blending two immiscible SM polymers characterized by two different transition temperatures [147], thus considering that the blending of two miscible polymers would lead to a homogeneous phase that would exhibit only one $T_{\text {trans }}$ and dual-SM behavior. Therefore, with the aim of fabricating a material that showed triple-SM behavior constituted by miscible materials, Sabzi et al. [148] designed a triple-SMP consisting of PLA and PVAc, materials with two distinct $T_{g}$, through the co-electrospinning method, Additionally, graphene nanoplatelets were included to improve the SM behavior [149]. The material presented excellent triple-SM behavior, revealing high values of $R_{r}$ and $R_{f}$ and from cytotoxicity tests, high cell growth and the proliferation of the osteoblasts on the fibrous scaffolds containing graphene were observed. With this purpose, Zare et al. [150] developed a polycaprolactone dimethacrylate (PCLDMA) and PEO composite scaffold, in which PCLDMA acted as the switching segment (with a $\mathrm{T}_{\mathrm{m}}$ close to body temperature) and PEO as the permanent segment, by self-assembly electrospinning and photo-crosslinking, which can be applied simultaneously $[105,126]$, finally obtaining a highly porous, sponge-like scaffold (Figure 15). 


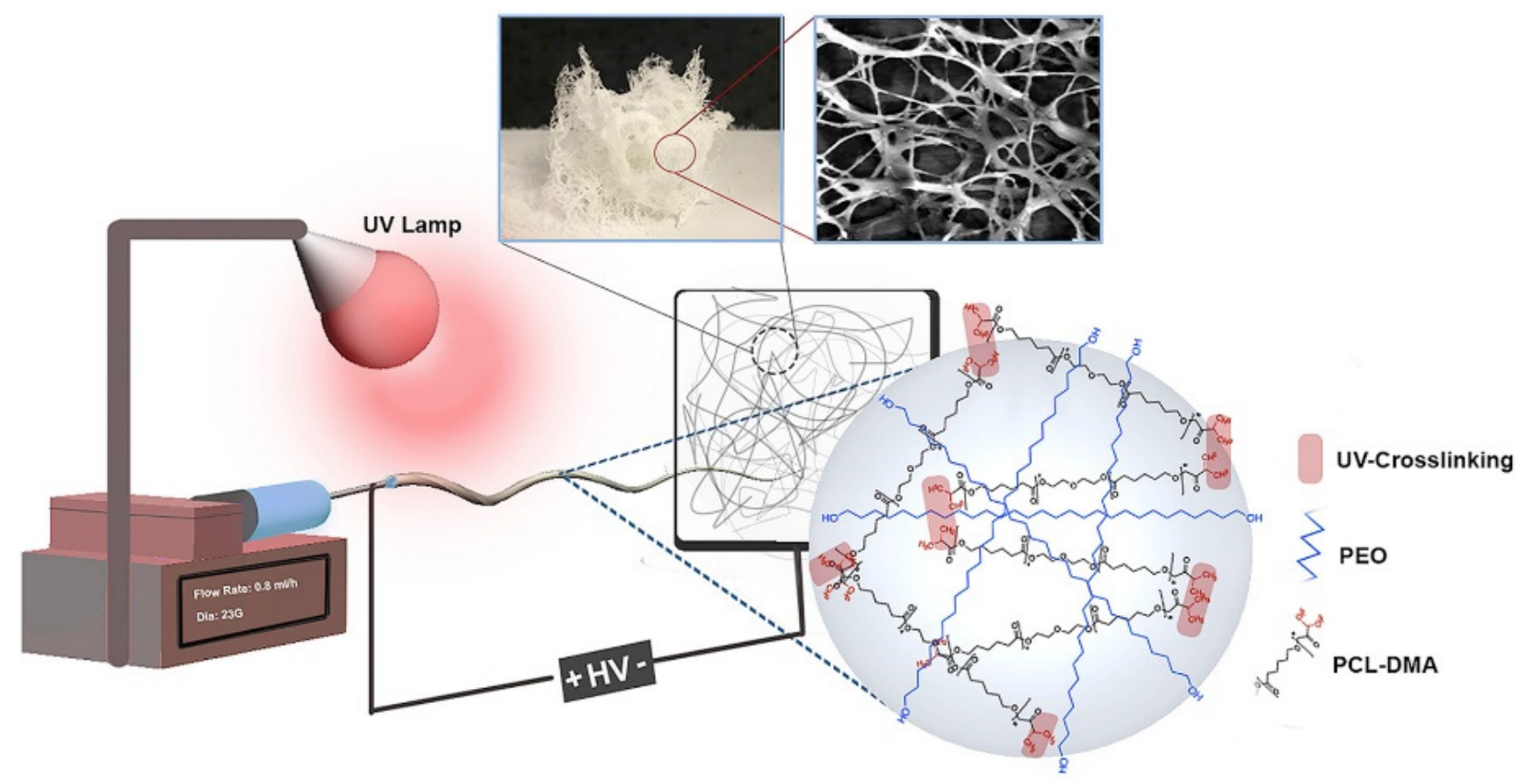

Figure 15. Representation of the sponge-like 3D scaffold [150].

Furthermore, gold nanoparticles (GNPs) of $10 \mathrm{~nm}$ were incorporated since they have been used in many biomedical applications, for photoablation, diagnostic imaging, as antioxidants, drug delivery vehicles, and for detecting cancer [151,152]. The sponge-like scaffold showed an average porosity of $93 \pm 1.8 \%$, providing high absorption abilities and good shape-memory capabilities, with $R_{f}$ and $R_{r}$ values of $97 \%$ and $88-89 \%$, respectively. Cytotoxicity tests with NIH3T3 cells revealed more than $75 \%$ cell viability, hence proving the low cytotoxicity of the 3D sponges.

Since the electrospinning technique produces 2D woven no-woven scaffolds, in order to produce more suitable scaffolds for tissue engineering, the development of 3D scaffolds was studied to extend the potential applications, as they better mimic the structure of ECM and regulate cellular biological behavior (adhesion, differentiation, and matrix deposition) [153,154]. With a view of producing a 3D scaffold for cartilage regeneration, Chen et al. [155] adopted a different approach by processing 1D gelatin/poly(lactic-coglycolic acid) (PLGA) electrospun fibers into inks ideal for 3D printing so as to obtain 3D scaffolds with a controlled shape and porous structure. Three-dimensional printing allows the fabrication of material with a precise form; however, the produced scaffolds presently lack fibrous surface structure, constituting a problem for the development of materials that mimic the ECM structure. Therefore, the combination of electrospinning and 3D printing should lead to the fabrication of a 3D scaffold with an appropriate, controlled shape and high porosity. The 3D scaffold presented showed good elasticity and water-induced shapememory behavior, and, in addition, when combined with chondrocytes, achieved cartilage regeneration in vivo [155].

In 2020, Chen et al. [156] developed an SM tubular scaffold for blood vessel replacement composed of poly(lactide-glycolide-trimethylene carbonate) (PLGATMC) as an outer layer and an inner layer of poly(lactide-glycolide) (PLGA)/chitosan, where smooth muscle cells (SMCs) were cultured. PLGATMC was chosen for programming the deformation from a 2D planar, in which cells can be located, to a 3D tubular shape, assuming the blood vessel structure, whereas PLGA was selected for its biocompatibility, biodegradability, and mechanical properties [157]. Nevertheless, it presents low cell affinity because of its poor wettability and lack of cellular recognition sites that permit the biological signals. These cell recognition sites were provided by chitosan (CS) [158]. PLGA/CS@PLGATMC was fixed in the temporary shape at $20^{\circ} \mathrm{C}$, where cells were cultured, and then the $3 \mathrm{D}$ tubular permanent shape was recovered at $37^{\circ} \mathrm{C}$. It was reported that among the fabricated 
scaffolds with different PLGA/CS ratios, the one with a PLGA/CS ratio of 7:3 turned out to be the most suitable for tissue engineering purposes, displaying the best biocompatibility for SMCs.

In order to fabricate materials for biomedical applications, polylactides have been widely used. However, as said before, their brittleness, low toughness, relatively poor retention, and recovery efficiency led the researchers to the production of polylactide-based shape-memory copolymers or blends with other polymers. In 2021, Wang et al. [159] modified PLLA by incorporating poly(3-hydroxybutyrate-co-3-hydroxyvalerate) (PHBV) to form ultrafine composite fibers by using the electrospinning technique. They identified the formulation of PLLA-PHBV (7:3) as the best formulation, since the presence of PHBV decreased the $\mathrm{T}_{\mathrm{g}}$ and increased the Young modulus of the material. In particular, the material showed an $R_{f}(>98 \%)$ and an $R_{r}(>96 \%)$ compared to neat PLLA. Moreover, electrospun PLLA-PHBV composite fibers showed enhanced osteogenic-inducing ability in the mouse bone mesenchymal stem cells, which makes this fabricated scaffold suitable for bone tissue repair applications.

Further studies have been reported in 2021 in order to produce scaffolds and medical devices. For instance, Sarabiyan et al. [160] fabricated SMPU/graphene quantum dot nanoparticle (GQDs) nanofibers. The presence of PCL as the soft segment in the structure contributed to the shape-memory behavior of the material. The GQD NPs improved the mechanical properties of the nanofibers and more uniform nanofibers were obtained due to the electrical conductivity of GQD NPs that support the electrospinning process. Additionally, the presence of this kind of NPs enhanced the proliferation and compatibility of 3T3 fibroblast cells with the scaffold.

Another interesting work related to tissue engineering was carried out by Feng et al. [161], by fabricating a sub-micron fiber patch of polyurethane/polyaniline/silicon oxide (PU/ $\mathrm{PANI} / \mathrm{SiO}_{2}$ ) with a $3 \mathrm{D}$ porous structure and improved electrical signal transduction and self-adhesion, which simulated the myocardium ECM for myocardial infarction (MI) therapy. SMPU has been used for its capability to recover its original shape after a few seconds to minutes under specific conditions, while the presence of conjugated polymers such as PANI provides conductivity since electrical signals are fundamental for the heart's activity, and, finally, the incorporation of $\mathrm{SiO}_{2}$ into biopolymers improves the bioactivity. The schematic procedure of the fabrication and self-adhesion of the sub-micron fibers cardiac patch is shown in Figure 16.

SMPUs were used also by Lv et al. [162] with the aim of fabricating light-responsive SMPs by the introduction of dopamine (DA) that was subsequently polymerized, obtaining a coating of polydopamine (PDA) onto the surface. PDA has good biocompatibility and presents the capability to produce heat when illuminated by NIR light, permitting the recovery of the permanent shape and observing the recovery of the initial shape by irradiating the material with a light intensity above $0.2 \mathrm{~W} \mathrm{~cm}^{-2}$ (taking $30 \mathrm{~s}$ under $0.6 \mathrm{~W} \mathrm{~cm}^{-2}$ and $18 \mathrm{~s}$ under $1.0 \mathrm{~W} \mathrm{~cm}^{-2}$ ).

With the aim of producing materials with shape-memory behavior, sometimes polymers without this property are modified in order to achieve the desired SM properties. For example, Liverani et al. [163] used PCL modified at chain-ends, producing a triethoxysilaneterminated poly(epsilon-caprolactone) (PCL-TES) loaded with bioactive glasses (BG), which are capable of binding the host tissue and generating a coating of hydroxycarbonate apatite. The $\mathrm{SiO}_{2}$ domains subsequently formed the reaction between the ends group, constituting the permanent crosslinking point. The chemical interactions between the PCL-TES chain ends and the silanol groups on the nanoparticle surface generated additional crosslinking points that permitted the recovery of the permanent shape, showing an $R_{r}$ and $R_{f}$ above $90 \%$. 
(a)

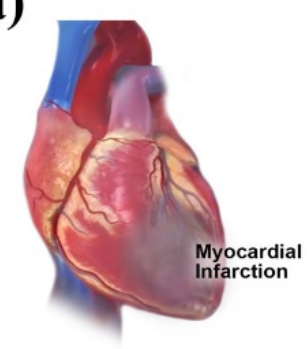

Self-adhesion conductive sub-micron fibers cardiac patch by shape memory polymers

to promote electrical signal transduction function
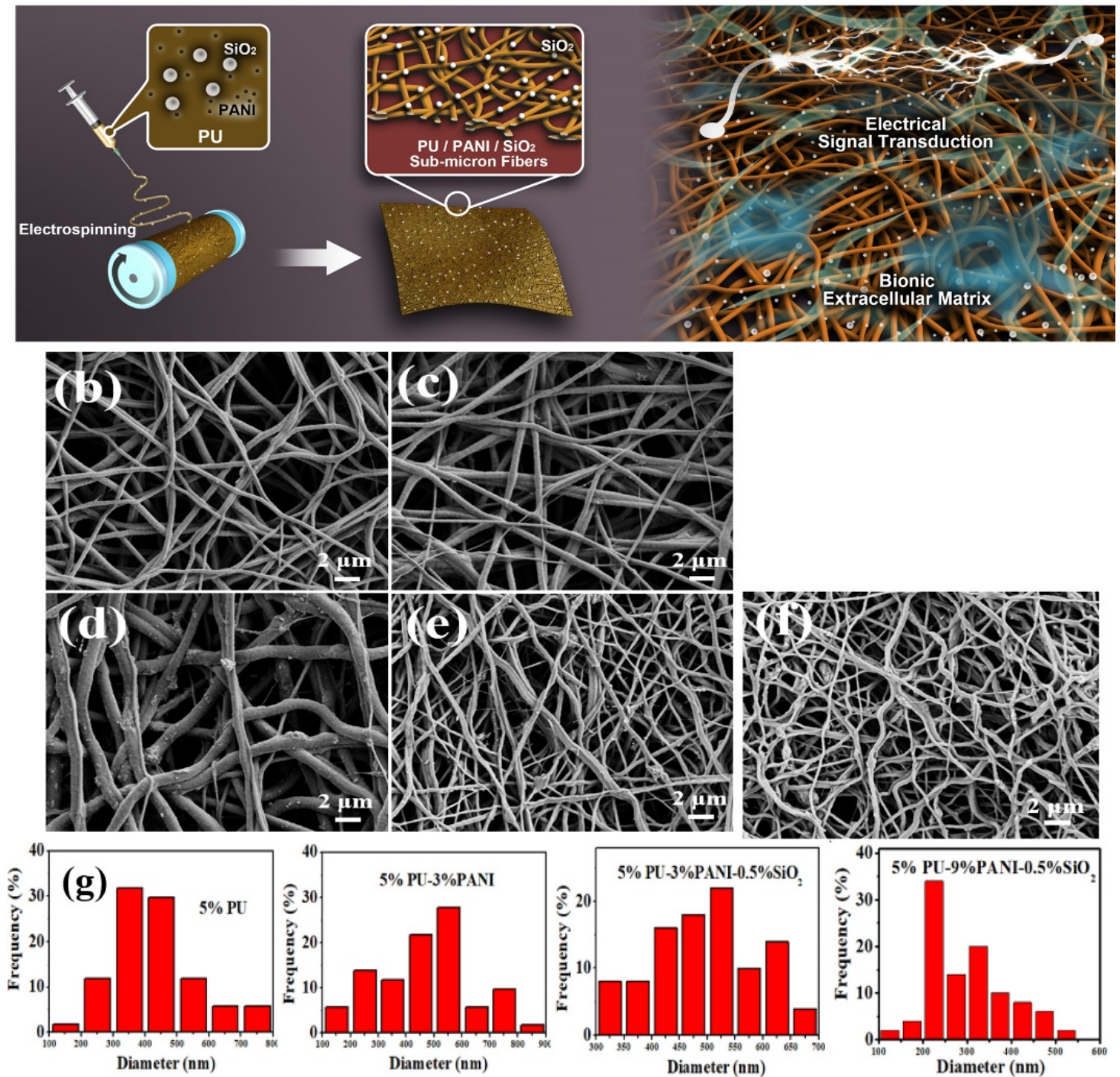

Figure 16. (a) Fabrication and self-adhesion of sub-micron fiber cardiac patch. SEM of (b) 5\% PU, (c) $5 \%$ PU-3\% PANI, and (d) $5 \%$ PU-3\% PANI-0.5\% SiO 2 , (e) $5 \%$ PU-6\% PANI-0.5\% $\mathrm{SiO}_{2}$, and (f) $5 \%$ PU-9\% PANI-0.5\% $\mathrm{SiO}_{2}$, and (g) fiber diameter distribution. Reprinted (adapted) with permission from [161]. Copyright 2021 American Chemical Society.

\subsection{Drug Delivery}

Even if nanofibers have been widely used in the biomedical field for tissue engineering, drug delivery is another important field of application. Actually, the large surface areas and high porosity provide high loading capacity and encapsulation efficiency [164,165], thus allowing the fabrication of new scaffolds as drug carriers suitable for post-surgical adhesions and infections and postoperative local chemotherapy [166]. 
Another polymer that has been investigated is polydioxanone (PDX) since electrospun PDX presents similar mechanical properties to collagen and elastin [167] and has been widely used in drug/gene delivery. Moreover, PDX nanofibers have been studied as anti-inflammatory agents [168] in rotator cuff repair [169]. For instance, Kratz et al. [170] designed a diblock PCL-b-PDX nanofibrous scaffold that revealed values of $R_{f}$ and $R_{r}$ in the range of $92-98 \%$. Besides that, they explored hydrolytic and enzymatic in vitro degradation.

Biocompatible SMPs have been widely produced, generally triggered by heating or by light. However, temperature activation is not always achievable or recommended. For this reason, some researchers have produced intelligent materials that can be triggered by biological activity: enzymatic triggering has been identified as one of the solutions, due to their biological activity and specific localization in the human body [171]. Additionally, SMPs triggered by enzymes can find applications in drug delivery, scaffolds for tissue regeneration, and platforms for stem cells. In 2019, Buffington et al. [172], designed a cytocompatible shape-memory polymer enzymatically triggered and constituted by PCL as a shape fixing component, which is vulnerable to enzymatic degradation, and Pellethane ${ }^{\circledR}$ (5863-80A) as a shape-memory component that is enzymatically stable. The temporary shape was fixed sequentially by heating above the $\mathrm{T}_{\mathrm{m}}$ of PCL, deforming the material, and, finally, by decreasing the temperature. In this step, PCL was maintained under compression and Pellethane ${ }^{\circledR}$ under tension. Afterwards, the material was placed in a solution of lipase, which is an enzyme produced by both eukaryotes and prokaryotes [173], the hydrolyzed ester bonds leading to PCL degradation and the Pellethane ${ }^{\circledR}$ recovered back its original shape. Through shape-memory properties evaluation, it was observed that such behavior was evident only when the highest lipase concentration was used $\left(0.5 \mathrm{mg} \mathrm{mL}^{-1}\right)$ within a 7 days test period. Indeed, lower concentrations of lipase degraded the PCL but no shape recovery was observed.

Lv et al. [174] designed an SMPU/HA composite (HA has been already used for bone tissue engineering given its large presence in bone ECM [47]), suitable as a drug carrier. Furthermore, they investigated the release of dexamethasone (DEX), a synthetic glucocorticoid that supports bone formation [175], which was previously loaded into the fibers. In this case, HA improved the degradation rate of the fibers: the weight loss after 10 weeks for the fibers with 1, 3, and 5 wt.\% was 14.5, 17.1, and 19.1 wt.\%, respectively, causing the simultaneous, controlled release of the drug that strongly depends on the polymer degradation. The material with $3 \mathrm{wt}$ \% of HA showed the best SM performance with an $R_{r}>97 \%$ and a recovery time of $\sim 6 \mathrm{~s}$.

Another drug delivery system (DDSs) was developed by Yin et al. [176] by designing a multilayered electrospun structure (sandwich structural membrane) through sequential electrospinning and consisting of three layers of electrospun SMPU with a $\mathrm{T}_{\text {trans }} \approx 42{ }^{\circ} \mathrm{C}$. A natural antibacterial compound, berberine hydrochloride $(\mathrm{BCH})$, was embedded in the middle layer, and the two outer hydrophobic layers were necessary to extend the drug release period. Such a design permitted the increase of the diffusion path of the drugs from the medium [177] to have better control over the drug's delivery. The experiments revealed that $80 \mathrm{wt} . \%$ of $\mathrm{BCH}$ was released in $144 \mathrm{~h}$ and that the release rate was increased by stretching and fixing the temporary shape.

Bil et al. [178] fabricated another drug delivery system based on two types of SMPUs: PU-PLGA and PU-PLLA/PEG, which differed in soft segment composition by introducing D,L-lactide-co-glycolide diol (o-PLGA), poly-L-lactide diol (o-PLLA), or polyethylene glycol (o-PEG) in order to modulate the SM properties and decrease the $T_{\text {trans }}$ to values close to body temperature. Both electrospun mats (PU-PLGA and PU-PLLA/PEG) showed an $R_{f}$ value above $90 \%$, and $R_{r}$ values of $98 \%$ and $99 \%$ for PU-PLLA/PEG and PU-PLGA, respectively. In general, the PU-PLGA scaffold presented the best features in terms of mechanical properties while both materials are suitable as drug delivery systems for rapamycin (Rap), revealing a controlled release over 45 days with therapeutic dosage. 


\subsection{Wound Dressing}

Among the various biomedical applications, SMPs as wound dressings have also been studied. When the skin is damaged, a physiological process called wound healing takes place, which includes cell proliferation, differentiation, and migration, leading to tissue repair and regeneration $[179,180]$. Composite nanofibers, derived from synthetic and natural polymers, satisfy the conditions of wound healing in terms of structure and properties [28,181]. For this purpose, in 2015, Tan et al. [182] fabricated novel composite nanofibrous mats (CNMs) consisting of chitosan, gelatin, and SMPU by electrospinning. Chitosan and gelatin were incorporated to enhance the hydrophilicity and biological properties of the material while SMPU acted as a mechanical matrix. Then, to improve the antimicrobial properties, the material was treated with a silver nitrate $\left(\mathrm{AgNO}_{3}\right)$ solution [183]. The SM properties were evaluated, obtaining an $R_{r}$ value above $95 \%$ after the first cycle and an $R_{f}$ value above $92 \%$ even after three cycles. Because of these SM properties, CNMs can be used for the wound closure process: the force accumulated by the pre-programming of CNMs is used to close the wound slowly, and later, this force is released when recovering the former shape (under body temperature) without applying any external force. Otherwise, immediate recovery could cause pain and nuisance (Figure 17).
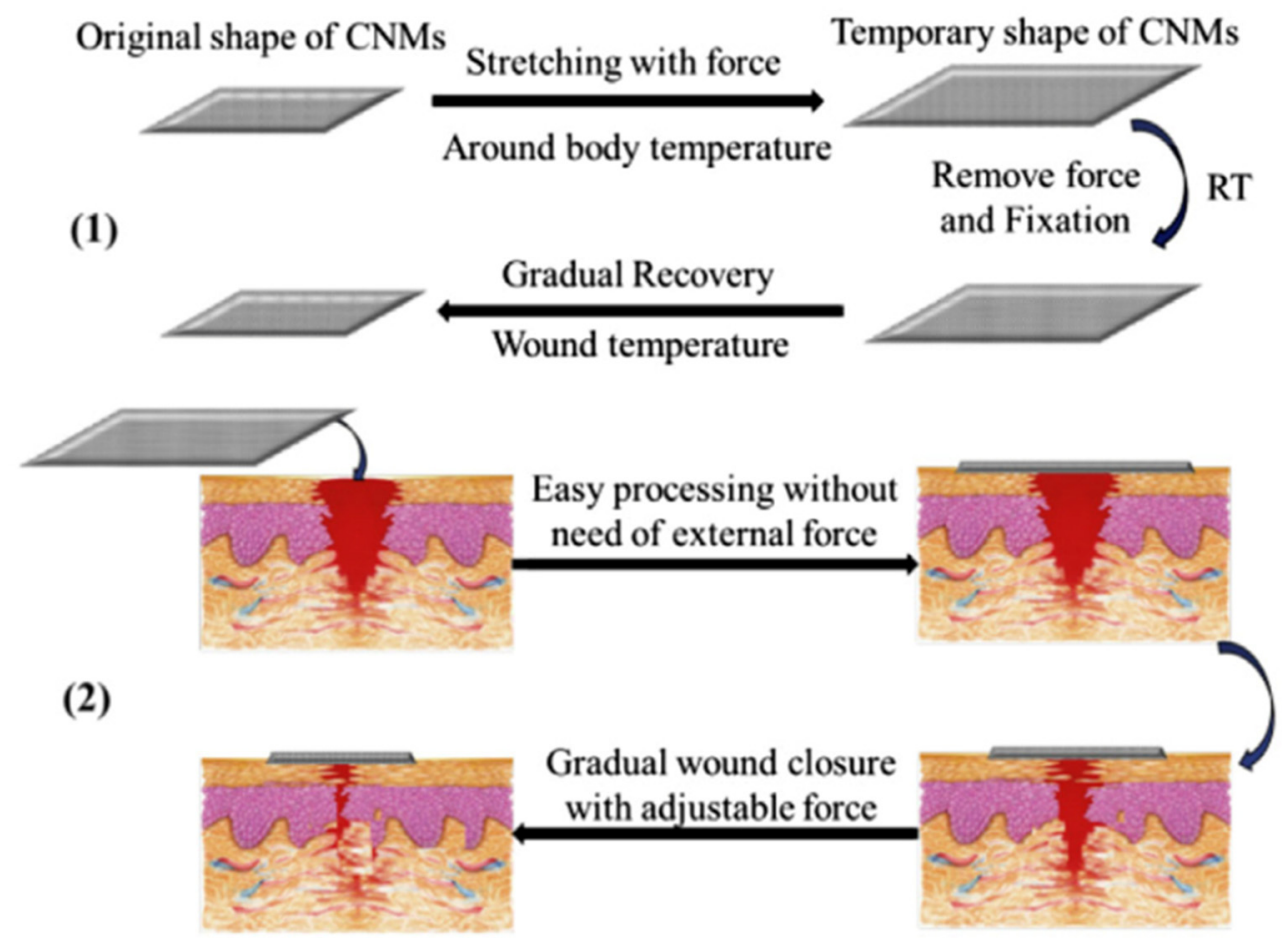

Figure 17. Schematic illustration of wound closure process by using CNMs [182].

\subsection{Biomedical Devices and Medical Imaging}

Other approaches have been used in order to fabricate smart materials for practical applications such as medical imaging and for the fabrication of biomedical devices. In 2011, Zhang et al. [184] aimed to design a microfiber film based on PCL which, compared to the bulk SMPU film, achieved a quicker recovery of the permanent shape when heated in a water bath, obtaining an improvement of such properties without changing the chemical composition of the starting material. The shape recovery of the microfiber film took $\sim \frac{1}{4}$ time of that needed for the bulk film to reach an $R_{r}$ value from $10 \%$ to $90 \%$. This behavior was attributed to the higher surface area of the fibers, leading to an easier diffusion of water and, consequently, a faster heating/cooling of the material.

Other studies have been directed to the design of dye-containing polymers. In particular, dyes that absorb and emit light in the near-IR spectrum have also found a place 
in medical imaging applications in order to replace other, more invasive techniques such as x-ray imaging. Near-infrared fluorescence (NIRF) (700-1000 nm) imaging has been investigated as an alternative since the main tissue absorbing components present minimal absorption in this range: oxy- and deoxyhemoglobin $\left(\lambda_{\max }<600 \mathrm{~nm}\right)$ and water $\left(\lambda_{\max }>1150 \mathrm{~nm}\right)$. In 2014, Torbati et al. [185] incorporated indocyanine green (ICG), which is a dye that presents an adsorption band around $700 \mathrm{~nm}$ and an emission band around $800 \mathrm{~nm}$ [186], into a PVAc matrix to produce a fibrous web by electrospinning, finding an optimum dye concentration $\left(0.0125 \mathrm{mg} \mathrm{mL}^{-1}\right)$ that gave the highest emission intensities. Moreover, they discovered that the fiber mats showed higher fluorescence intensity and higher uniform dye incorporation with respect to the cast films. Furthermore, fibers contract upon heating or in contact with water due to the SM properties of PVAc. Such behavior can be used for applications such as feeding tubes or catheters.

Zhang et al. [187] developed a core/shell composite fiber by coaxial electrospinning, in which epoxy is the reinforced core layer that provides good mechanical properties and PCL is used as a shell layer, which improves the biocompatibility of the composite; indeed, a cytotoxicity test was carried out. SM properties were also evaluated: the material can recover its initial shape when heating at $70{ }^{\circ} \mathrm{C}$, the complete shape recovery took $6.2 \mathrm{~s}$, and the $\mathrm{R}_{\mathrm{r}}$ was about $100 \%$. From the cytotoxicity test, performed with a CCK-8 assay, it was observed that the cell viability of the PCL/epoxy membrane was more than $80 \%$ after 4 days of cultivation, proving the non-toxicity of the material.

Kuang et al. [188] used PU-based architecture and 3,4-dihydroxy-1-butene (DHB) as a chain extender with a pendant allyl group suitable for the formation of crosslinks and for controlling the melting temperature of the material, consequently altering the SM properties. Their aim was to fabricate a biodegradable, crosslinkable, and electrospinnable thermoplastic PU with two-way reversible SM behavior. The material showed good shape fixing and recovering behavior and, additionally, they observed that PCL $3 \mathrm{k}$-TPUs underwent enzymatic degradation in a two-step way that depends on their crystalline structure and their crosslinking degree, demonstrating the biodegradability of the material, which makes it potentially suitable for biomedical applications.

Peng et al. [189] fabricated PLA nanofibers reinforced with hyperbranched PLAmodified cellulose nanocrystals (H-PLA-CNCs) by electrospinning, potentially suitable as a membrane. PLA has been widely studied as a biocompatible and biodegradable material, used particularly in the biomedical sector [190]. However, it presents poor mechanical properties and hydrophilicity. Thus, to overcome these problems, CNCs were added as reinforcement, presenting an abundance of hydroxyl groups on the surface that led to easy incorporation and dispersion into the matrix [191]. The SM performance was evaluated and compared to that of neat PLA, which showed an $R_{f}$ value of $90 \%$ and an $R_{r}$ of $56 \%$, and it was observed that by adding 1,3 , and $5 \mathrm{wt} . \%$ of H-PLA-CNCs, the $R_{r}$ increased from 67 to 77 and $93 \%$, respectively. On the other hand, by adding $7 \mathrm{wt}$. \% of H-PLA-CNCs, the $R_{r}$ decreased to a value of $42.9 \%$. The presence of hydrogen bonds between H-PLA-CNCs and PLA allowed the recovery of the initial shape under the traction of the hydrogen bond force, but with the highest amount of H-PLA-CNCs, the membrane was subjected to an irreversible deformation, leading to a lower $R_{r}$ value.

Hsieh et al. [192] developed electrospun copolymer nanofibers with potential applications as medical shrinkable tubing and wire, based on PCL and PDMS with different PCL/PDMS ratios, where PCL acted as the switching segment and determined the crystallinity of the copolymer nanofibers. The fabricated copolymers performed SM properties with a response of $10 \mathrm{~s}$ to recover its original shape and $R_{r}$ and $R_{f}$ values around $98 \%$ and $100 \%$, respectively, triggered by a temperature around $37^{\circ} \mathrm{C}$, which is the melting temperature revealed from all the produced materials for all compositions.

Many studies were focused on the study of structure, properties, and the optimization of parameters in order to obtain fibers with high performance and to be used for several applications; in particular, in the biomedical field. However, the SM properties are suitable for applications in many other fields. 


\section{Other Applications}

Even though shape-memory nanofibers have found applications in tissue engineering, wound dressing, and drug delivery, some researchers have been focusing their attention on the improvement/modulation of the properties of these materials for further potential uses.

One of the fields investigated is robotics, in which SM fibers can find applications as microswitches, microactuators, and micromanipulators (actuators and sensors). However, the polymeric material, in order to be potentially used, should respond to an external stimulus such as a current or electric field with a subsequent strain. Some of them, in reverse, show the capability to transform mechanical movement into an electrical response $[193,194]$. In 2010, McDowell et al. [194] fabricated an electroactive polyferrocenylsilane (PFS) functionalized with pendant alkoxysilane groups, subsequently hydrolytically gelled by adding $p$-toluene sulfonic acid hydrate $\left(\mathrm{PTSA} \cdot \mathrm{H}_{2} \mathrm{O}\right)$ that also increased the conductivity of the electrospinning solutions, leading to a production of fibers with a low number of structural defects. These materials demonstrated strain-induced deformation on electroactuation at $1.5-2.0 \mathrm{~V}$ anodic potential, producing a reversible $20 \%$ longitudinal strain, revealing, therefore, the capability to convert an electrical signal to a mechanical response, whereas the application of $2.0 \mathrm{~V}$ cathodic potential led to the recovery of the initial shape.

Among the various alternative applications, additional studies have been carried out by investigating the antibacterial activity to use them as active antibacterial nanomaterials [195]. In 2011, Zhuo et al. [196] fabricated SMPU core-shell nanofibers by coaxial electrospinning, constituted by a core of polycaprolactone-based SMPU (CLSMPU) and a shell of pyridine-containing polyurethane (PySMPU) and obtaining both the core-shell and bead-on-string structure. The shape-memory performances of the core-shell nanofibers were studied and the material revealed an $R_{f}$ value above $95 \%$, significantly improved compared to that of pure CLSMPU nanofibers, which present a lower $R_{f}$ value $(\sim 80 \%)$ [34], while the $R_{r}$ showed values above $90 \%$. The CLSMPU-PySMPU nanofiber revealed outstanding antibacterial activity by showing no growth of S. aureus and K. pneumoniae bacteria beneath the mat, while this growth was observed with the pure CLSMPU mat.

Additionally, since the electrospinning technique permits the fabrication of porous materials, the application of shape-memory electrospun nanofibers as a membrane has been also studied. Ahn et al. [197] developed SMPU membranes with two-way shapememory behavior in order to modify the size of the nanopores. The material was subjected to one cycle of SM behavior and then the material changed from the permanent to the temporary shape without the "programming" step. With a bias load (constant stress) applied, the material expanded upon cooling and then shrunk by heating at temperatures higher than $\mathrm{T}_{\text {trans }}$, recovering the initial shape when the retracting force exceeded the stress applied. Upon cooling, the average pore size increased from 154 to $444 \mathrm{~nm}$, thus allowing the separation of substances with different sizes only by changing the temperature. The modulation of the pore dimensions by changing the temperature has been used also for the development of intelligent clothing material.

Chung et al. [198] aimed to fabricate electrospun nanowebs (ESWs) of SMPU with different hard segment content and PCL molecular weight $\left(\mathrm{M}_{\mathrm{n}}\right)$. The specimen with higher PCL M $\mathrm{n}_{\mathrm{n}}\left(4000 \mathrm{~g} \mathrm{~mol}^{-1}\right.$ ) with higher hard segment content (33 wt.\%), which showed an $\mathrm{R}_{\mathrm{f}}$ value of $86 \%$ and an $R_{r}$ value of $85 \%$, was chosen to fabricate the ESW, revealing good moisture and air permeability due to the high porosity when kept in its expanded state below the transition temperature.

In 2013, Rodriguez et al. [199] fabricated a soft anisotropic shape-memory elastomeric composite (A-SME-C) that can be used in the automotive and aerospace industries in laminated composite elastomers. They aimed to produce a material that could mimic the skin membrane of a bat wing, which presents anisotropic properties: the wing membrane skin shows high stiffness and strength parallel to the skeleton and high extensibility parallel to the wing's trailing edge. This anisotropy is caused by the disposition of the fibers of both collagen and elastin [200]. A poly(vinyl acetate) (PVAc) mat was incorporated as reinforcement into a Sylgard-184 silicone (Sylgard) elastomeric matrix. Moreover, the elastic 
modulus $\left(\mathrm{E}_{\mathrm{y}}\right)$, strain-to-failure $\left(\varepsilon_{\mathrm{f}}\right)$, and yield stress $\left(\sigma_{\mathrm{y}}\right)$ were evaluated according to the fiber orientation angle $\chi: 0^{\circ}$ (longitudinal), 22.5, 45, 67.5, and $90^{\circ}$ (transverse), observing $E_{\mathrm{y}}$ average values of $48.8 \mathrm{MPa}$ and $4.0 \mathrm{MPa}, \varepsilon_{\mathrm{f}}$ of $198 \%$ and $351 \%$, and $\sigma_{\mathrm{y}}$ of $4.6 \mathrm{MPa}$ and $0.9 \mathrm{MPa}$ for longitudinal and transversal loading, respectively. From the SM performance, a decrease in $R_{f}$ was observed by decreasing the orientation angle $\chi$ : from $95.6 \%$ for $0^{\circ}$ to $86.2 \%$ for transversal oriented fibers $\left(90^{\circ}\right)$, while $R_{r}$ maintained high values (around $99 \%$ ) independently from the fiber orientation.

Zhang et al. [201] developed Nafion ${ }^{\circledR}$-based quintuple shape-memory membranes that can find applications in robotics and aerospace engineering, and also as a catalyst. Electrospun Nafion ${ }^{\circledR}$ nanofiber membranes (ENNMs) presented higher specific surface area, higher aspect ratio, and higher pore diameter compared with the bulk films, and these features were employed to improve the catalytic activity [202], which was also enhanced by adjusting the shape of the material by varying the temperature. The quintuple-SM behavior was achieved by establishing four $\mathrm{T}_{\text {trans: }}: 160,125,90$, and $55^{\circ} \mathrm{C}$, and the Nafion membrane revealed $R_{f}$ and $R_{r}$ values around $80 \%$, while the $R_{r}$ to recover the initial and permanent shape was above $70 \%$.

In 2014, the same authors reported another research developing an SM nanocomposite constituted by a Nafion ${ }^{\circledR}$ polymeric matrix with shape-memory behavior and PAN-based carbonization nanofiber, which makes the material sensitive to electrical stimulus [203]. The PAN nanofibers were firstly subjected to stabilization and carbonization processes [204] to obtain a network and finally integrated into the matrix. The average fiber diameter decreased from $618 \pm 67$ to $327 \pm 38 \mathrm{~nm}$, caused by the chemical changes to which the material was subjected during the consecutive procedures. Additionally, by increasing the applied voltage from 20 to 25 and $30 \mathrm{kV}$, the average diameter of the PAN-based carbonization fibers also increased from $343 \pm 49$ to $483 \pm 48 \mathrm{~nm}$, leading to a decrease in conductivity. The recovery of the permanent shape was triggered by applying a $14 \mathrm{~V}$ constant electrical current, taking only $5 \mathrm{~s}$, and the material revealed excellent $\mathrm{SM}$ properties with an $R_{r}$ value of approximately $100 \%$.

In 2015, Nejad et al. [205] carried out the production of a composite material consisting of PVAc and PCL by dual-electrospinning and manifesting both self-healing (SH) and SM behavior upon thermal activation in order to obtain an SH coating or a potential packaging material. Such material manifested dual-SM behavior in the dry state and triple-SM behavior in the wet state.

Fan et al. [206] fabricated a hierarchical porous carbon nanofibrous (CNF) membrane by electrospinning and doping with different contents of $\mathrm{SiO}_{2}(5,10$, and $20 \mathrm{wt} . \%)$, which can find applications in the adsorption of proteins. The $\mathrm{SiO}_{2} @ \mathrm{CNF}$ exhibited improved mechanical properties, high water permeability, and enhanced protein absorption capacity for bull serum albumin. The introduction of $\mathrm{SiO}_{2}$ nanoparticles significantly improved the mechanical properties: in fact, by increasing the nanoparticle content, the stiffness of the membranes was decreased, as was revealed by the decrease in the elastic modulus. The shape-memory capabilities were observed by previously bending the sample with $20 \mathrm{wt} . \%$ of $\mathrm{SiO}_{2}$ to a radius of $<100 \mu \mathrm{m}$, without observing any rupture, followed by a subsequent recovery of the initial shape. The enhanced mechanical properties were attributed to the "plasticizer effect" of the embedded nanoparticles.

In 2018, Del Sorbo et al. [207] carried out the production of light, non-woven mats by electrospinning a solution of PVP where graphene was previously dispersed, observing, for the first time, the non-monotonous effects of the addition of graphene. Graphene is considered an "environment-friendly material" that exhibits high-flame retarding, and for this reason, is widely used in engineering [208]. They observed that the graphene concentration affected, in a non-monotonous way, the electrospinning process: at low concentrations, greater fiber stretching and lower fiber diameter were observed, whereas, at higher concentrations, the diameter of the fibers increased. The reason for this trend was attributed to the instability of the electrospun jet, particularly evident at low graphene 
concentrations, which seemed to be strongly connected to the acoustic properties of the material that changed in a non-monotonous manner.

Zhang et al. [209] fabricated a conductive shape-memory microfiber membrane suitable as a sensor and actuator, consisting of SM PLA microfibers obtained by electrospinning and a polypyrrole (PPy) coating obtained through chemical vapor polymerization by using $\mathrm{FeCl}_{3}$ as a catalyst. PPy, in this case, substituted the conductive particles that are generally added in order to provide electrical actuation; however, these fillers can present limitations related to non-uniform dispersion, thus the authors adopted another approach that consisted of the fabrication of core-shell fibers to obtain an almost uniform temperature within the material when electrically activated. The membrane showed a maximum conductivity of $0.5 \mathrm{~S} \mathrm{~cm}^{-1}$ and the recovery of the permanent shape was achieved in $2 \mathrm{~s}$ by applying a voltage of $30 \mathrm{~V}$. Furthermore, it was observed that above $40 \mathrm{~V}$, the heating damaged the membrane, while no SM effect was observed by applying a voltage below $15 \mathrm{~V}$.

Moreover, Khalili et al. [210] aimed to develop a material suitable as a sensor, in particular a strain sensor, which converts the mechanical compression into electrical signals and that, among various applications, can be used to monitor the motion of the human body by evaluating the strain-dependent changes in device performance [211]. Hence, they fabricated a nanofibrous mat composed of TPU and PLA at different percentages, coated with single-walled carbon nanotubes (SWCNT) to provide electrical conductivity to the surface of the fibers. The fibers could be stretched to $100 \%$ strain without influencing the mechanical properties, and the material that showed the best performance in terms of maximum mechanical and electrical recovery was TPU/PLA 25:75 wt.\%. Additionally, the fibers exhibited shrinkage in length by increasing the PLA content and the TPU/PLA $25: 75 \mathrm{wt} . \%$ underwent a maximum length reduction of $50 \%$.

In 2019, Zhang et al. [212] developed electrospun fiber meshes that were able to display a reversible stimuli-responsive pore size change under stress-free conditions, for potential application as a membrane for air filtration, given the high porosity, large range of pore sizes, and high permeability for gases [213]. Semi-crystalline linear PCL, which was further chemically cross-linked, was utilized to produce electrospun fibrous meshes with reversible bidirectional shape-memory polymer actuation. The polymers that perform this behavior can be actuated under stress-free conditions between two different shapes [214]. The actuation performance was carried out by running heating-cooling cycles between $60{ }^{\circ} \mathrm{C}$ ( $\mathrm{T}_{\mathrm{m}}$ of PCL) and $10{ }^{\circ} \mathrm{C}$, with the specimen programmed with a strain of $100 \%$ and $300 \%$. It was observed that when heating above $60^{\circ} \mathrm{C}$, the material was subjected to contraction, and to elongation when cooling. Furthermore, the reversible strain was measured [214] for PCL, obtaining a value of $6 \pm 1 \%$ when a programming strain of $100 \%$ was applied, and an increased value of $22 \pm 1 \%$ when applying a programming strain of $300 \%$. Additionally, a change in the pore size was observed, from an average value of $10.5 \pm 0.5$ at $60{ }^{\circ} \mathrm{C}$ to $11.8 \pm 0.6 \mu \mathrm{m}$ at $10^{\circ} \mathrm{C}$.

The interest in the fabrication of devices suitable for health services has widely increased in the last years, for example in the development of systems to purify different proteins that can be used as therapeutic agents [215] and that can be separated through high-performance liquid chromatography. Therefore, a lot of researchers have realized the fabrication of high-performance chromatographic media to substitute the conventional particle-based ion-exchange chromatographic (IEX) media [216], which is considered the reference technique since it separates charge variants by differential interactions on charge support. This number increases with the molecular weight of the sample; however, these media are limited by long retention times, low throughput, and high-pressure drops due to the small pores and the limited accessibility of adsorption sites [217].

To overcome these limitations, in 2019, Fu et al. [218] aimed to design nanofiber-based protein adsorption media with a high specific surface area and continuous structure. In particular, a highly phosphorylated nanofibrous aerogel (PNFAs) was designed through subsequent electrospinning, cryogenic induced phase separation regulation, and in situ phosphorylation modification. PNFAs exhibited high underwater superelasticity with a large initial 
modulus and high compression fatigue resistance ( $\sim \%$ plastic deformation even after 1000 cycles), even in ultra-cold liquid nitrogen, and good shape-memory behavior, and in this way could provide good column-packing properties and high-pressure resistance. Furthermore, the media showed a high protein adsorption capability of $3.3 \pm 10^{3} \mathrm{mg} \mathrm{g}^{-1}$, a large liquid flux of $1.5 \pm 10^{4} \mathrm{~L} \mathrm{~m}^{-2} \mathrm{~h}^{-1}$, and high selectivity to lysozyme from egg white.

Ambient energy harvesting has become the object of interest of many researchers in order to produce mobile devices for capturing, accumulating, and storing energy for later use [219,220]. In 2019, Xiong et al. [221] designed tunable, microarchitectured shapememory triboelectric nanogenerators (mSM-TENG). Triboelectric nanogenerators (TENGs), in particular, are devices able to convert ambient mechanical energy into electricity and have found applications in energy harvesting [222]. SMPU was used to produce three types of microstructural mats: microfibers (MFs), microspheres (MSs), and microspheresnanofibers (MSNFs), with tunable surface roughness, self-restoring capabilities, and SM behavior triggered by temperature, among the produced mats. In particular, MSs were chosen to design a water temperature sensor on the deformed mat that showed increased surface roughness during recovery, which could increase the electrical output.

Moreover, Guan et al. [223], in 2020, aimed to develop multifunctional nanofibers composed of lead zirconate titanate (PZT) and SMPU with piezoelectric and shape-memory behavior for energy harvesting. Piezoelectric materials can convert mechanical vibration into electrical energy, and these materials are widely used for energy harvesting [224]. These particles are often coated with coupling agents to improve their dispersion in the polymer matrix. In this case, PZT particles were added in different contents and modified by silane-coupling agents, resulting in a better dispersion. Therefore, PZT/SMPU harvested energy from sinusoidal vibrations and the sample with $80 \%$ of PZT produced voltages of $120.3 \mathrm{mV}$ (peak-to-peak). Furthermore, SM performance was evaluated and all the PZT/SMPU nanofibers exhibited $R_{r}$ values above $94 \%$ after the first cycle and $R_{f}$ values higher than $98 \%$ in all three cycles.

Yoon et al. [225] fabricated an SMP-TSE (transparent and stretchable electrode) composite constituted by a continuous silver nanofiber (AgNF) network with optical and electrical properties, where electrical conductivity can be increased with flexibility, and crosslinked polycyclooctene (PCO) as a stretchable substrate with shape-memory behavior, showing $R_{f}$ values above $96 \%$ and $R_{r}$ values above $97 \%$, which revealed switchable optical transparency and potential applications as skin-like electronic devices.

Shape-memory polymers are widely used in the field of aeronautics, intelligent robots, and electronics. However, the traditional fabrication methods, e.g., injection molding and liquid molding, produced materials that could crack when they are twisted, limiting their applications. In order to overcome these problems, in 2021, Liu et al. [226] developed a novel device that can be used in an electrical circuit on graphene nanosheets, using sisal cellulose microcrystals as reinforcements, polyamine-functionalized perylene bisimide derivative (APBI) as a surfactant, and PVA. Additionally, they deposited Ag nanowires by spin-coating to improve the conductivity of the PVA films. The film, prepared by electrospinning, was made into an origami crane with the wing opened at $90^{\circ}$ at room temperature (permanent shape), then heated at $90^{\circ} \mathrm{C}$ for $2 \mathrm{~min}$ in order to modify the shape of the film. Subsequently, the temporary shape with the wing opened at $0^{\circ}$ was fixed by cooling, and finally, the former shape was almost totally recovered $\left(88^{\circ}\right)$ by heating at $86^{\circ} \mathrm{C}$.

More recently, concerns regarding the energy crisis related to global electricity consumption led researchers to develop new materials in order to find new solutions for these issues. In this regard, for instance, Feng et al. [227] fabricated a smart textile through coaxial electrospinning with moisture and thermal management capabilities which is capable of regulating the skin temperature and therefore reducing the usage of air conditioning. Elastic PU elastomer, which possesses soft-hard segments that permit the recovery of the permanent shape, was used as a "shell" and the PEG as a "core". The $\mathrm{T}_{\text {trans }}$ is determined by the melting temperature of PEG $\left(60^{\circ} \mathrm{C}\right)$, then the fixation of the temporary shape and 
the recovery of the permanent shape can be triggered by the phase transition of PEG. The membrane presented excellent shape-memory behavior, which also allows the adjustment of the pore size of the membrane, to transport the moisture in excess and keep the skin dry.

Izraylit et al. [228] developed a soft actuator that has found applications in soft robotics by blending a multi-block copolymer containing PLLA and PCL segments with oligo(dlactide) (ODLA) and studied the influence of the sample hierarchical structure on the shape-memory actuation capabilities.

One of the last works was carried out by Zhang et al. [229] by fabricating a fire alarm sensor via electrospinning and vacuum-assisted filtering and constituted by SMPU and MXene, which is a new generation of 2D materials constituted by a few layers of metal carbides or nitrides, finding applications in electrocatalysis and photocatalysis [230]. They found that the recovery of the permanent shape can be triggered by electricity with a voltage of $5 \mathrm{~V}$ due to the Joule heat produced by the MXene coating or by heating above the $\mathrm{T}_{\mathrm{g}}$ of SMPU within $10 \mathrm{~s}$. The mechanism of shape recovery and its potential use as a stimuliresponsive sensor is shown in Figure 18. They fixed the rolled-up shape as the temporary shape, maintained below the $\mathrm{T}_{\mathrm{g}}$ of SMPU, and the circuit remained disconnected. When heated above $\mathrm{T}_{\mathrm{g}}$, the paper recovered the unrolled shape, connecting the two copper tapes and forming a closed circuit. Furthermore, the SMPU/MXene showed self-extinguishing performance and fire retardancy with respect to SMPU paper, due to the barrier effect of Mxene, with a peak of heat release rate (pHRR) and total heat rate (THR) of 66.0 and $49.8 \%$, respectively.

(a)
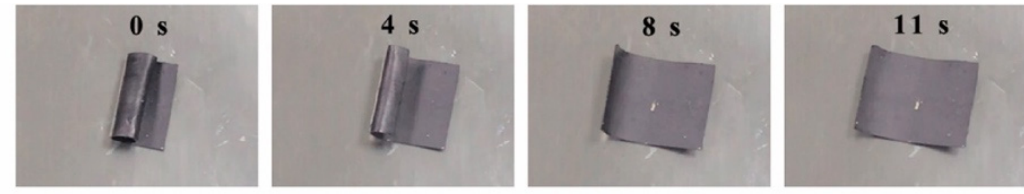

(b)

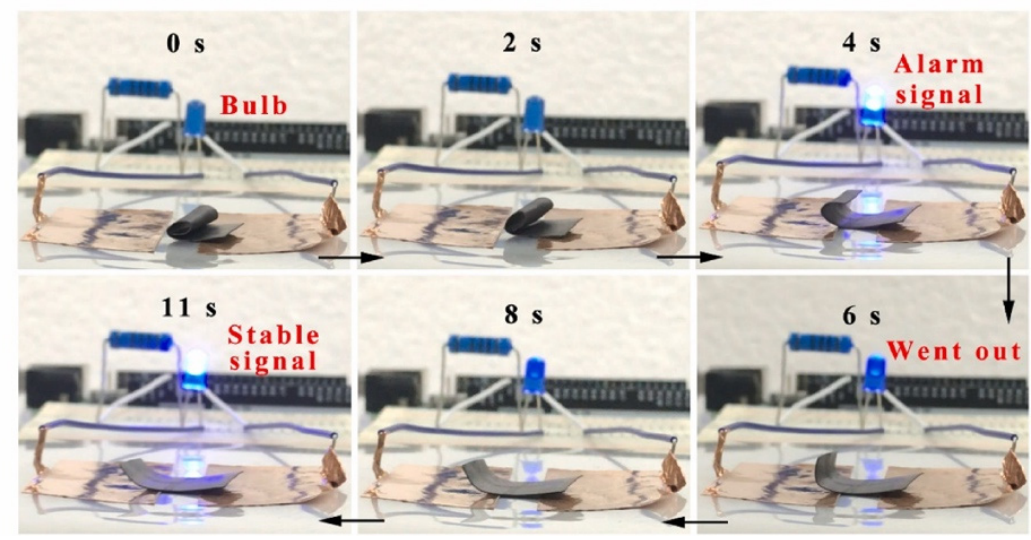

Figure 18. (a) Shape recovery of rolled-up paper. (b) Shape-memory behavior of the SMPU/MXene and its potential use as a fire alarm sensor [229].

\section{Conclusions and Future Perspectives}

The progress in the optimization of the parameters, the architecture, the shape-memory behavior, the triggering methods, and the various applications of electrospun shapememory nanofibers have been summarized in this review.

Tremendous progress has been made since the first research was reported in terms of the study of the electrospinning parameters, which is a suitable, versatile, and costeffective method that allows a simple way to fabricate continuous polymeric fibers. These electrospun fibers can show shape-memory properties, adjusting their architecture in order to obtain materials with one-way, two-way, and multiple SM behavior. Moreover, the fabrication of electrospun nanocomposites has also been studied and optimized in order to improve their properties and thus extend their field of applications and the triggering stimulus, such as temperature, $\mathrm{pH}$, water, and electric fields as the most important. 
Different application fields have been reviewed, with particular attention to the use of shape-memory electrospun nanofibers in the biomedical field, taking advantage of their capability to mimic the structure of the extracellular matrix as scaffolds in tissue engineering, tissue repair, wound dressing, and drug delivery. The cell behavior after culturing on the electrospun fibrous scaffold and the shape-memory behavior of the materials have been widely evaluated in vitro, however, it is still a challenge to study these features on cells in vivo. Furthermore, shape-memory electrospun nanofibers, particularly those triggered by the magnetic or electric fields, have recently extended their applications due to novel fabrication techniques in the aerospace field and in robotics, as actuators, sensors, for energy harvesting, etc.

Finally, despite the significant and recent progress in the fabrication of shape-memory polymers obtained by electrospinning, further studies are required and several challenges still need to be addressed to optimize the working parameters. Moreover, deeper efforts on the material design are required to exploit the advantages of polymers with multiple shape-memory behaviors with great potential for specific advanced applications in the biomedicine field, robotics, and electronics.

Funding: This research received no external funding.

Data Availability Statement: Not applicable.

Conflicts of Interest: The authors declare no conflict of interest.

\begin{tabular}{|c|c|}
\hline A-SME-C & anisotropic shape-memory elastomeric composites \\
\hline AgNF & silver nanofibers \\
\hline $\mathrm{AgNO}_{3}$ & silver nitrate \\
\hline APBI & polyamine-functionalized perylene bisimide derivative \\
\hline ASCs & adipose-derived cells \\
\hline APS & $\gamma$-aminopropyltriethoxysilane \\
\hline ASPU & end-capped polyurethane oligomer \\
\hline $\mathrm{BCH}$ & berberine hydrochloride \\
\hline $\mathrm{BD}$ & 1,4-butanediol \\
\hline BG & bioactive glasses \\
\hline$\beta-C D$ & $\beta$-cyclodextrin \\
\hline $\mathrm{C} 3 \mathrm{H} / 10 \mathrm{~T} 1 / 2$ & murine mesenchymal stem cell line \\
\hline CLSMPU & polycaprolactone based SMPU \\
\hline CNF & carbon nanofibrous \\
\hline CNMs & composite nanofibrous mats \\
\hline CS & chitosan \\
\hline 1D & one-dimensional \\
\hline $2 \mathrm{D}$ & two-dimensional \\
\hline 3D & three-dimensional \\
\hline DA & dopamine \\
\hline DDSs & drug delivery system \\
\hline DEX & dexamethasone \\
\hline DHB & 3,4-dihydroxy-1-butene \\
\hline DLLA & D,L-lactide \\
\hline $\mathrm{DMF}$ & dimethylformamide \\
\hline DGEBA & diglycidyl ether of bisphenol A \\
\hline $\mathrm{E}_{\mathrm{y}}$ & Young modulus \\
\hline EAP & electroactive \\
\hline ECM & extracellular matrix \\
\hline
\end{tabular}




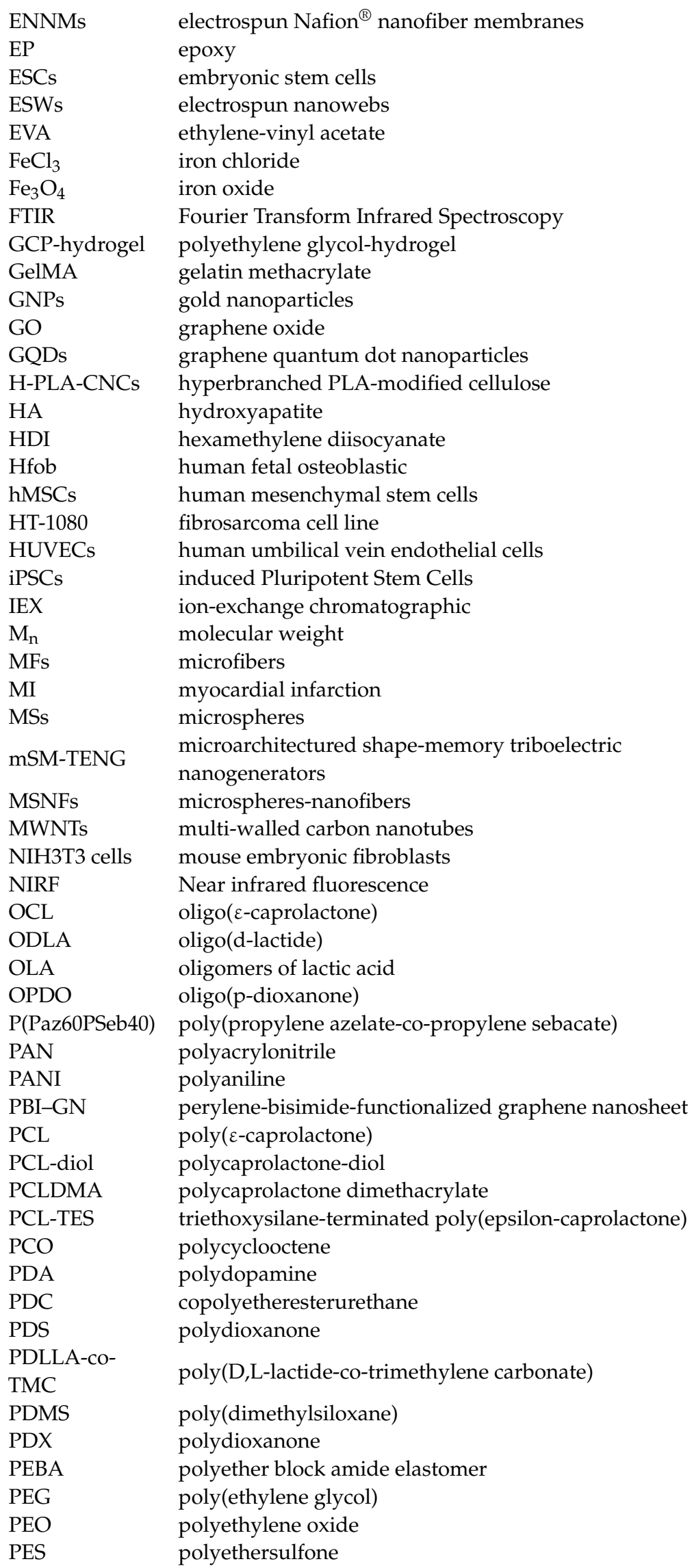




\begin{tabular}{|c|c|}
\hline PEU & polyetherurethane \\
\hline PFS & polyferrocenylsilane \\
\hline PHBV & poly(3-hydroxybutyrate-co-3-hydroxyvalerate) \\
\hline pHRR & peak of heat release rate \\
\hline PLGA & poly(lactide-glycolide) \\
\hline PLGATMC & poly(lactide-glycolide-trimethylene carbonate \\
\hline PLA & poly(lactid acid) \\
\hline PLLA & poly(L-lactic acid) \\
\hline PLMC & poly(D,L-lactide-co-trimethylene carbonate) \\
\hline PMMA & poly(methyl methacrylate) \\
\hline PNFAs & phosphorylated nanofibrous aerogels \\
\hline PNS & peripheral nervous system \\
\hline PPDL & poly(x-pentadecalactone) \\
\hline PPy & polypyrrole \\
\hline PS & polystyrene \\
\hline $\mathrm{PTSA} \cdot \mathrm{H}_{2} \mathrm{O}$ & $p$-Toluene sulfonic acid hydrate \\
\hline PU & polyurethanes \\
\hline PVA & poly(vinyl alcohol) \\
\hline PVAc & poly(vinyl acetate) \\
\hline PVP & polyvinylpyrrolidone \\
\hline PySMPU & pyridine containing polyurethane \\
\hline PZT & zirconate titanate \\
\hline$R_{f}$ & strain fixity ratio \\
\hline$R_{r}$ & strain recovery ratio \\
\hline Rap & rapamycin \\
\hline $\mathrm{SH}$ & self-healing \\
\hline $\mathrm{SiO}_{2}$ & silicon oxide \\
\hline SM & shape memory \\
\hline SMCs & smooth muscle cells \\
\hline SMPs & shape-memory polymers \\
\hline SMP-TSE & transparent and stretchable electrode \\
\hline SNC & smart nerve conduit \\
\hline SWCNT & single-walled carbon nanotubes \\
\hline $\mathrm{T}_{\mathrm{g}}$ & glass transition temperature \\
\hline $\mathrm{T}_{\mathrm{m}}$ & melting temperature \\
\hline $\mathrm{T}_{\text {trans }}$ & transition temperature \\
\hline TSPCs & triple-shape polymeric composites \\
\hline TDI & 2,4,2,6-Toluene diisocyante \\
\hline TENGs & triboeletric nanogenerators \\
\hline THR & total heat rate \\
\hline TMC & trimethylene carbonate \\
\hline TPS & thermoplastic starch \\
\hline TPU & thermoplastic polyurethane \\
\hline TSMPs & triple shape-memory polymer \\
\hline$\varepsilon_{\mathrm{f}}$ & strain-to-failure \\
\hline$\sigma_{\mathrm{y}}$ & yield stress \\
\hline
\end{tabular}

\section{References}

1. Zhang, F.; Zhou, T.; Liu, Y.; Leng, J. Microwave synthesis and actuation of shape memory polycaprolactone foams with high speed. Sci. Rep. 2015, 5, 1-12. [CrossRef] [PubMed]

2. Leng, J.; Lan, X.; Liu, Y.; Du, S. Shape-memory polymers and their composites: Stimulus methods and applications. Prog. Mater. Sci. 2011, 56, 1077-1135. [CrossRef]

3. Razzaq, M.Y.; Behl, M.; Lendlein, A. Magnetic memory effect of nanocomposites. Adv. Funct. Mater. 2012, 22, 184-191. [CrossRef]

4. Huang, W.M.; Yang, B.; An, L.; Li, C.; Chan, Y.S. Water-driven programmable polyurethane shape memory polymer: Demonstration and mechanism. Appl. Phys. Lett. 2005, 86, 114105. [CrossRef]

5. Pilate, F.; Toncheva, A.; Dubois, P.; Raquez, J.M. Shape-memory polymers for multiple applications in the materials world. Eur. Polym. J. 2016, 80, 268-294. [CrossRef] 
6. Leng, J.; Lu, H.; Liu, Y.; Huang, W.M.; Du, S. Shape-memory polymers-A class of novel smart materials. MRS Bull. 2009, 34, 848-855. [CrossRef]

7. Chow, W.S.; Mohd Ishak, Z.A. Smart polymer nanocomposites: A review. Express Polym. Lett. 2020, 14, 416-435. [CrossRef]

8. Meng, H.; Li, G. A review of stimuli-responsive shape memory polymer composites. Polymer 2013, 54, 2199-2221. [CrossRef]

9. Zare, M.; Davoodi, P.; Ramakrishna, S. Electrospun shape memory polymer micro-/nanofibers and tailoring their roles for biomedical applications. Nanomaterials 2021, 11,933. [CrossRef]

10. Zhao, Q.; Qi, H.J.; Xie, T. Recent progress in shape memory polymer: New behavior, enabling materials, and mechanistic understanding. Prog. Polym. Sci. 2015, 49-50, 79-120. [CrossRef]

11. Peponi, L.; Navarro-Baena, I.; Sonseca, A.; Gimenez, E.; Marcos-Fernandez, A.; Kenny, J.M. Synthesis and characterization of PCL-PLLA polyurethane with shape memory behavior. Eur. Polym. J. 2013, 49, 893-903. [CrossRef]

12. Leonés, A.; Sonseca, A.; López, D.; Fiori, S.; Peponi, L. Shape memory effect on electrospun PLA-based fibers tailoring their thermal response. Eur. Polym. J. 2019, 117, 217-226. [CrossRef]

13. Liu, C.; Qin, H.; Mather, P.T. Review of progress in shape-memory polymers. J. Mater. Chem. 2007, 17, 1543-1558. [CrossRef]

14. Lendlein, A.; Langer, R. Biodegradable, elastic shape-memory polymers for potential biomedical applications. Science 2002, 296, 1673-1676. [CrossRef]

15. Liu, Y.; Du, H.; Liu, L.; Leng, J. Shape memory polymers and their composites in aerospace applications: A review. Smart Mater Struct. 2014, 23. [CrossRef]

16. Arrieta, M.P.; Sessini, V.; Peponi, L. Biodegradable poly(ester-urethane) incorporated with catechin with shape memory and antioxidant activity for food packaging. Eur. Polym. J. 2017, 94, 111-124. [CrossRef]

17. Kunzelman, J.; Chung, T.; Mather, P.T.; Weder, C. Shape memory polymers with built-in threshold temperature sensors. J. Mater. Chem. 2008, 18, 1082-1086. [CrossRef]

18. Peng, Q.; Wei, H.; Qin, Y.; Lin, Z.; Zhao, X.; Xu, F.; Leng, J.; He, X.; Cao, A.; Li, Y. Shape-memory polymer nanocomposites with a 3D conductive network for bidirectional actuation and locomotion application. Nanoscale 2016, 8, 18042-18049. [CrossRef]

19. Zarek, M.; Layani, M.; Cooperstein, I.; Sachyani, E.; Cohn, D.; Magdassi, S. 3D Printing of Shape Memory Polymers for Flexible Electronic Devices. Adv. Mater. 2016, 28, 4449-4454. [CrossRef]

20. Tercjak, A.; Gutierrez, J.; Peponi, L.; Rueda, L.; Mondragon, I. Arrangement of conductive TiO2 nanoparticles in hybrid inorganic/organic thermosetting materials using liquid crystal. Macromolecules 2009, 42, 3386-3390. [CrossRef]

21. Ognibene, G.; Gangemi, C.M.A.; Spitaleri, L.; Gulino, A.; Purrello, R.; Cicala, G.; Fragalà, M.E. Role of the surface composition of the polyethersulfone-TiiP-H 2 T 4 fibers on lead removal: From electrostatic to coordinative binding. J. Mater. Sci. 2019, 54, 8023-8033. [CrossRef]

22. Jung, J.W.; Lee, C.L.; Yu, S.; Kim, I.D. Electrospun nanofibers as a platform for advanced secondary batteries: A comprehensive review. J. Mater. Chem. A 2016, 4, 703-750. [CrossRef]

23. Leonés, A.; Mujica-Garcia, A.; Arrieta, M.P.; Salaris, V.; Lopez, D.; Kenny, J.M.; Peponi, L. Organic and inorganic PCL-based electrospun fibers. Polymers 2020, 12, 1325. [CrossRef]

24. Leonés, A.; Salaris, V.; Mujica-garcia, A.; Arrieta, M.P.; Lopez, D.; Lieblich, M.; Kenny, M.; Peponi, L. PLA Electrospun Fibers Reinforced with Organic and Inorganic Nanoparticles: A Comparative Study. Molecules 2021, 26, 4925. [CrossRef]

25. Kotek, R. Recent advances in polymer fibers. Polym. Rev. 2008, 48, 221-229. [CrossRef]

26. Hu, J.; Meng, Q.; Zhu, Y.; Lu, J.; Zhuo, H. Shape Memory Fibers Prepared via Wet, Reaction, Dry, Melt, and Electro Spinning. U.S. Patent Application 11/907,012, 9 April 2009.

27. Formhals, A. Process and Apparatus for Preparing Artificial Threads. U.S. Patent 1,975,504, 2 October 1934.

28. Leonés, A.; Lieblich, M.; Benavente, R.; Gonzalez, J.L.; Peponi, L. Potential applications of magnesium-based polymeric nanocomposites obtained by electrospinning technique. Nanomaterials 2020, 10, 1524. [CrossRef]

29. Taylor, G.I. Electrically driven jets. Proc. R. Soc. Lond. A Math. Phys. Sci. 1969, 313, 453-475. [CrossRef]

30. Bhardwaj, N.; Kundu, S.C. Electrospinning: A fascinating fiber fabrication technique. Biotechnol. Adv. 2010, 28, 325-347. [CrossRef]

31. Sundaray, B.; Subramanian, V.; Natarajan, T.S.; Xiang, R.Z.; Chang, C.C.; Fann, W.S. Electrospinning of continuous aligned polymer fibers. Appl. Phys. Lett. 2004, 84, 1222-1224. [CrossRef]

32. Demir, M.M.; Yilgor, I.; Yilgor, E.; Erman, B. Electrospinning of polyurethane fibers. Polymer 2002, 43, 3303-3309. [CrossRef]

33. Deitzel, J.M.; Kosik, W.; McKnight, S.H.; Beck Tan, N.C.; DeSimone, J.M.; Crette, S. Electrospinning of polymer nanofibers with specific surface chemistry. Polymer 2001, 43, 1025-1029. [CrossRef]

34. Zhuo, H.; Hu, J.; Chen, S. Electrospun polyurethane nanofibres having shape memory effect. Mater. Lett. 2008, 62, 2074-2076. [CrossRef]

35. Kim, S.J.; Lim, J.Y.; Kim, I.Y.; Lee, S.H.; Lee, T.S.; Kim, S.I. Optimum parameters for production of nanofibres based on poly(2acrylamido-2-methyl-1-propane sulfonic acid) by electro-spinning. Smart Mater. Struct. 2005, 14, N16. [CrossRef]

36. Flemming, R.G.; Murphy, C.J.; Abrams, G.A.; Goodman, S.L.; Nealey, P.F. Effects of synthetic micro- and nano-structured surfaces on cell behavior. Biomaterials 1999, 20, 573-588. [CrossRef]

37. Matthews, J.A.; Wnek, G.E.; Simpson, D.G.; Bowlin, G.L. Electrospinning of collagen nanofibers. Biomacromolecules 2002, 3, 232-238. [CrossRef] 
38. Lamastra, F.R.; Puglia, D.; Monti, M.; Vella, A.; Peponi, L.; Kenny, J.M.; Nanni, F. Poly( $\varepsilon$-caprolactone) reinforced with fibres of Poly(methyl methacrylate) loaded with multiwall carbon nanotubes or graphene nanoplatelets. Chem. Eng. J. 2012, 195-196, 140-148. [CrossRef]

39. Arrieta, M.P.; García, A.D.; López, D.; Fiori, S.; Peponi, L. Antioxidant bilayers based on PHBV and plasticized electrospun PLA-PHB fibers encapsulating catechin. Nanomaterials 2019, 9, 346. [CrossRef] [PubMed]

40. Carrasco-Hernandez, S.; Gutierrez, J.; Peponi, L.; Tercjak, A. Optimization of the Electrospinning Processing-Window to Fabricate Nanostructured PE-b-PEO and Hybrid PE-b-PEO/EBBA Fibers. Polym. Eng. Sci. 2017, 57, 1157-1167. [CrossRef]

41. Salmeri, M.; Ognibene, G.; Saitta, L.; Lombardo, C.; Genovese, C.; Barcellona, M.; D’Urso, A.; Spitaleri, L.; Blanco, I.; Cicala, G.; et al. Optimization of $\mathrm{ZnO}$ nanorods growth on polyetheresulfone electrospun mats to promote antibacterial properties. Molecules 2020, 25, 1696. [CrossRef]

42. Abutaleb, A. Catalytic and photocatalytic electrospun nanofibers for hydrogen generation from ammonia borane complex: A review. Polymers 2021, 13, 2290. [CrossRef]

43. Niiyama, E.; Tanabe, K.; Uto, K.; Kikuchi, A.; Ebara, M. Shape-memory nanofiber meshes with programmable cell orientation. Fibers 2019, 7, 20. [CrossRef]

44. Boland, E.D.; Coleman, B.D.; Barnes, C.P.; Simpson, D.G.; Wnek, G.E.; Bowlin, G.L. Electrospinning polydioxanone for biomedical applications. Acta Biomater. 2005, 1, 115-123. [CrossRef]

45. Gordon, R.F. The Properties and Applications of Shape Memory Polyurethanes. Mater. Technol. 1993, 8, 254-258. [CrossRef]

46. Auad, M.L.; Contos, V.S.; Nutt, S.; Aranguren, M.I.; Marcovich, N.E. Characterization of nanocellulose- reinforced shape memory polyurethanes. Polym. Int. 2008, 57, 651-659. [CrossRef]

47. Chong, L.H.; Hassan, M.I.; Sultana, N. Electrospun Polycaprolactone (PCL) and PCL/ nano-hydroxyapatite (PCL/nHA)-based nanofibers for bone tissue engineering application. In Proceedings of the 2015 10th Asian Control Conference (ASCC), Kota Kinabalu, Malaysia, 31 May-3 June 2015; pp. 5-8. [CrossRef]

48. Cha, D.I.; Kim, H.Y.; Lee, K.H.; Jung, Y.C.; Cho, J.W.; Chun, B.C. Electrospun nonwovens of shape-memory polyurethane block copolymers. J. Appl. Polym. Sci. 2005, 96, 460-465. [CrossRef]

49. Navarro-Baena, I.; Kenny, J.M.; Peponi, L. Thermally-activated shape memory behaviour of bionanocomposites reinforced with cellulose nanocrystals. Cellulose 2014, 21, 4231-4246. [CrossRef]

50. Mujica-Garcia, A.; Navarro-Baena, I.; Kenny, J.M.; Peponi, L. Influence of the processing parameters on the electrospinning of biopolymeric fibers. J. Renew. Mater. 2014, 2, 23-34. [CrossRef]

51. Tan, L.; Gan, L.; Hu, J.; Zhu, Y.; Han, J. Functional shape memory composite nanofibers with graphene oxide filler. Compos. Part A Appl. Sci. Manuf. 2015, 76, 115-123. [CrossRef]

52. Rana, S.; Cho, J.W. Core-sheath polyurethane-carbon nanotube nanofibers prepared by electrospinning. Fibers Polym. 2011, 12, 721-726. [CrossRef]

53. Fujii, M.; Zhang, X.; Xie, H.; Ago, H.; Takahashi, K.; Ikuta, T.; Abe, H.; Shimizu, T. Measuring the Thermal Conductivity of a Single Carbon Nanotube. Phys. Rev. Lett. 2005, 95, 065502. [CrossRef]

54. Xu, Z.; Wang, S.; Li, Y.; Wang, M.; Shi, P.; Huang, X. Covalent functionalization of graphene oxide with biocompatible poly(ethylene glycol) for delivery of paclitaxel. ACS Appl. Mater. Interfaces 2014, 6, 17268-17276. [CrossRef] [PubMed]

55. Rana, S.; Cho, J.W.; Tan, L.P. Graphene-crosslinked polyurethane block copolymer nanocomposites with enhanced mechanical, electrical, and shape memory properties. RSC Adv. 2013, 3, 13796-13803. [CrossRef]

56. Zhang, Q.; Kratz, K.; Lendlein, A. Shape-memory properties of degradable electrospun scaffolds based on hollow microfibers. Polym. Adv. Technol. 2015, 26, 1468-1475. [CrossRef]

57. Alhazov, D.; Azra, C.; Zussman, E. Electrospinning-induced shape memory effect in thermoplastic polyurethane characterization and thermoviscoelastic modeling. J. Polym. Sci. Part B Polym. Phys. 2015, 53, 1590-1602. [CrossRef]

58. Alhazov, D.; Gradys, A.; Sajkiewicz, P.; Arinstein, A.; Zussman, E. Thermo-mechanical behavior of electrospun thermoplastic polyurethane nanofibers. Eur. Polym. J. 2013, 49, 3851-3856. [CrossRef]

59. Budun, S.; İşgören, E.; Erdem, R.; Yüksek, M. Morphological and mechanical analysis of electrospun shape memory polymer fibers. Appl. Surf. Sci. 2016, 380, 294-300. [CrossRef]

60. Ang, J.Y.; Chan, B.Q.Y.; Kai, D.; Loh, X.J. Engineering Porous Water-Responsive Poly(PEG/PCL/PDMS Urethane) Shape Memory Polymers. Macromol. Mater. Eng. 2017, 302. [CrossRef]

61. Chan, B.Q.Y.; Heng, S.J.W.; Liow, S.S.; Zhang, K.; Loh, X.J. Dual-responsive hybrid thermoplastic shape memory polyurethane. Mater. Chem. Front. 2017, 1, 767-779. [CrossRef]

62. Wang, X.; Hsiao, B.S. Electrospun nanofiber membranes. Curr. Opin. Chem. Eng. 2016, 12, 62-81. [CrossRef]

63. Li, J.J.; Zhou, Y.N.; Jiang, Z.D.; Luo, Z.H. Electrospun Fibrous Mat with pH-Switchable Superwettability That Can Separate Layered Oil/Water Mixtures. Langmuir 2016, 32, 13358-13366. [CrossRef] [PubMed]

64. Sessini, V.; Raquez, J.M.; Lo Re, G.; Mincheva, R.; Kenny, J.M.; Dubois, P.; Peponi, L. Multiresponsive Shape Memory Blends and Nanocomposites Based on Starch. ACS Appl. Mater. Interfaces 2016, 8, 19197-19201. [CrossRef] [PubMed]

65. Castillo-Cruz, O.; Avilés, F.; Vargas-Coronado, R.; Cauich-Rodríguez, J.V.; Chan-Chan, L.H.; Sessini, V.; Peponi, L. Mechanical properties of L-lysine based segmented polyurethane vascular grafts and their shape memory potential. Mater. Sci. Eng. C 2019, 102, 887-895. [CrossRef] [PubMed] 
66. Nissenbaum, A.; Greenfeld, I.; Wagner, H.D. Shape memory polyurethane-Amorphous molecular mechanism during fixation and recovery. Polymer 2020, 190. [CrossRef]

67. Lendlein, A.; Kelch, S. Shape-Memory Effect From permanent shape. Angew. Chem. Int. Ed. Engl. 2002, 41, 2034-2057. [CrossRef]

68. Larranaga, A.; Lizundia, E. Strain-induced crystallization. In Crystallization in Multiphase Polymer Systems; Elsevier: Amsterdam, The Netherlands, 2018; ISBN 9780128094310.

69. Chen, H.; Cao, X.; Zhang, J.; Zhang, J.; Ma, Y.; Shi, G.; Ke, Y.; Tong, D.; Jiang, L. Electrospun shape memory film with reversible fibrous structure. J. Mater. Chem. 2012, 22, 22387-22391. [CrossRef]

70. Mangiacapra, P.; Raimondo, M.; Tammaro, L.; Vittoria, V. Nanometric dispersion of a Mg/AI layered double hydroxide into a chemically modified polycaprolactone. Biomacromolecules 2007, 8, 773-779. [CrossRef] [PubMed]

71. Gorrasi, G.; Tortora, M.; Vittoria, V.; Pollet, E.; Alexandre, M.; Dubois, P. Physical Properties of Poly( $(\varepsilon$-caprolactone) Layered Silicate Nanocomposites Prepared by Controlled Grafting Polymerization. J. Polym. Sci. Part B Polym. Phys. 2004, 42, 1466-1475. [CrossRef]

72. Matsumoto, H.; Ishiguro, T.; Konosu, Y.; Minagawa, M.; Tanioka, A.; Richau, K.; Kratz, K.; Lendlein, A. Shape-memory properties of electrospun non-woven fabrics prepared from degradable polyesterurethanes containing poly $(\omega$-pentadecalactone) hard segments. Eur. Polym. J. 2012, 48, 1866-1874. [CrossRef]

73. Luo, X.; Mather, P.T. Triple-shape polymeric composites (TSPCs). Adv. Funct. Mater. 2010, 20, 2649-2656. [CrossRef]

74. Ware, T.; Hearon, K.; Lonnecker, A.; Wooley, K.L.; Maitland, D.J.; Voit, W. Triple-shape memory polymers based on selfcomplementary hydrogen bonding. Macromolecules 2012, 45, 1062-1069. [CrossRef] [PubMed]

75. Karger-Kocsis, J.; Kéki, S. Review of progress in shape memory epoxies and their composites. Polymers 2017, 10, 34. [CrossRef] [PubMed]

76. Fejos, M.; Molnár, K.; Karger-Kocsis, J. Epoxy/polycaprolactone systems with triple-shape memory effect: Electrospun nanoweb with and without graphene Versus co-continuous morphology. Materials 2013, 6, 4489-4504. [CrossRef] [PubMed]

77. Yao, Y.; Wang, J.; Lu, H.; Xu, B.; Fu, Y.; Liu, Y.; Leng, J. Thermosetting epoxy resin/thermoplastic system with combined shape memory and self-healing properties. Smart Mater. Struct. 2015, 25, 015021. [CrossRef]

78. Birjandi Nejad, H.; Garrison, K.L.; Mather, P.T. Comparative analysis of shape memory-based self-healing coatings. J. Polym. Sci. Part B Polym. Phys. 2016, 54, 1415-1426. [CrossRef]

79. Rodriguez, E.D.; Luo, X.; Mather, P.T. Linear/network poly( $\varepsilon$-caprolactone) blends exhibiting shape memory assisted self-healing (SMASH). ACS Appl. Mater. Interfaces 2011, 3, 152-161. [CrossRef] [PubMed]

80. Yao, Y.; Zhou, T.; Wang, J.; Li, Z.; Lu, H.; Liu, Y.; Leng, J. 'Two way' shape memory composites based on electroactive polymer and thermoplastic membrane. Compos. Part A Appl. Sci. Manuf. 2016, 90, 502-509. [CrossRef]

81. Carpi, F.; Kornbluh, R.; Sommer-Larsen, P.; Alici, G. Electroactive polymer actuators as artificial muscles: Are they ready for bioinspired applications? Bioinspir. Biomim. 2011, 6, 045006. [CrossRef]

82. Merlettini, A.; Pandini, S.; Agnelli, S.; Gualandi, C.; Paderni, K.; Messori, M.; Toselli, M.; Focarete, M.L. Facile fabrication of shape memory poly( $\epsilon$-caprolactone) non-woven mat by combining electrospinning and sol-gel reaction. RSC Adv. 2016, 6, 43964-43974. [CrossRef]

83. Iregui, A.; Irusta, L.; Llorente, O.; Martin, L.; Calvo-Correas, T.; Eceiza, A.; González, A. Electrospinning of cationically polymerized epoxy/polycaprolactone blends to obtain shape memory fibers (SMF). Eur. Polym. J. 2017, 94, 376-383. [CrossRef]

84. Iregui, A.; Irusta, L.; Martin, L.; González, A. Analysis of the process parameters for obtaining a stable electrospun process in different composition epoxy/poly $\varepsilon$-Caprolactone blends with shape memory properties. Polymers 2019, 11, 475. [CrossRef]

85. Buffington, S.L.; Posnick, B.M.; Paul, J.; Mather, P.T. Ternary Polymeric Composites Exhibiting Bulk and Surface Quadruple-Shape Memory Properties. ChemPhysChem 2018, 19, 2014-2024. [CrossRef] [PubMed]

86. Luo, Y.; Guo, Y.; Gao, X.; Li, B.G.; Xie, T. A general approach towards thermoplastic multishape-memory polymers via sequence structure design. Adv. Mater. 2013, 25, 743-748. [CrossRef]

87. Sessini, V.; López Galisteo, A.J.; Leonés, A.; Ureña, A.; Peponi, L. Sandwich-Type Composites Based on Smart Ionomeric Polymer and Electrospun Microfibers. Front. Mater. 2019, 6, 301. [CrossRef]

88. Yao, Y.; Wei, H.; Wang, J.; Lu, H.; Leng, J.; Hui, D. Fabrication of hybrid membrane of electrospun polycaprolactone and polyethylene oxide with shape memory property. Compos. Part B Eng. 2015, 83, 264-269. [CrossRef]

89. Zhang, F.; Zhang, Z.; Liu, Y.; Leng, J. Fabrication of shape memory nanofibers by electrospinning method. In Electroactive Polymer Actuators and Devices (EAPAD); Centre for Composite Materials and Structures, Harbin Institute of Technology (HIT): Harbin, China, 2013; Volume 8687.

90. Heitner-Wirguin, C. Recent advances in perfluorinated ionomer membranes: Structure, properties and applications. J. Memb. Sci. 1996, 120, 1-33. [CrossRef]

91. Zhang, F.; Zhang, Z.; Liu, Y.; Leng, J. Shape memory properties of electrospun nafion nanofibers. Fibers Polym. 2014, 15, 534-539. [CrossRef]

92. Lu, H.; Yao, Y.; Yin, J.; Lin, L. Functionally graded carbon nanotube and nafion/silica nanofibre for electrical actuation of carbon fibre reinforced shape memory polymer. Pigment Resin Technol. 2016, 45, 93-98. [CrossRef]

93. Lu, H.; Yao, Y.; Zhu, S.; Yang, Y.; Lin, L. Fabrication of free-standing octagon-shaped carbon nanofibre assembly for electrical actuation of shape memory polymer nanocomposites. Pigment Resin Technol. 2015, 44, 157-164. [CrossRef] 
94. Shirole, A.; Sapkota, J.; Foster, E.J.; Weder, C. Shape Memory Composites Based on Electrospun Poly(vinyl alcohol) Fibers and a Thermoplastic Polyether Block Amide Elastomer. ACS Appl. Mater. Interfaces 2016, 8, 6701-6708. [CrossRef]

95. Guan, X.; Dong, Y.; Xia, H.; Yao, J.; Ni, Q.Q. Mechanical and shape memory performance of shape memory polyurethane-based aligned nanofibers. Polym. Test. 2020, 91, 106778. [CrossRef]

96. Banikazemi, S.; Rezaei, M.; Rezaei, P.; Babaie, A.; Eyvazzadeh-Kalajahi, A. Preparation of electrospun shape memory polyurethane fibers in optimized electrospinning conditions via response surface methodology. Polym. Adv. Technol. 2020, 31, $2199-2208$. [CrossRef]

97. Nahavandizadeh, N.; Rezaei, M. Preparation of Shape Memory Polyurethane/Hydroxyapatite Nanocomposite Scaffolds by Electrospinning Method and Investigation of Their Microstructure and Physical-Mechanical Properties. Polym. Technol. Mater. 2020, 59, 1562-1573. [CrossRef]

98. Liu, K.; Peng, Q.; Li, Z.; Cheng, J.; Lao, L.; Li, X.; Zhang, Z.; Lu, S.; Li, Y. Electrospinning preparation of perylene-bisimidefunctionalized graphene/polylactic acid shape-memory films with excellent mechanical and thermal properties. New J. Chem. 2021, 45, 772-779. [CrossRef]

99. Fang, F.; Wang, H.; Wang, H.; Huang, W.M.; Chen, Y.; Cai, N.; Chen, X.; Chen, X. Stimulus-responsive shrinkage in electrospun membranes: Fundamentals and control. Micromachines 2021, 12, 920. [CrossRef]

100. Sauter, T.; Kratz, K.; Heuchel, M.; Lendlein, A. Fiber diameter as design parameter for tailoring the macroscopic shape-memory performance of electrospun meshes. Mater. Des. 2021, 202, 109546. [CrossRef]

101. da Silva, D.; Kaduri, M.; Poley, M.; Adir, O.; Krinsky, N.; Shainsky-Roitman, J.; Schroeder, A. Biocompatibility, biodegradation and excretion of polylactic acid (PLA) in medical implants and theranostic systems. Chem. Eng. J. 2018, 340, 9-14. [CrossRef]

102. Zhang, F.; Zhang, Z.; Zhou, T.; Liu, Y.; Leng, J. Shape memory polymer nanofibers and their composites: Electrospinning, structure, performance, and applications. Front. Mater. 2015, 2. [CrossRef]

103. Tseng, L.-F.; Mather, P.T.; Henderson, J.H. Shape-memory-actuated change in scaffold fiber alignment directs stem cell morphology. Acta Biomater. 2013, 9, 8790-8801. [CrossRef]

104. Davis, K.A.; Burke, K.A.; Mather, P.T.; Henderson, J.H. Dynamic cell behavior on shape memory polymer substrates. Biomaterials 2011, 32, 2285-2293. [CrossRef]

105. Gong, T.; Li, W.; Chen, H.; Wang, L.; Shao, S.; Zhou, S. Remotely actuated shape memory effect of electrospun composite nanofibers. Acta Biomater. 2012, 8, 1248-1259. [CrossRef]

106. Laurent, S.; Forge, D.; Port, M.; Roch, A.; Robic, C.; Vander Elst, L.; Muller, R.N. Magnetic iron oxide nanoparticles: Synthesis, stabilization, vectorization, physicochemical characterizations and biological applications. Chem. Rev. 2008, 108, 2064-2110. [CrossRef] [PubMed]

107. Shao, S.; Zhou, S.; Li, L.; Li, J.; Luo, C.; Wang, J.; Li, X.; Weng, J. Osteoblast function on electrically conductive electrospun PLA/MWCNTs nanofibers. Biomaterials 2011, 32, 2821-2833. [CrossRef] [PubMed]

108. Bao, M.; Lou, X.; Zhou, Q.; Dong, W.; Yuan, H.; Zhang, Y. Electrospun biomimetic fibrous scaffold from shape memory polymer of PDLLA- co -TMC for bone tissue engineering. ACS Appl. Mater. Interfaces 2014, 6, 2611-2621. [CrossRef] [PubMed]

109. Andronova, N.; Albertsson, A.C. Resilient bioresorbable copolymers based on trimethylene carbonate, L-lactide, and 1,5-dioxepan2-one. Biomacromolecules 2006, 7, 1489-1495. [CrossRef]

110. Pêgo, A.P.; Poot, A.A.; Grijpma, D.W.; Feijen, J. Biodegradable elastomeric scaffolds for soft tissue engineering. J. Control. Release 2003, 87, 69-79. [CrossRef]

111. Lendlein, A.; Zotzman, J.; Feng, Y.; Alteheld, A.; Kelch, S. Controlling the switching temperature of biodegradable, amorphous, shape-memory poly(rac-lactide)urethane networks by incorporation of different comonomers. Biomacromolecules 2009, 10, 975-982. [CrossRef]

112. Wei, H.; Zhang, F.; Zhang, D.; Liu, Y.; Leng, J. Shape-memory behaviors of electrospun chitosan/poly(ethylene oxide) composite nanofibrous membranes. J. Appl. Polym. Sci. 2015, 132. [CrossRef]

113. Alford, J.W.; Bradley, M.P.; Fadale, P.D.; Crisco, J.; Moore, D.C.; Ehrlich, M.G. Resorbable fillers reduce stress risers from empty screw holes. J. Trauma 2007, 63, 647-654. [CrossRef]

114. Bao, M.; Wang, X.; Yuan, H.; Lou, X.; Zhao, Q.; Zhang, Y. HAp incorporated ultrafine polymeric fibers with shape memory effect for potential use in bone screw hole healing. J. Mater. Chem. B 2016, 4, 5308-5320. [CrossRef]

115. Schmidt, C.E.; Leach, J.B. Neural Tissue Engineering: Strategies for Repair and Regeneration. Annu. Rev. Biomed. Eng. 2003, 5, 293-347. [CrossRef]

116. Panseri, S.; Cunha, C.; Lowery, J.; Del Carro, U.; Taraballi, F.; Amadio, S.; Vescovi, A.; Gelain, F. Electrospun micro- and nanofiber tubes for functional nervous regeneration in sciatic nerve transections. BMC Biotechnol. 2008, 8, 39. [CrossRef] [PubMed]

117. Kratz, K.; Voigt, U.; Lendlein, A. Temperature-memory effect of copolyesterurethanes and their application potential in minimally invasive medical technologies. Adv. Funct. Mater. 2012, 22, 3057-3065. [CrossRef]

118. Chen, C.; Hu, J.; Huang, H.; Zhu, Y.; Qin, T. Design of a Smart Nerve Conduit Based on a Shape-Memory Polymer. Adv. Mater. Technol. 2016, 1, 1600015. [CrossRef]

119. Kai, D.; Prabhakaran, M.P.; Chan, B.Q.Y.; Liow, S.S.; Ramakrishna, S.; Xu, F.; Loh, X.J. Elastic poly(E-caprolactone)polydimethylsiloxane copolymer fibers with shape memory effect for bone tissue engineering. Biomed. Mater. 2016, $11,015007$. [CrossRef] [PubMed] 
120. Kai, D.; Tan, M.J.; Prabhakaran, M.P.; Chan, B.Q.Y.; Liow, S.S.; Ramakrishna, S.; Loh, X.J. Biocompatible electrically conductive nanofibers from inorganic-organic shape memory polymers. Colloids Surfaces B Biointerfaces 2016, 148, 557-565. [CrossRef] [PubMed]

121. Ghasemi-Mobarakeh, L.; Prabhakaran, M.P.; Morshed, M.; Nasr-Esfahani, M.H.; Ramakrishna, S. Electrical stimulation of nerve cells using conductive nanofibrous scaffolds for nerve tissue engineering. Tissue Eng.-Part A 2009, 15, 3605-3619. [CrossRef] [PubMed]

122. Mejia, M.A.; Hoyos, L.M.; Zapata, J.; Restrepo, L.M.; Moneada, M.E. Electrospinning of gelatin and SMPU with carbon nanotubes for tissue engineering scaffolds. In Proceedings of the 38th Annual International Conference of the IEEE Engineering in Medicine and Biology Society, EMBC 2016, Orlando, FL, USA, 16-20 August 2016; Institute of Electrical and Electronics Engineers Inc.: Medellin, Colombia, 2016; pp. 4181-4184.

123. Marois, Y.; Chakfé, N.; Deng, X.; Marois, M.; How, T.; King, M.W.; Guidoin, R. Carbodiimide cross-linked gelatin: A new coating for porous polyester arterial prostheses. Biomaterials 1995, 16, 1131-1139. [CrossRef]

124. Merlettini, A.; Gigli, M.; Ramella, M.; Gualandi, C.; Soccio, M.; Boccafoschi, F.; Munari, A.; Lotti, N.; Focarete, M.L. Thermal Annealing to Modulate the Shape Memory Behavior of a Biobased and Biocompatible Triblock Copolymer Scaffold in the Human Body Temperature Range. Biomacromolecules 2017, 18, 2490-2508. [CrossRef]

125. Pérez-Fonseca, A.A.; Robledo-Ortíz, J.R.; González-Núñez, R.; Rodrigue, D. Effect of thermal annealing on the mechanical and thermal properties of polylactic acid-cellulosic fiber biocomposites. J. Appl. Polym. Sci. 2016, 133, 1-10. [CrossRef]

126. Pandini, S.; Agnelli, S.; Merlettini, A.; Chiellini, F.; Gualandi, C.; Paderni, K.; Focarete, M.L.; Messori, M.; Toselli, M. Mutifunctional Electrospun Nonwoven Mats with Two-Way Shape Memory Behavior Prepared from Sol-Gel Crosslinked Poly(E-Caprolactone). Macromol. Mater. Eng. 2017, 302, 1600519. [CrossRef]

127. Paderni, K.; Pandini, S.; Passera, S.; Pilati, F.; Toselli, M.; Messori, M. Shape-memory polymer networks from sol-gel cross-linked alkoxysilane-terminated poly( $\varepsilon$-caprolactone). J. Mater. Sci. 2012, 47, 4354-4362. [CrossRef]

128. Chung, S.; Ingle, N.P.; Montero, G.A.; Kim, S.H.; King, M.W. Bioresorbable elastomeric vascular tissue engineering scaffolds via melt spinning and electrospinning. Acta Biomater. 2010, 6, 1958-1967. [CrossRef] [PubMed]

129. Greenhalgh, E.S.; Mathew, W.D. Modeling Blood Flow Through Vascular Grafts. In National Textile Center Report; National Textile Center: Wilmington, DE, USA, 1998; pp. 1-10.

130. Montoya, Y.; Valencia, R.A.; Ortiz, I.C.; Hoyos, L.M.; Bustamante, J. In vitro study of proliferation and cellularisation on electrospun membranes for vascular prosthesis. In Proceedings of the 7th Latin American Congress on Biomedical Engineering, CLAIB 2016, Bucaramanga, Santander, Colombia, 26-28 October 2016; Springer: Singapore, 2017; Volume 60, pp. 589-592.

131. Rozario, T.; DeSimone, D.W. The extracellular matrix in development and morphogenesis: A dynamic view. Dev. Biol. 2010, 341, 126-140. [CrossRef] [PubMed]

132. Provenzano, P.P.; Eliceiri, K.W.; Campbell, J.M.; Inman, D.R.; White, J.G.; Keely, P.J. Collagen reorganization at the tumor-stromal interface facilitates local invasion. BMC Med. 2006, 4, 38. [CrossRef] [PubMed]

133. Wang, J.; Quach, A.; Brasch, M.E.; Turner, C.E.; Henderson, J.H. On-command on/off switching of progenitor cell and cancer cell polarized motility and aligned morphology via a cytocompatible shape memory polymer scaffold. Biomaterials 2017, 140, 150-161 [CrossRef]

134. Grulova, I.; Slovinska, L.; Nagyova, M.; Cizek, M.; Cizkova, D. The effect of hypothermia on sensory-motor function and tissue sparing after spinal cord injury. Spine J. 2013, 13, 1881-1891. [CrossRef] [PubMed]

135. Thonhoff, J.; Ojeda, L.; Wu, P. Stem Cell-Derived Motor Neurons: Applications and Challenges in Amyotrophic Lateral Sclerosis. Curr. Stem Cell Res. Ther. 2011, 4, 178-199. [CrossRef] [PubMed]

136. Wang, C.; Yue, H.; Feng, Q.; Xu, B.; Bian, L.; Shi, P. Injectable Nanoreinforced Shape-Memory Hydrogel System for Regenerating Spinal Cord Tissue from Traumatic Injury. ACS Appl. Mater. Interfaces 2018, 10, 29299-29307. [CrossRef]

137. Collins, M.N.; Birkinshaw, C. Hyaluronic acid based scaffolds for tissue engineering-A review. Carbohydr. Polym. 2013, 92, 1262-1279. [CrossRef]

138. Yao, Y.; Luo, Y.; Lu, H.; Wang, B. Remotely actuated porous composite membrane with shape memory property. Compos. Struct. 2018, 192, 507-515. [CrossRef]

139. Inverardi, N.; Ginestra, P.S.; Ferraro, R.M.; Tonello, S.; Marziano, M.; Merlettini, A.; Gualandi, C. Shape memory electrospun nonwovens based on crosslinked poly( $\epsilon$-caprolactone) for multifunctional biological applications. In Proceedings of the 9th International Conference on Times of Polymers and Composites: From Aerospace to Nanotechnology, Ischia, Italy, 17-21 June 2018; American Institute of Physics Inc.: Brescia, Italy, 2018; Volume 1981.

140. Murugan, R.; Ramakrishna, S. Design strategies of tissue engineering scaffolds with controlled fiber orientation. Tissue Eng. 2007, 13, 1845-1866. [CrossRef] [PubMed]

141. Davignon, J.; Ganz, P. Role of endothelial dysfunction in atherosclerosis. Circulation 2004, 109, III-27-III-32. [CrossRef] [PubMed]

142. Epstein, F.H.; Gibbons, G.H.; Dzau, V.J. The emerging concept of vascular remodeling. N. Engl. J. Med. 1994, 330, 1431-1438. [CrossRef] [PubMed]

143. Zhao, Q.; Wang, J.; Cui, H.; Chen, H.; Wang, Y.; Du, X. Programmed Shape-Morphing Scaffolds Enabling Facile 3D Endothelialization. Adv. Funct. Mater. 2018, 28, 1801027. [CrossRef]

144. Tillman, B.W.; Yazdani, S.K.; Lee, S.J.; Geary, R.L.; Atala, A.; Yoo, J.J. The in vivo stability of electrospun polycaprolactone-collagen scaffolds in vascular reconstruction. Biomaterials 2009, 30, 583-588. [CrossRef] [PubMed] 
145. Sun, X.; Lang, Q.; Zhang, H.; Cheng, L.; Zhang, Y.; Pan, G.; Zhao, X.; Yang, H.; Zhang, Y.; Santos, H.A.; et al. Electrospun Photocrosslinkable Hydrogel Fibrous Scaffolds for Rapid In Vivo Vascularized Skin Flap Regeneration. Adv. Funct. Mater. 2017, 27, 1604617. [CrossRef]

146. Wang, K.; Jia, Y.G.; Zhu, X.X. Biocompound-Based Multiple Shape Memory Polymers Reinforced by Photo-Cross-Linking. ACS Biomater. Sci. Eng. 2015, 1, 855-863. [CrossRef] [PubMed]

147. Khademeh Molavi, F.; Ghasemi, I.; Messori, M.; Esfandeh, M. Nanocomposites based on poly(L-lactide)/poly( $\varepsilon$-caprolactone) blends with triple-shape memory behavior: Effect of the incorporation of graphene nanoplatelets (GNps). Compos. Sci. Technol. 2017, 151, 219-227. [CrossRef]

148. Sabzi, M.; Ranjbar-Mohammadi, M.; Zhang, Q.; Kargozar, S.; Leng, J.; Akhtari, T.; Abbasi, R. Designing triple-shape memory polymers from a miscible polymer pair through dual-electrospinning technique. J. Appl. Polym. Sci. 2019, 136, 47471. [CrossRef]

149. Keramati, M.; Ghasemi, I.; Karrabi, M.; Azizi, H.; Sabzi, M. Incorporation of surface modified graphene nanoplatelets for development of shape memory PLA nanocomposite. Fibers Polym. 2016, 17, 1062-1068. [CrossRef]

150. Zare, M.; Parvin, N.; Prabhakaran, M.P.; Mohandesi, J.A.; Ramakrishna, S. Highly porous 3D sponge-like shape memory polymer for tissue engineering application with remote actuation potential. Compos. Sci. Technol. 2019, 184, 107874. [CrossRef]

151. Jazayeri, M.H.; Amani, H.; Pourfatollah, A.A.; Pazoki-Toroudi, H.; Sedighimoghaddam, B. Various methods of gold nanoparticles (GNPs) conjugation to antibodies. Sens. Bio-Sens. Res. 2016, 9, 17-22. [CrossRef]

152. Patra, H.K.; Banerjee, S.; Chaudhuri, U.; Lahiri, P.; Dasgupta, A.K. Cell selective response to gold nanoparticles. Nanomedicine Nanotechnol. Biol. Med. 2007, 3, 111-119. [CrossRef] [PubMed]

153. Sun, B.; Long, Y.Z.; Yu, F.; Li, M.M.; Zhang, H.D.; Li, W.J.; Xu, T.X. Self-assembly of a three-dimensional fibrous polymer sponge by electrospinning. Nanoscale 2012, 4, 2134-2137. [CrossRef] [PubMed]

154. Wei, G.; Ma, P.X. Nanostructured biomaterials for regeneration. Adv. Funct. Mater. 2008, 18, 3568-3582. [CrossRef]

155. Chen, W.; Xu, Y.; Liu, Y.; Wang, Z.; Li, Y.; Jiang, G.; Mo, X.; Zhou, G. Three-dimensional printed electrospun fiber-based scaffold for cartilage regeneration. Mater. Des. 2019, 179. [CrossRef]

156. Chen, M.; Li, L.; Xia, L.; Zhang, F.; Jiang, S.; Hu, H.; Li, X.; Wang, H. Temperature Responsive Shape-Memory Scaffolds with Circumferentially Aligned Nanofibers for Guiding Smooth Muscle Cell Behavior. Macromol. Biosci. 2020, 20, 1900312. [CrossRef]

157. Reisch, A.; Didier, P.; Richert, L.; Oncul, S.; Arntz, Y.; Mély, Y.; Klymchenko, A.S. Collective fluorescence switching of counterionassembled dyes in polymer nanoparticles. Nat. Commun. 2014, 5, 4089. [CrossRef] [PubMed]

158. Xu, T.; Yang, H.; Yang, D.; Yu, Z.Z. Polylactic Acid Nanofiber Scaffold Decorated with Chitosan Islandlike Topography for Bone Tissue Engineering. ACS Appl. Mater. Interfaces 2017, 9, 21094-21104. [CrossRef] [PubMed]

159. Wang, X.; Yan, H.; Shen, Y.; Tang, H.; Yi, B.; Qin, C.; Zhang, Y. Shape Memory and Osteogenesis Capabilities of the Electrospun Poly(3-Hydroxybutyrate-co-3-Hydroxyvalerate) Modified Poly(l-Lactide) Fibrous Mats. Tissue Eng.-Part A 2021, 27, 142-152. [CrossRef]

160. Sarabiyan Nejad, S.; Razzaghi, D.; Rezaei, M.; Bagheri, M.; Babaie, A.; Abbasi, F. Preparation and characterization of electrospun shape memory polyurethane/graphene quantum dot nanocomposite scaffolds for tissue engineering. Int. J. Polym. Mater. Polym. Biomater. 2021, 1-9. [CrossRef]

161. Feng, J.; Shi, H.; Yang, X.; Xiao, S. Self-Adhesion Conductive Sub-micron Fiber Cardiac Patch from Shape Memory Polymers to Promote Electrical Signal Transduction Function. ACS Appl. Mater. Interfaces 2021, 13, 19593-19602. [CrossRef] [PubMed]

162. Lv, H.; Chi, H.; Yang, X.; Peng, J.; Wang, W.; Tang, D. Polydopamine-assisted shape memory of polyurethane nanofibers with light-induced tunable responsiveness and improved cell adhesiveness. Colloids Surfaces A Physicochem. Eng. Asp. 2021, 627, 127100. [CrossRef]

163. Liverani, L.; Liguori, A.; Zezza, P.; Gualandi, C.; Toselli, M.; Boccaccini, A.R.; Focarete, M.L. Nanocomposite electrospun fibers of $\operatorname{poly}(\varepsilon$-caprolactone)/bioactive glass with shape memory properties. Bioact. Mater. 2022, 11, 230-239. [CrossRef] [PubMed]

164. Hu, X.; Liu, S.; Zhou, G.; Huang, Y.; Xie, Z.; Jing, X. Electrospinning of polymeric nanofibers for drug delivery applications. J. Control. Release 2014, 185, 12-21. [CrossRef] [PubMed]

165. Pillai, C.K.S.; Sharma, C.P. Electrospinning of Chitin and Chitosan nanofibres. Trends Biomater. Artif. Organs 2009, $22,179-201$.

166. Prabaharan, M.; Jayakumar, R.; Nair, S.V. Electrospun Nanofibrous Scaffolds-Current Status and Prospects in Drug Delivery. In Biomedical Applications of Polymeric Nanofibers; Springer: Berlin/Heidelberg, Germany, 2011; Volume 5, pp. $241-262$. ISBN 9781118056776.

167. Goonoo, N.; Jeetah, R.; Bhaw-Luximon, A.; Jhurry, D. Polydioxanone-based bio-materials for tissue engineering and drug/gene delivery applications. Eur. J. Pharm. Biopharm. 2015, 97, 371-391. [CrossRef] [PubMed]

168. Gollapudi, S. Safety and Efficacy of Polydioxanone Nano-Fibers as Anti-Inflammatory Agents. J. Nanomed. Biother. Discov. 2014, 4, 2-7. [CrossRef]

169. Hakimi, O.; Murphy, R.; Stachewicz, U.; Hislop, S.; Carr, A.J. An electrospun polydioxanone patch for the localisation of biological therapies during tendon repair. Eur. Cells Mater. 2012, 24, 344-357. [CrossRef] [PubMed]

170. Kratz, K.; Habermann, R.; Becker, T.; Richau, K.; Lendlein, A. Shape-memory properties and degradation behavior of multifunctional electro-spun scaffolds. Int. J. Artif. Organs 2011, 34, 225-230. [CrossRef]

171. Phillips, D.J.; Wilde, M.; Greco, F.; Gibson, M.I. Enzymatically Triggered, Isothermally Responsive Polymers: Reprogramming Poly(oligoethylene glycols) to Respond to Phosphatase. Biomacromolecules 2015, 16, 3256-3264. [CrossRef] [PubMed] 
172. Buffington, S.L.; Paul, J.E.; Ali, M.M.; Macios, M.M.; Mather, P.T.; Henderson, J.H. Enzymatically triggered shape memory polymers. Acta Biomater. 2019, 84, 88-97. [CrossRef]

173. Rice, M.A.; Sanchez-Adams, J.; Anseth, K.S. Exogenously triggered, enzymatic degradation of photopolymerized hydrogels with polycaprolactone subunits: Experimental observation and modeling of mass loss behavior. Biomacromolecules 2006, 7, $1968-1975$. [CrossRef] [PubMed]

174. Lv, H.; Tang, D.; Sun, Z.; Gao, J.; Yang, X.; Jia, S.; Peng, J. Electrospun PCL-based polyurethane/HA microfibers as drug carrier of dexamethasone with enhanced biodegradability and shape memory performances. Colloid Polym. Sci. 2020, 298, 103-111. [CrossRef]

175. Su, Y.; Su, Q.; Liu, W.; Lim, M.; Venugopal, J.R.; Mo, X.; Ramakrishna, S.; Al-Deyab, S.S.; El-Newehy, M. Controlled release of bone morphogenetic protein 2 and dexamethasone loaded in core-shell PLLACL-collagen fibers for use in bone tissue engineering. Acta Biomater. 2012, 8, 763-771. [CrossRef] [PubMed]

176. Yin, X.; Tan, P.; Luo, H.; Lan, J.; Shi, Y.; Zhang, Y.; Fan, H.; Tan, L. Study on the release behaviors of berberine hydrochloride based on sandwich nanostructure and shape memory effect. Mater. Sci. Eng. C 2020, 109, 110541. [CrossRef]

177. Laha, A.; Sharma, C.S.; Majumdar, S. Sustained drug release from multi-layered sequentially crosslinked electrospun gelatin nanofiber mesh. Mater. Sci. Eng. C 2017, 76, 782-786. [CrossRef]

178. Bil, M.; Kijeńska-Gawrońska, E.; Głodkowska-Mrówka, E.; Manda-Handzlik, A.; Mrówka, P. Design and in vitro evaluation of electrospun shape memory polyurethanes for self-fitting tissue engineering grafts and drug delivery systems. Mater. Sci. Eng. C 2020, 110, 110675. [CrossRef]

179. Gurtner, G.C.; Werner, S.; Barrandon, Y.; Longaker, M.T. Wound repair and regeneration. Nature 2008, 453, 314-321. [CrossRef] [PubMed]

180. Zhao, R.; Li, X.; Sun, B.; Tong, Y.; Jiang, Z.; Wang, C. Nitrofurazone-loaded electrospun PLLA/sericin-based dual-layer fiber mats for wound dressing applications. RSC Adv. 2015, 5, 16940-16949. [CrossRef]

181. Lee, K.Y.; Jeong, L.; Kang, Y.O.; Lee, S.J.; Park, W.H. Electrospinning of polysaccharides for regenerative medicine. Adv. Drug Deliv. Rev. 2009, 61, 1020-1032. [CrossRef] [PubMed]

182. Tan, L.; Hu, J.; Huang, H.; Han, J.; Hu, H. Study of multi-functional electrospun composite nanofibrous mats for smart wound healing. Int. J. Biol. Macromol. 2015, 79, 469-476. [CrossRef] [PubMed]

183. Bowler, P. Efficacy of silver-containing dressings. J. Wound Care 2006, 15, 417-420.

184. Zhang, J.N.; Ma, Y.M.; Zhang, J.J.; Xu, D.; Yang, Q.L.; Guan, J.G.; Cao, X.Y.; Jiang, L. Microfiber SMPU film affords quicker shape recovery than the bulk one. Mater. Lett. 2011, 65, 3639-3642. [CrossRef]

185. Torbati, A.H.; Mather, R.T.; Reeder, J.E.; Mather, P.T. Fabrication of a light-emitting shape memory polymeric web containing indocyanine green. J. Biomed. Mater. Res.-Part B Appl. Biomater. 2014, 102, 1236-1243. [CrossRef]

186. Haritoglou, C.; Freyer, W.; Priglinger, S.G.; Kampik, A. Light absorbing properties of indocyanine green (ICG) in solution and after adsorption to the retinal surface-An ex-vivo approach. Graefe's Arch. Clin. Exp. Ophthalmol. 2006, 244, 1196-1202. [CrossRef]

187. Zhang, F.; Zhang, Z.; Liu, Y.; Cheng, W.; Huang, Y.; Leng, J. Thermosetting epoxy reinforced shape memory composite microfiber membranes: Fabrication, structure and properties. Compos. Part A Appl. Sci. Manuf. 2015, 76, 54-61. [CrossRef]

188. Kuang, W.; Mather, P.T. A latent crosslinkable PCL-based polyurethane: Synthesis, shape memory, and enzymatic degradation. J. Mater. Res. 2018, 33, 2463-2476. [CrossRef]

189. Peng, Q.; Cheng, J.; Lu, S.; Li, Y. Electrospun hyperbranched polylactic acid-Modified cellulose nanocrystals/polylactic acid for shape memory membranes with high mechanical properties. Polym. Adv. Technol. 2020, 31, 15-24. [CrossRef]

190. Peponi, L.; Sessini, V.; Arrieta, M.P.; Navarro-Baena, I.; Sonseca, A.; Dominici, F.; Gimenez, E.; Torre, L.; Tercjak, A.; López, D.; et al. Thermally-activated shape memory effect on biodegradable nanocomposites based on PLA/PCL blend reinforced with hydroxyapatite. Polym. Degrad. Stab. 2018, 151, 36-51. [CrossRef]

191. Peponi, L.; Puglia, D.; Torre, L.; Valentini, L.; Kenny, J.M. Processing of nanostructured polymers and advanced polymeric based nanocomposites. Mater. Sci. Eng. R Rep. 2014, 85, 1-46. [CrossRef]

192. Hsieh, C.H.; Razali, N.A.M.; Lin, W.C.; Yu, Z.W.; Istiqomah, D.; Kotsuchibashi, Y.; Su, H.H. Development of thermo-responsive polycaprolactone-polydimethylsiloxane shrinkable nanofibre mesh. Nanomaterials 2020, 10, 1427. [CrossRef] [PubMed]

193. Bar-Cohen, Y.; Zhang, Q. Electroactive Polymer Actuators and Sensors. MRS Bull. 2008, 33, 173-181. [CrossRef]

194. McDowell, J.J.; Zacharia, N.S.; Puzzo, D.; Manners, I.; Ozin, G.A. Electroactuation of alkoxysilane-functionalized polyferrocenylsilane microfibers. J. Am. Chem. Soc. 2010, 132, 3236-3237. [CrossRef]

195. Arrieta, M.P.; Peponi, L.; Rodríguez-Hernández, J. Antimicrobial Fibers Obtained by Electrospinning; Elsevier: Amsterdam, The Netherlands, 2019; ISBN 9780128184356.

196. Zhuo, H.T.; Hu, J.L.; Chen, S.J. Coaxial electrospun polyurethane core-shell nanofibers for shape memory and antibacterial nanomaterials. Express Polym. Lett. 2011, 5, 182-187. [CrossRef]

197. Ahn, J.-S.; Yu, W.-R.; Youk, J.H.; Ryu, H.Y. In situ temperature tunable pores of shape memory polyurethane membranes. Smart Mater. Struct. 2011, 20, 105024. [CrossRef]

198. Chung, S.E.; Park, C.H.; Yu, W.-R.; Kang, T.J. Thermoresponsive shape memory characteristics of polyurethane electrospun web. J. Appl. Polym. Sci. 2011, 120, 492-500. [CrossRef]

199. Rodriguez, E.D.; Weed, D.C.; Mather, P.T. Anisotropic shape-memory elastomeric composites: Fabrication and testing. Macromol. Chem. Phys. 2013, 214, 1247-1257. [CrossRef] 
200. Swartz, S.M.; Groves, M.S.; Kim, H.D.; Walsh, W.R. Mechanical properties of bat wing membrane skin. J. Zool. 1996, $239,357-378$. [CrossRef]

201. Zhang, F.; Zhang, Z.; Liu, Y.; Lu, H.; Leng, J. The quintuple-shape memory effect in electrospun nanofiber membranes. Smart Mater. Struct. 2013, 22, 085020. [CrossRef]

202. Xuefei, C.; Yang, H.; Zhen-Liang, X. Poly(vinyl alcohol)-perfluorinated sulfonic acid nanofiber mats prepared via electrospinning as catalyst. Mater. Lett. 2011, 65, 1719-1722. [CrossRef]

203. Zhang, F.; Zhang, Z.; Liu, Y.; Leng, J. Electrospun nanofiber membranes for electrically activated shape memory nanocomposites. Smart Mater. Struct. 2014, 23, 065020. [CrossRef]

204. Ra, E.J.; An, K.H.; Kim, K.K.; Jeong, S.Y.; Lee, Y.H. Anisotropic electrical conductivity of MWCNT/PAN nanofiber paper. Chem. Phys. Lett. 2005, 413, 188-193. [CrossRef]

205. Birjandi Nejad, H.; Robertson, J.M.; Mather, P.T. Interwoven polymer composites via dual-electrospinning with shape memory and self-healing properties. MRS Commun. 2015, 5, 211-221. [CrossRef]

206. Fan, G.; Ge, J.; Kim, H.Y.; Ding, B.; Al-Deyab, S.S.; El-Newehy, M.; Yu, J. Hierarchical porous carbon nanofibrous membranes with an enhanced shape memory property for effective adsorption of proteins. RSC Adv. 2015, 5, 64318-64325. [CrossRef]

207. Del Sorbo, G.R.; Truda, G.; Bifulco, A.; Passaro, J.; Petrone, G.; Vitolo, B.; Ausanio, G.; Vergara, A.; Marulo, F.; Branda, F. Non monotonous effects of noncovalently functionalized graphene addition on the structure and sound absorption properties of Polyvinylpyrrolidone (1300 kDa) electrospun mats. Materials 2018, 12, 108. [CrossRef]

208. Sang, B.; Li, Z.W.; Li, X.H.; Yu, L.G.; Zhang, Z.J. Graphene-based flame retardants: A review. J. Mater. Sci. 2016, 51, 8271-8295. [CrossRef]

209. Zhang, F.; Xia, Y.; Wang, L.; Liu, L.; Liu, Y.; Leng, J. Conductive Shape Memory Microfiber Membranes with Core-Shell Structures and Electroactive Performance. ACS Appl. Mater. Interfaces 2018, 10, 35526-35532. [CrossRef]

210. Khalili, N.; Asif, H.; Naguib, H.E. Towards development of nanofibrous large strain flexible strain sensors with programmable shape memory properties. Smart Mater. Struct. 2018, 27, 055002. [CrossRef]

211. Yamada, T.; Hayamizu, Y.; Yamamoto, Y.; Yomogida, Y.; Izadi-Najafabadi, A.; Futaba, D.N.; Hata, K. A stretchable carbon nanotube strain sensor for human-motion detection. Nat. Nanotechnol. 2011, 6, 296-301. [CrossRef]

212. Zhang, Q.; Rudolph, T.; Benitez, A.J.; Gould, O.E.C.; Behl, M.; Kratz, K.; Lendlein, A. Temperature-controlled reversible pore size change of electrospun fibrous shape-memory polymer actuator based meshes. Smart Mater. Struct. 2019, 28, 055037. [CrossRef]

213. Gopal, R.; Kaur, S.; Ma, Z.; Chan, C.; Ramakrishna, S.; Matsuura, T. Electrospun nanofibrous filtration membrane. J. Memb. Sci. 2006, 281, 581-586. [CrossRef]

214. Behl, M.; Kratz, K.; Zotzmann, J.; Nöchel, U.; Lendlein, A. Reversible bidirectional shape-memory polymers. Adv. Mater. 2013, 25, 4466-4469. [CrossRef]

215. Lazarus, R.A.; Scheiflinger, F. Mining ancient proteins for next-generation drugs. Nat. Biotechnol. 2017, 35, 28-29. [CrossRef] [PubMed]

216. Fekete, S.; Beck, A.; Veuthey, J.L.; Guillarme, D. Ion-exchange chromatography for the characterization of biopharmaceuticals. J. Pharm. Biomed. Anal. 2015, 113, 43-55. [CrossRef] [PubMed]

217. Yao, Y.; Lenhoff, A.M. Determination of pore size distributions of porous chromatographic adsorbents by inverse size-exclusion chromatography. J. Chromatogr. A 2004, 1037, 273-282. [CrossRef] [PubMed]

218. Fu, Q.; Liu, L.; Si, Y.; Yu, J.; Ding, B. Shapeable, Underwater Superelastic, and Highly Phosphorylated Nanofibrous Aerogels for Large-Capacity and High-Throughput Protein Separation. ACS Appl. Mater. Interfaces 2019, 11, 44874-44885. [CrossRef]

219. Kim, H.S.; Kim, J.H.; Kim, J. A review of piezoelectric energy harvesting based on vibration. Int. J. Precis. Eng. Manuf. 2011, 12, 1129-1141. [CrossRef]

220. Cottone, F.; Vocca, H.; Gammaitoni, L. Nonlinear energy harvesting. Phys. Rev. Lett. 2009, 102, 080601. [CrossRef]

221. Xiong, J.; Luo, H.; Gao, D.; Zhou, X.; Cui, P.; Thangavel, G.; Parida, K.; Lee, P.S. Self-restoring, waterproof, tunable microstructural shape memory triboelectric nanogenerator for self-powered water temperature sensor. Nano Energy 2019, 61, 584-593. [CrossRef]

222. Wang, J.; Wu, C.; Dai, Y.; Zhao, Z.; Wang, A.; Zhang, T.; Wang, Z.L. Achieving ultrahigh triboelectric charge density for efficient energy harvesting. Nat. Commun. 2017, 8, 88. [CrossRef] [PubMed]

223. Guan, X.; Chen, H.; Xia, H.; Fu, Y.; Qiu, Y.; Ni, Q.-Q. Multifunctional composite nanofibers with shape memory and piezoelectric properties for energy harvesting. J. Intell. Mater. Syst. Struct. 2020, 31, 956-966. [CrossRef]

224. Sodano, H.A.; Inman, D.J.; Park, G. A review of power harvesting from vibration using piezoelectric materials. Shock Vib. Dig. 2004, 36, 197-205. [CrossRef]

225. Yoon, J.; An, Y.; Hong, S.B.; Myung, J.H.; Sun, J.Y.; Yu, W.R. Fabrication of a Highly Stretchable, Wrinkle-Free Electrode with Switchable Transparency Using a Free-Standing Silver Nanofiber Network and Shape Memory Polymer Substrate. Macromol. Rapid Commun. 2020, 41, 2000129. [CrossRef] [PubMed]

226. Liu, K.; Yang, D.; Yang, H.; Lu, S.; Cai, R.; Tan, W. Multifunctional Shape Memory Films for a Flexible Electrical Sensor. Macromol. Mater. Eng. 2021, 2100580, 2100580. [CrossRef]

227. Feng, W.; Zhang, Y.S.; Shao, Y.W.; Huang, T.; Zhang, N.; Yang, J.H.; Qi, X.D.; Wang, Y. Coaxial electrospun membranes with thermal energy storage and shape memory functions for simultaneous thermal/moisture management in personal cooling textiles. Eur. Polym. J. 2021, 145, 110245. [CrossRef] 
228. Izraylit, V.; Heuchel, M.; Kratz, K.; Lendlein, A. Non-woven shape-memory polymer blend actuators. MRS Adv. 2021, 6, 781-785. [CrossRef]

229. Zhang, L.; Huang, Y.; Dong, H.; Xu, R.; Jiang, S. Flame-retardant shape memory polyurethane/MXene paper and the application for early fire alarm sensor. Compos. Part B Eng. 2021, 223, 109149. [CrossRef]

230. Kuang, P.; Low, J.; Cheng, B.; Yu, J.; Fan, J. MXene-based photocatalysts. J. Mater. Sci. Technol. 2020, 56, 18-44. [CrossRef] 